Florida International University FIU Digital Commons

$11-14-2013$

\title{
Operant and Respondent Procedures to Establish Social Stimuli as Reinforcers in Children with Autism
}

Paloma Rodriguez

ppedraza@fiu.edu

DOI: $10.25148 /$ etd.FI13120202

Follow this and additional works at: https://digitalcommons.fiu.edu/etd

Part of the Applied Behavior Analysis Commons, and the Developmental Psychology Commons

\section{Recommended Citation}

Rodriguez, Paloma, "Operant and Respondent Procedures to Establish Social Stimuli as Reinforcers in Children with Autism" (2013). FIU Electronic Theses and Dissertations. 961.

https://digitalcommons.fiu.edu/etd/961 


\title{
FLORIDA INTERNATIONAL UNIVERSITY
}

Miami, FL

\section{OPERANT AND RESPONDENT PROCEDURES TO ESTABLISH SOCIAL STIMULI AS REINFORCERS IN CHILDREN WITH AUTISM}

\author{
A dissertation submitted in partial fulfillment of the \\ requirements for the degree of \\ DOCTOR OF PHILOSOPHY \\ in \\ PSYCHOLOGY \\ by \\ Paloma Rodriguez
}

2013 
To: Dean Kenneth Furman

College of Arts and Sciences

This dissertation, written by Paloma Rodriguez, and entitled Operant and Respondent Procedures to Establish Social Stimuli as Reinforcers in Children with Autism, having been approved in respect to style and intellectual content, is referred to you for judgment.

We have read this dissertation and recommend that it be approved.

$\begin{array}{r}\hline \text { Anthony Dick } \\ \hline \text { Daniel Bagner } \\ \hline \text { Kyle Bennett } \\ \hline \text { Anibal Gutierrez, Major Professor }\end{array}$

Date of Defense: November 14, 2013

The dissertation of Paloma Rodriguez is approved.

$\begin{array}{r}\hline \begin{array}{c}\text { Dean Kenneth G. Furton } \\ \text { College of Arts and Sciences }\end{array} \\ \hline \begin{array}{r}\text { Dean Lakshmi N. Reddi } \\ \text { University Graduate School }\end{array}\end{array}$

Florida International University, 2013 


\section{DEDICATION}

I dedicate this dissertation to my wonderful husband, Dan. It was with his support, love and patience that I was able to focus on my studies and complete this dissertation. I would also like to dedicate this dissertation to my daughter, Emma. In completing this degree, I hope to inspire her to pursue her education as far as it can take her. 


\section{ACKNOWLEDGMENTS}

I would like to thank all of the members of my committee for all of their support and assistance in completing this dissertation. I would also like to thank Dr. Jacob Gewirtz, who inspired me to follow his academic path, merging the behavioral and

developmental literature. In addition, I would like to thank all of the families who participated in this study. Without their commitment to their children and to this study, this dissertation would not be possible. Finally, I would like to thank my wonderful research assistant, Sandra Castellon, who continued my work while I began life as a new mom. 


\title{
ABSTRACT OF THE DISSERTATION \\ OPERANT AND RESPONDENT PROCEDURES TO ESTABLISH SOCIAL STIMULI AS REINFORCERS IN CHILDREN WITH AUTISM
}

\author{
by \\ Paloma Rodriguez \\ Florida International University, 2013 \\ Miami, Florida

\section{Professor Anibal Gutierrez, Major Professor}

According to the DSM-IV- TR (American Psychiatric Association, 2000), one of the core deficits in autism is in the impairment of social interaction. Some have suggested that underlying these deficits is the reality that individuals with autism do not find social stimuli to be as reinforcing as other types of stimuli (Dawson, 2008). An interesting and growing body of literature supports the notion that symptoms in autism may be caused by a general reduction in social motivation (Chevallier et al., 2012). A review of the literature suggests that social orienting and social motivation are low in individuals with autism, and including social motivation as a target for therapeutic intervention should be pursued (Helt et al., 2008). Through our understanding of learning processes, researchers in behavior analysis and related fields have been able to use conditioning procedures to change the function of neutral or ineffective stimuli, including tokens (Ayllon \& Azrin, 1968), facial expressions (Gewirtz \& Pelaez-Nogueras, 1992) and praise (Dozier et al., 2012). The current study aimed to use operant and respondent procedures to condition social stimuli that were empirically shown to not be reinforcing prior to conditioning. Further, this study aimed to compare the two procedures in their effectiveness to 
condition social stimuli to function as reinforcers, and in their maintenance of effects over time. Using a multiple-baseline, multi-element design, one social stimulus was conditioned under each procedure to compare the different response rates following conditioning. Finally, the study sought to determine if conditioning social stimuli to function as reinforcers had any effect on the social functioning of young children with autism. Six children diagnosed with autism between the ages of 18 months and 3 years participated. Results show that the respondent procedure (pairing) resulted in more robust and enduring effects than the operant procedure (Sd procedure). Results of a social communication assessment (ESCS, Mundy et al., 2003) before and after conditioning demonstrate gains in all areas of social communication, particularly in the areas of initiating and responding to joint attention. 


\section{TABLE OF CONTENTS}

CHAPTER

PAGE

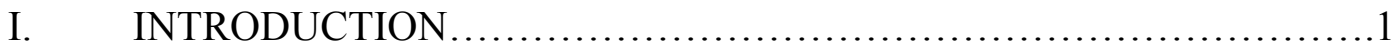

II. THEORETICAL PERSPECTIVE

Assumptions of Learning and Development............................... 3

Operant Learning Theory .............................................

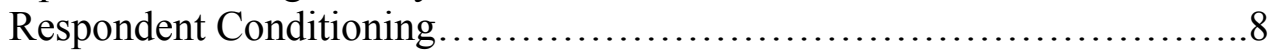

Respondent and Operant Interactions................................ 10

III. LITERATURE REVIEW

Autism Spectrum Disorder...........................................13

Autism Prevalence.................................................... 15

Autism Intervention............................................ 17

Social Orienting as a Core Deficit in Autism..............................19

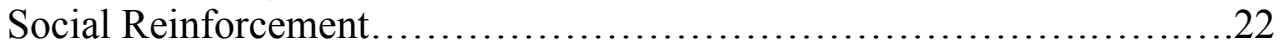

Social Reinforcement in Autism...........................................24

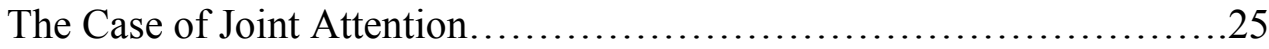

Are Social Stimuli Reinforcing in Autism? .............................29

Social Motivation Theory............................................ 31

Establishing Social Conditioned Reinforcers.............................33

Stimulus-Stimulus Pairing .............................................

Discriminative Stimulus Procedure (Sd Procedure) ........................... 30

The Current Study ..................................................40

IV. METHODOLOGY

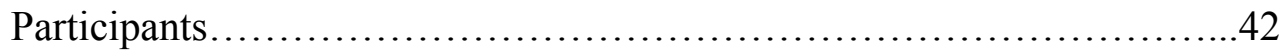

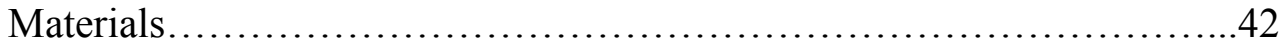

Procedure ............................................................ 43

Data Collection/Validity Measures...................................48

Analysis................................................................ 49

V. RESULTS

Reinforcer Assessments................................................

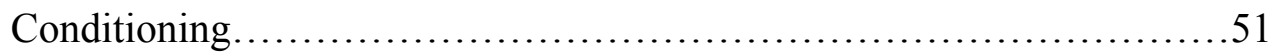

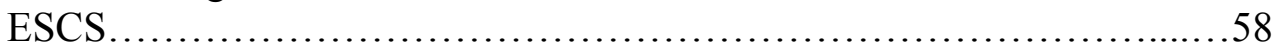

VI. DISCUSSION

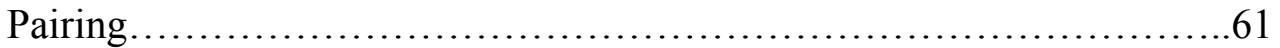

Discriminative Stimulus Procedure........................................65

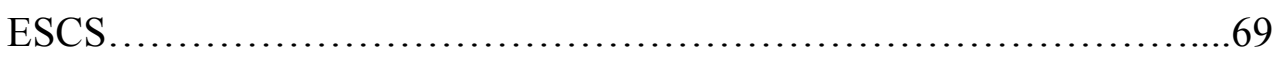

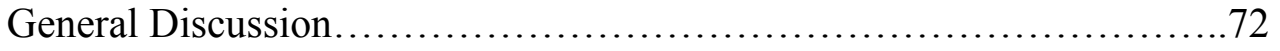

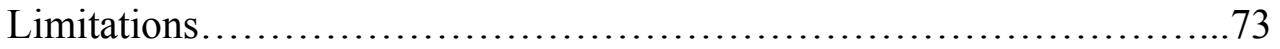


Future Directions............................................. 76

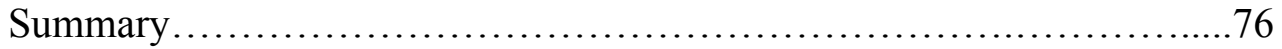

REFERENCES........................................................ 78

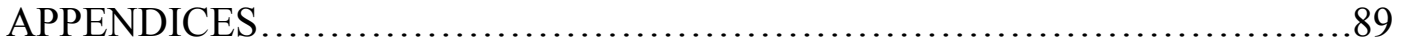

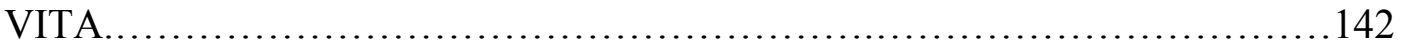




\section{INTRODUCTION}

According to the Diagnostic and Statistical Manual of Mental Disorders, Fourth Edition, Text Revised (American Psychiatric Association, 2000), one of the core deficits in autism is in the impairment of social interaction. Specifically, these deficits are manifested in the failure to develop peer relationships, the lack of spontaneous seeking to share enjoyment, interests or achievement with other people, and the lack of social or emotional reciprocity. Some have suggested that underlying these deficits is the reality that individuals with autism do not find social stimuli to be as reinforcing as other types of stimuli (Dawson et al., 2004; Dawson, 2008). Because social interactions are well known to impact much of typical development, then it stands to reason that there will be differences in development as a result of differences in the effectiveness of social stimuli as consequences. If changes can be made early in development in the way social stimuli function, perhaps other social behaviors may develop (Dawson, 2008; Helt et al., 2008).

The current study aimed to use an operant and a respondent procedure to condition social stimuli that were empirically shown to be ineffective as reinforcers prior to conditioning. Following a series of reinforcer assessments, the least effective social stimulus was conditioned to function as a reinforcer for a simple task. The purpose of this study was to compare the two procedures in their effectiveness to condition social stimuli to function as reinforcers. By conditioning a separate stimulus for each procedure, differences in response rates following conditioning may demonstrate a difference in each procedure's effectiveness. This study also sought to determine if the effects of such 
procedures maintained over time, and had effects on general social behaviors, such as joint attention.

It was hypothesized that each conditioning procedure would result in different response rates for each of the stimuli conditioned. Further, it was hypothesized that each conditioning procedure would result in different response rates following a break from intervention, demonstrating a difference in the maintenance of effects from each procedure. Finally, it was hypothesized that the conditioning procedures, examined in tandem, would have a positive effect on social behaviors as demonstrated by increases in scores in a social communication assessment conducted before and after the procedures were implemented. 


\section{THEORETICAL PERSPECTIVE}

Assumptions of Learning and Development

This study is based on two assumptions of learning: operant and respondent conditioning. That is, there are two primary mechanisms that operate to create lasting behavior change in organisms (Pierce \& Cheney, 2008; Rescorla \& Solomon, 1967). Operant learning theory states that behavior is regulated by the consequences that follow it, while repondent conditioning states that the association between two stimuli can change the function of one of those stimuli (Pierce \& Cheney, 2008). Both of these processes result in lasting change that can be classified as learning, or in some cases development (Schindler, 1995).

These assumptions are the primary conceptual bases for the field of behavior analysis, which informs the methods employed in this study. Further, development is viewed from a behavior analytic perspective, in the tradition of Sid Bijou and Don Baer, among others. In this perspective, development is defined as "progressive changes in interactions between the behavior of individuals and the events in their environment" (Bijou \& Baer, 1978, cited in Schlinger, 1995, p. 42). In other words, the development of individuals is described in terms of the observable and measurable changes in behavior related to changes in the environment, without the use of age or maturation as an explanation for behavior change (Gewirtz, 1969; Schindler, 1995). In this perspective, the analysis of development is at the level of behavior, and is primarily concerned with the adaptability of human behavior. 
Again, the variables that behavior analysts are concerned with are those that can be observed, measured and at times manipulated. With this perspective comes the assumption that genetic and biologic structures underlie behavior change, and are responsible for the adaptability of human behavior (Schinder, 1995). However, the processes that underlie behavior change are at a different level of analysis, and research is best conducted when levels of analysis are not confounded (Gewirtz, 1969). The subsequent literature review will touch on some of the underlying processes of social interaction in autism, however, the experimental manipulations will remain at the behavioral level of analysis.

\section{Operant Learning Theory}

B.F. Skinner is often credited with being the father of operant conditioning because of his coining of the term, which refers to the way in which behavior "operates" on the environment to create consequences that affect the future likelihood of the same response (Pierce \& Cheney, 2008). However, the basis of operant conditioning was more likely discovered by Edward Lee Thorndike, who discovered the Law of Effect (Pierce \& Cheney, 2008). The Law of Effect operates on the principle of trial-and-error learning, where successes "stamp in" responses and make them more likely to occur again in the same context, while failures "stamp out" behavior and make them less likely to occur again. In other words, in the same situation, the organism would be likely to engage in the same behavior again, because in the past that behavior was successful in accessing an object or event that was found "pleasurable" (Pierce \& Cheney, 2008). Although the terminology has changed, the concept is the same: behavior that is reinforced is more 
likely to occur again in the same context. Further, a reinforcer is defined as a stimulus that increases the future likelihood of a behavior (Cooper, Heward \& Heron, 2007). It is important to highlight that the definition of reinforcement does not include whether a stimulus is preferred or desired, but rather that it is defined by its effects on behavior.

In the operant framwork, behavior is analyzed in terms of the events that immediately preceed it and those that immediately follow it. This results in a three-term contingency often referred to as the A-B-Cs of behavior, which stand for the antencedents, the behavior and the consequences under analysis (Malott, 2008). This three term contingency is the basic unit of analysis, and all behavior is considered in these terms. To further clarify this theoretical perspective, each of these terms will be defined.

Antecedents include any environmental event or stimulus change that preceeds behavior. They set the occasion for a behavior, but are not required for behvaior to occur, since responses are not elicited (Skinner, 1953, cited in Hayes \& Rehfeldt, 1998). Antecedent stimuli primarily include motivating operations and discriminative stimuli, though setting events (distal antecedent stimuli) are also sometimes discussed (Miltenberger, 2008). The term motivating operation, which was coined by Jack Michael, reflects the fluid nature of the value of a particular reinforcer at any given moment. Motivating operations specify the value of a reinforcer, and the corresponding likelihood that a behavior will occur to access the same stimulus (Malott, 2008). The term is broken down into establishing and abolishing operations, where establishing operations increase the value of a reinforcer, and make a response that accesses that 
stimulus more likely, while abolishing operations decrease the value of a reinforcer, and make a response that accesses that stimulus less likely (Michael, 1993). The most common examples of establishing and abolishing operations are those of deprivation and satiation, where, for example, the deprivation of food increases the value of food as a reinforcer, and makes the response of getting food more likely. Discriminative stimuli, on the other hand, discriminate the availability of reinforcement for a particular response (Cooper, Heron \& Heward, 2007). In other words, reinforcement is context specific, and behavior is reflective of that. An individual is unlikely to pick up a telephone and expect to hear someone on the other end without the ringing sound of a call coming in first. In this example, the ring serves as a discriminative stimulus for reinforcement in the form of another person's voice for picking up the phone. If, in fact, hearing another person's voice is a reinforcer, then the ringing sound of the telephone has the potential to derive reinforcing properties itself. To extend the example, the behavior that preceeds hearing the ringing telephone could also be reinforced such that sitting by the telephone could be reinforced by the ringing phone. This principle is the foundation for one of the procedures under investigation in this study, and will be discussed in greater detail in the literature review. Discriminative stimuli work in tandem with reinforcement to condition certain responses to occur in particular contexts (Miltenberger, 2008). Thus, reinforcement is responsible for designating the discriminative value of antecendent stimuli.

Behavior, the second term in the three-term contingency, is defined as anything that an organism does, which includes covert or private behaviors such as thoughts and 
feelings (Pierce \& Cheney, 2008). However, in behavior analysis, intervention and analysis are limited to behaviors that can be observed and measured. Terms describing behavior are objectively and operationally defined such that a second observer might detect the same response equally (Miltenberger, 2008). Further, behavior is stated in terms of occuring versus not occuring. Some authors use the "dead man's test" to identify behaviors, where if a dead man can engage in the response, it cannot be defined as behavior (Malott, 2008). For example, a dead man can wait, but he cannot stand with his arms at his side, in line at the grocery store. Although the difference is semantic, the implication is important in that it aids in the selection of target behaviors for intervention.

The final part of the three term contingency is the consequence, or the maintaining variable. Most notably, reinforcement is the consequence that helps shape our behavior, for better or for worse, and that helps maintain those responses as part of our behavioral reperiore (Cooper, Heron, \& Heward, 2008; Malott, 2008; Miltenberger, 2008, Skinner, 1953). Reinforcement is defined as the process by which behavior becomes selected. This conception was formulated as such by B.F. Skinner in his book The Behavior of Organisms (1938) and is modeled after the selection of species described by Darwin (Pierce \& Cheney, 2008). In this conception, behavior that is reinforced is maintained and behavior that is not reinforced, or that is punished, is reduced and evetually eliminated from the behavioral repertoire of any given individual or organism. This is important, because it is assumed that many of the stimuli in our environment, particularly those that are socially mediated, can function as reinforcers, and thus contribute to our behavior. 
A reinforcer, then, is the stimulus that follows a response, which results in the future occurance of the same respose (Miltenberger, 2008). The stimulus that functions as a reinforcer is fluid, dynamic and unique to the individual and the context (Malott, 2008). That is, a stimulus can function as a reinforcer in one moment, but not in the next. It can function as a reinforcer for one individual, and not another; and in one situation but not another. Further, the stimulus is defined as a reinforcer only after it has been determined to cause changes in behavior (Miltenberger, 2008). This is an important concept to this study, because the stimuli that are addressed here are typically reinforcing, by virtue of functioning as such for a large part of the population. However, they do not hold the same value for a segment of the population. However, it is not suffient to say that these stimuli function as reinforcers for some and not others. Emprirical evidence is required to demonstrate the functionality (or lack thereof) of the stimuli selected for experimental manipulation.

\section{Repondent Conditioning}

The other major assumption under this theoretical perspective is that learning also occurs via the association of stimuli. This mechanism of learning differs from the operant approach in that in the operant approach a relation is made between a response and a stimulus (R-S), and in the respondent approach relations are made between stimuli (S-S) (Hayes \& Rehfeldt, 1998). In respondent conditioning, one stimulus that functions to elicit some reflexive response essentially passes on its functionality to another stimulus that is neutral, and that occurs simultaneously in space and time (Pierce \& Cheney, 2008). Respondent conditioning, known also as associative learning and classical 
conditioning, is responsible for behaviors termed conditiond reflexes, and works alongside operant conditioning (Hayes \& Rehfeldt, 1998; Pierce \& Cheney, 2008). However, it should be noted that respondent processes tend to be studied independently of operant relations, and each paradigm has evolved as a distinct field of study (Hayes \& Rehfeldt, 1998).

Accoring to Pierce \& Cheney (2008), unconditioned responses are elicited by unconditioned stimuli, and are lawful and predictable. That is, when an unconditioned stimulus is detected, there is a high probability that an unconditioned response will occur. Unconditioned responses include only those executed by the autonomic nervous system, or "visceral responses" and do not account for behavior that is termed intentional outside of behavior analysis, and operant within (Mower, 1947, cited in Rescorla \& Solomon, 1967). Some examples include a change in heart rate, the excretion of sweat and saliva, and the dilation of pupils. Unconditioned, or reflexive resonses are thought to be evolutionarily learned and contribute to the survival of a species (Pierce \& Cheney, 2008). For example, a human infant will cry when he is in discomfort in order to garner attention from his parents. The infant did not need to learn to cry, but rather the system that triggers crying is genetically endowed. It should be noted here, though, that behaviors that started out as reflexive or respondent can become operant when they operate on the environment (Hayes \& Rehfeldt, 1998), such that the child cries because crying resulted in parent attention in the past. The fact that the parent's attention to the child functions as a mechanism to modify behavior is important to the development of the 
child and "the ability to detect contingencies... is one of the quintessential feautres of adaptation throughout development” (Tarabulsy, Tessier, \& Kappas, 1996).

Conditioned reflexes are essentially the same in form as unconditioned reflexes, except that they are elicited by conditioned stimuli, rather than unconditioned stimuli. They also tend to have slighly diminished response strength, though that depends on a variety of factors (Pierce \& Cheney, 2008). Conditioned stimuli become conditioned via the association of a neutral stimulus and an unconditioned stimulus. Thus, neutral stimuli that are associated with unconditioned stimuli acquire similar response eliciting properties. For example, the pain of a dog bite is linked to the presense of the dog, potentially making the presence of the dog aversive. Many aspects of the stimuli involved affect the outcome of the association, and are discussed in detail in the literature review. Often, groups of conditioned responses are labeled to describe emotions (Vartayan \& Petrov, 1993). For example, the term fear is used colloquially to describe an increase in heart rate and the excretion of sweat, when it follows the presentation of a feared conditioned stimulus (Davis, 1988). However, these types of responses are difficult to observe, and have been largly ignored in applied behavior analysis. (Hayes \& Rehfeldt, 1998).

Respondent and Operant Interactions

Stimuli that result in pleasurable sensations can function as reinforcers for operant behaviors, and stimuli that result in aversive sensations can function as punishers for operant beahviors, demonstrating one of the ways that operant and respondent 
conditioning interact (Pierce \& Cheney, 2008). For example, the sight of a conditioned aversive stimulus (say a dog that has bitten you before) elicits an increase in heart rate and the secretion of sweat in the palms (the conditioned response). This sensation, frequently described as anxiety or stress, creates an aversive condition that the individual is likely to respond to by attempting to avoid or escape, a process known as conditioned avoidance (Mower, 1947, cited in Hayes \& Rehfeldt, 1998). Removing onself from the sight of the dog is then reinforced via negative reinforcement, where the removal of the aversive stimulus is reinforcing, thus perpetuating the avoidance or escape response. Mower (1947) described this process as the problem-posing process where:

Previously neutral environmental events come to have the conditioned power to evoke visceral responses. These visceral responses create emotional and motivational tensions which must then be resolved by problem-solving behavior. The problem solving behavior is done by the skeletal motor respones alone, as reinforced by drive reduction (in Mower's terms, reduction of visceral tensionstates). Therefore, condtioned reflexes are a powerful mediatior of instrumental responses (Rescorla \& Richardson, 1967, p. 154).

The interaction between operant and respondent processes is one that requires further investigation. For example, most of the theoretical posturing in these articles references the effects of aversive emotional states instead of pleasurable ones. Although theoretically it stands to reason that the interaction between operant and respondent processes would be equivalent for pleasurable emotional states, the literature avoids making the claim. The interaction between operant and repondent processes is important 
to the present study, in that operant and respondent processes were used to achieve reinforcing qualities in previously neutral stimuli that then function operantly to reinforce behavior.

The present study used concepts and methods from both the operant and respondent literature to condition social stimuli that were found to be non-reinforcing. The stimuli selected were meant to include stimuli that tend to have reinforcing properties in the natural environment, and that are often delivered in an attempt to modify the behavior of others. For example, praise is often used by parents in order to encourage particular behaviors exhibited by their children (Vollmer \& Hackenberg, 2001). Through these conditioning (learning) processes it was expected that there would be some change in the functionality and value of the selected stimuli. 


\section{LITERATURE REVIEW}

Autism Spectrum Disorder

Autism Spectrum Disorder (ASD) is a pervasive developmental disorder categorized by qualitative impairments in social interaction and communication, and by restricted, repetetive and stereotyped patterns of behavior, interest and activities (4th ed., text rev.; DSM-IV-TR, American Psychiatric Association, 2000). In order to meet criteria, individuals must demonstrate at least two manifestations of social impairment, including:

a) marked impairment in the use of multiple nonverbal behaviors, such as eye-toeye gaze, facial expression, body postures, and gestures to regulate social interaction.

b) failure to develop peer relationships appropraite to developmental level

c) a lack of spontaneous seeking to share enjoyment, interests, or achievements with other people (e.g., by a lack of showing, bringing, or pointing out objects of interest). (4th ed., text rev.; DSM-IV-TR, American Psychiatric Association, 2000, Pervasive Developmental Disorders, para. 1)

This emphasis on impairments in social interaction highlights one of the fundamental aspects of autism, distinguishing it from general language or cognitive delays. When Leo Kanner first described the condition in 1943, he described the children as having a "tendency to live within themselves" but showing "indications of good cognitive intelligence" (Kanner, 1944, p. 211), again highlighting the same distinction. In fact, the 
CDC reports that $62 \%$ of children with ASD do not have an intellectual disability (CDC, 2008). However, many individuals with autism do have language impairments, and learn language later in life than typically developing individuals (Mitchell, et al., 2006). Further, children with autism appear to learn language differently than most individuals, with rates of receptive language outweighing rates of expressive language by a greater margin than is observed in typical development (Hudry, et al., 2010).

Individuals with autism who do learn to communicate functionally often do so only with direct training (Kelley, Shillingsburg, Castro, Addison, \& LaRue, 2007; Michael \& Sundberg, 2001; Stone \& Yoder, 2001). However, the language that does emerge early on in individuals with autism is more likely to be imperative rather than declarative (Goodhart \& Baron-Cohen, 1993). Loveland and Landry (1986) for example, compared mental age- and mean length of utterance-matched children with autism and developmental delays in their use of gestural joint attention and spontaneous communicative behavior. Their findings showed that children with autism had less spontaneous communicative behavior, and were more likely to use imperative gestures to access objects instead of declarative gestures to point or show than the children with developmental delays. This demonstrated a distinction in the function of the language used between the groups that could not be attributed to mental age nor language ability. In other words, children who had the same mental age and level of language ability had distinct communication styles reflective of distinct functions of language.

Many communication training programs begin by teaching children with autism to mand, or to request desired objects or activities, because this type of communication tends to develop earlier and more easily in children with autism (Michael \& Sundberg, 
2001). Further, there is evidence to show that mand training decreases problem behaviors in children with autism, presumably because the children are able to access preferred stimuli, thereby reducing inappropriate behaviors that serve the same function (Plavnick \& Ferreri, 2012). While this type of language training is important and benefits the child as well as his caregivers, it does not satisfy some of the more social functions of language. This distinction in the function of verbal behavior again highlights the social impairment in autism, and distinguishes it from a more general language or cognitive delay.

As defined in the DSM-IV-TR (American Psychiatric Association, 2000), individuals with autism also engage in restricted, repetitive and stereotyped patterns of behavior. These patterns of behavior tend to be nonsocial and "self-stimulatory" (Cunningham \& Schreibman, 2008) contributing to the social impairments found in autism. When individuals with autism engage in these types of behavior patterns, they are prevented from interacting socially with others around them. Often, individuals with autism have very specific and narrow interests that are difficult to share with others (Frith, 1997). It is difficult to say if the restricted, repetitive and stereotyped patterns of behavior contribute to the social impairment, or if the social impairment contributes to these types of behavior patterns, but regardless of the origin, it is likely that a social impairment decreases the motivation to disengage from repetitive and stereotyped behavior.

\section{Autism Prevalence}

According to the CDC, about one in 88 children have been diagnosed with ASD (CDC, 2008). The likelihood of being diagnosed with autism is about five times greater 
for boys than for girls, where one in 54 boys are diagnosed but only one in 252 girls are diagnosed with the disorder $(\mathrm{CDC}, 2008)$. Further, the rate of diagnosis appears to be increasing, with prevalence rates growing from one in 150 in the year 2000, to one in 125 in 2004, and one in 88 in 2008, with more than double the number of sites reporting in 2008 as compared to the year 2000 (CDC, 2008). Additionally, ASD diagnoses appear to affect all racial, ethnic and socioeconomic groups, and prevalence rates reported in studies from Asia, Europe and North America are similar those reported by the CDC at about 1\% (CDC, 2008), making autism a global concern that demands attention from researchers and clinicians alike.

The risks for being diagnosed with autism are still being discovered, however some data are available. For example a study that looked at 1,251 cases of autism indicated that firstborn children of two older parents (mothers older than 35 and fathers older than 40) were three times more likely to be diagnosed with autism than third- or later-born children of younger parents (Durkin et al., 2008). Another study investigating gestational age and birth weight determined that babies born with a birth weight less than 2500 grams, and with a gestational age of less than 33 weeks were twice as likely to be diagnosed with autism (Schendel \& Bhasin, 2008). Finally, the incidence rates within families indicate a potential genetic component. Studies investigating prevalence within families show that parents who have one child diagnosed with ASD have a $2-18 \%$ chance of having a second child who is diagnosed; and among identical twins there is a $36-95 \%$ chance that both twins will be affected (CDC, 2008). That number drops off to $0-31 \%$ for non-identical twins (CDC, 2008). 
Autism can be diagnosed reliably at two years of age. In a longitudinal study looking at 192 children with autism, Lord et al. (2006) demonstrated stability in diagnoses made at two years at age nine, with $67 \%$ agreement in best-estimate diagnoses. Diagnostic changes came primarily from changes in initial diagnoses of pervasive developmental disorder not otherwise specified that were later upgraded to autism. Early, reliable diagnoses are important for early intervention. However, most children are not diagnosed until age four, and although the trend is towards earlier diagnoses, only about $18 \%$ of children are diagnosed by age three (CDC, 2008). Parents with children who are later diagnosed with autism report that they have concerns about their child's development within the first year (CDC, 2008). Toward the goal of earlier identification to facilitate early intervention, researchers have been developing measures that may identify autism symptoms in the first year. One of these is the First Year Inventory, which is a parent questionnaire designed to assess behaviors in 12-month old children at risk for being diagnosed with ASD (Watson et al., 2007).

\section{Autism Intervention}

Applied behavior analysis (ABA) has been applied to behavioral deficits and excesses related to autism since the 1960's when Ivar Lovaas conceptualized an intensive intervention for children requiring 40 hours per week of one-to-one training (Smith \& Eikeseth, 2011). Since then ABA has continued to gain acceptance among health care professionals and educators, and is used in many schools and treatment clinics (CDC, 2008). The use of ABA for autism intervention is supported by the United States Surgeon General, and has been used successfully for over 35 years in residential and nonresidential settings (Foxx, 2008). There have been over 1,000 peer-reviewed 
scientific articles describing successful ABA interventions, and the National Institutes of Mental Health have funded ABA research for autism intervention continuously for the last 40 hears (Foxx, 2008). However, methodological issues related to variability in intervention features such as treatment intensity, duration and format, and inconsistencies in research design and metrics used to gauge success have prevented meta-analyses to validate ABA treatments in general (Virues-Ortega, 2010). Regardless, current best practices for the treatment of individuals with autism includes the use of ABA principles (Foxx, 2008), broad as that statement may be.

Early intensive behavioral intervention (EIBI) is the application of behavior analytic principles to young children diagnosed with autism (Smith \& Eikeseth 2011). All bona fide EIBI programs have some common elements including: a) individualized and comprehensive interventions b) that are guided by typical developmental sequences c) and that are implemented in a one-to-one fashion d) using parents and other caregivers as active participants in program implementation. They e) use behavior analytic procedures to address behavioral excesses and skill deficits and are f) supervised or directed by individuals with advanced training in behavior analysis (Eldevik et al., 2009). Intervention normally lasts about two years, and starts when children are between three and four years of age (Eldevik et al., 2009).

The content of EIBI programs differs across clinics and schools, making broad comparisons difficult to make (Virues-Ortega, 2010). However, there are a few manualized programs that are widely used and can be used to discuss the types of skills that are typically targeted. One commonly used manual is the Assessment of Basic Language and Learning Skills Revised (ABLLS - R; Partington, 2006) that includes 544 
skills, broken down into 25 skill areas including language and social interaction (Partington, 2006). The Verbal Behavior Milestones Assessment and Placement Program (VB-MAPP; Sundberg, 2008) is another commonly used manual that includes 170 milestones and over 900 tasks divided into different content areas.

These manuals allow clinicians to assess current skill levels in children with autism. They also provide a list of skills to be taught following a developmental sequence. As comprehensive as these manuals are, the focus of them is on teaching individual behaviors, which may or may not address some of the fundamental issues with autism. As described in the diagnostic manual, one of the diagnostic criteria is in the failure to "spontaneously seek to share enjoyment" (4th ed., text rev.; DSM-IV-TR, American Psychiatric Association, 2000, Pervasive Developmental Disorders, para. 1), which may not be a skill deficit, per se, but can be seen as a difference in the source of motivation for behavior. One potential area that is not often targeted in early behavioral intervention, and may be recommended, is at the social-emotional level, rather than at the behavioral level (Panskeep \& Sahley, 1987; Helt et al., 2008).

\section{Social Orienting as a Core Deficit in Autism}

One of the earliest markers of autism is a failure to orient to social stimuli (Dawson, Meltzoff, Osterling, Rinaldi, \& Brown, 1998). Studies using retrospective analysis of home videos have shown pronounced differences in eye-contact and eyecontact quality in children later diagnosed with autism within the first year of life, with discrepancies across groups increasing with age (Clifford \& Dissanayake, 2008). Further, research using the First Year Inventory (Watson et al., 2007) used retrospective parent responses to show that high-risk scores on social orienting tended to be rare among 
children with developmental delays, but were common among children with ASD (Watson et al., 2007). This may indicate that the social orienting deficit is specific to autism, relative to other developmental delays, and may in fact be indicative of a risk for developing the disorder. In a cross-sectional study, Elison, Sasson, Turner-Brown, Dichter, and Bodfish (2012) compared the visual exploration of social and nonsocial scenes of children with autism and typically developing children 2-18 years of age. Their findings show that children with autism have a "disproportionate attentional bias for [nonsocial] stimuli from very early in life," (p. 849) which results in less change in overall visual exploration. In other words, typically developing children have a bias towards social stimuli early in life (Elsabbagh et al., 2013). As typically developing children get older, they tend to engage in more complete visual exploration, extending to nonsocial stimuli. Klin, Lin, Gorrindo, Ramsay, and Jones (2012) confirmed this finding in a study that showed that two-year olds with autism oriented to nonsocial contingencies, rather than biological motion. In their study, the typically developing control group disregarded the nonsocial, physical contingencies that the children with autism attended to, highlighting a very basic but important difference in their visual exploration. It seems that children with autism do not have the initial bias towards social stimuli that typically developing children do (Klin, Lin, Gorrindo, Ramsay, \& Jones, 2009).

The problem of orienting to social stimuli continues throughout development for individuals diagnosed with autism. During an orienting task, Dawson, Melztoff, Osterling, Rinaldi, and Brown (1998) showed that children with autism (mean CA $=64.6$ months) failed to orient to a social stimulus in about $50 \%$ of trials, compared to almost $100 \%$ orienting in the groups with typically developing individuals and those with Down 
Syndrome. These differences were not significant when the stimulus being oriented to was nonsocial, demonstrating the effects of the type of stimuli involved, and not just a general orienting disturbance. In a more recent study using older participants, eyetracking technology was used to examine spontaneous viewing patterns when observing a social scene (Klin, Jones, Schultz, Volkmar, \& Cohen, 2002). Fifteen matched adolescents and young adults watched video clips of a popular movie, revealing that participants in the ASD group focused " 2 times more on the mouth region, 2 times more on the body region, and 2 times more on the object region relative to age- and verbal IQmatched controls" (p. 812). Further, results from the eye-tracking data were correlated with measures of social adaptation and social disability, which showed that greater fixation time on the object region of the screen was correlated with lower social adaptation and greater autistic impairment.

An inability or a lack of motivation to orient to social stimuli in the environment can have detrimental effects on development (Dawson et al., 1998; 2004; 2008; Watson et al., 2007; Helt et al., 2008). When infants and children observe the social environment around them they learn about the meaning of facial expressions, the association between words used and objects in the environment and how to communicate effectively with other people, which are all necessary to function successfully as part of a social network (Mundy, Sullivan, \& Mastergeorge, 2009). Therefore, it is possible that targeting early orientation to social stimuli may have a profound effect on development. However, the mechanism for targeting these responses is unclear. Using contrived, nonsocial reinforcers to maintain orienting to social stimuli may not have the same function as 
orienting to social stimuli that is maintained by social reinforcement, and thus may not maintain.

\section{Social Reinforcement}

Skinner (1953) discussed the amplitude of social stimuli that can function as reinforcers, such as a smile, verbal praise, acceptance or approval, and physical contact. Social stimuli have been empirically shown to function as reinforcers for simple tasks such as lever pressing by college students (Lamberth, Gay, \& Dyck, 1972) and more complex behaviors such as general play by second grade students (McArthur \& Zigler, 1969). For example, Lamberth et al. (1972) demonstrated a reinforcing effect of varying magnitude that directly correlated with the magnitude of the social reinforcer delivered in a discrete trial training, demonstrating not only that social stimuli can have a reinforcing effect, but also that the magnitude of the reinforcer (i.e., quality and quantity) mattered.

Social reinforcement has also been linked to improved achievement and behavior in elementary-age students (Stein, 1969; Fisher \& Wollersheim, 1986), better outcomes in parent-child interaction therapy (Borrego \& Urquiza, 1998), a decrease in seclusion behavior in agoraphobic patients (Agras, Leitenberg, \& Barlow, 1968) and positive affect in young children (Furman \& Masters, 1980) to name a few. For example, Borrego \& Urquiza (1998) discuss the importance of the use of social reinforcement within therapy sessions with parents and children as a way to increase treatment fidelity, as well as a method of indirect instruction where modeling of social reinforcement resulted in increased use of social reinforcement by parents. Similarly, Furman and Masters (1980) discussed the value of positive social interactions on the affective expression of four- and five-year-old children, reporting that children who were observed in a setting where 
positive social reinforcement was readily available had more positive affective reactions than those in settings where punishing or neutral responses were delivered. Although these results may seem self-evident, it is important to describe the ways in which social reinforcers affect most individuals, and children in particular. Without question, the role of social reinforcement is evident in the literature of the fields of education, psychology and social science; and though it may be discussed in different ways, the presentation of social reinforcers contingent on a variety of behaviors lends itself to an operant analysis.

As evidenced in typical development, social stimuli tend to reinforce many of the behaviors acquired very early in life (Skinner, 1953; Gewirtz, 1969). Even in infancy, behaviors such as crying and smiling are sensitive to social reinforcers, and entire patterns of behavior can be attributed to maternal interaction. For example, Gewirtz and Pelaez (2000) discussed many studies that demonstrated how phenomena such as infant attachment, fear of the dark, fear of strangers, jealousy, and depression were under the control of maternal behavior (e.g., social reinforcement via the mother's attention). Although these studies "do not rule out definitively the literature's predominant notions that the behaviors denoting attachment, fear, jealousy and depression are innately determined" (p. 272), they at least demonstrated that social reinforcement plays an important role in the maintenance of the responses under these labels. When "probabilities $(\mathrm{p}<.001)$ in favor of the operant hypothesis [are] found in every instance" (p. 272) it is difficult to ignore the relationship between social reinforcement and infant behaviors. However, children with autism do not always seem to respond to social reinforcers in the same way. 


\section{Social Reinforcement in Autism}

Social stimuli do not always function as reinforcers for individuals with autism (Lovaas et al., 1966). Some children may even find social interaction aversive (Hagopian, Wilson, \& Wilder, 2001; Taylor \& Carr, 1992). Behavior analysts who provide interventions for individuals with autism attempt to use social reinforcers in most cases (Vollmer \& Hackenberg, 2001), but when the reinforcing effects of social stimuli are not evident, other, nonsocial reinforcers are used. For some behaviors, the presentation of nonsocial reinforcers is sufficient to increase desirable behaviors such as appropriately requesting preferred objects (Gutierrez et al., 2007) and breaks from a task (Lalli \& Kates, 1995). However, communicative behaviors, such as recounting the day's events or telling a funny story, that are maintained exclusively by social reinforcement may not maintain when nonsocial reinforcers are used.

Studies that examine the verbal behavior of children with autism often cite the different levels of protodeclarative (the purely social motive of sharing attention to something) and protoimperative responses (getting another's attention for the sake of obtaining a desired item or change in the environment) (Goodhart \& Baron-Cohen, 1993). The general finding in most of these studies is that children with autism do not have substantial deficits in engaging in protoimperative communication, but do have substantial deficits in engaging in protodeclarative communication (e.g., Leekam, Lopez, \& Moore, 2000; Loveland \& Landry, 1986). In a study conducted by Goodhart and Baron-Cohen (1993), 20 typically developing children and 20 children with autism who had some language were tested on their propensity to spontaneously point, or to point when the experimenter asked about a book. They reported that $90 \%$ of all of the children 
were observed engaging in referential pointing, or pointing that was done to respond to the question "what is in the book?" However, only $25 \%$ of the children with autism engaged in protodeclarative pointing, or pointing that was done spontaneously to show something to the experimenter, as compared to $90 \%$ of the typically developing children. This meant that when the children with autism communicated, it was more likely to be in response to a command, rather than for the purely social motive of sharing enjoyment in the object or event.

Regardless of the differences in the propensity to engage in one type of communication over another, the developmental goals of intervention should, and often do, include more social forms of communication. One example that is currently being investigated in the field of $\mathrm{ABA}$ intervention is in the training of joint attention (e.g., Isaksen \& Holth, 2009). However, a major limitation to this type of training has been that when training social behaviors; and when the natural consequence of a behavior is exclusively social, the use of nonsocial reinforcers may be inappropriate (Whalen \& Schreibman, 2003).

\section{The Case of Joint Attention}

Joint Attention is the coordination of attention between two people and an object or event in the environment (Charman et al., 1997; Mundy, 1995; Mundy \& Newel, 2007). Its importance to the development of language and social cognition has been widely documented in the developmental and behavioral literature (Charman et al., 1997; Jones, Carr, \& Feeley, 2006; Morales et al., 2000). For example, Morales et al. (2000) used a longitudinal study to evaluate the relationship between the ability to respond to joint attention in infancy and subsequent language development. Twenty-two infants 
were evaluated for joint attention at two-month intervals between the ages of six and 12 months, and three-month intervals between the ages of 12 and 24 months. They were subsequently assessed for language development using parent reports at 24 and 30 months of age, and using standardized language assessments at 30 months. Results of a regression analysis indicated that greater performance in joint attention between six and 18 months of age predicted larger receptive and expressive language vocabularies at 30 months, illuminating the role of joint attention in language learning. Similarly, Brooks and Meltzoff (2005) demonstrated a positive correlation between responding to joint attention behavior at 10-11 months and language scores at 18 months. Further, Brooks and Meltzoff (2008) indicated that pointing (a behavior often linked to initiating joint attention) strengthened language development when gaze following predicted it. Joint attention deficits are common in autism (Mundy, 1995; Mundy et al., 2009). Some researchers have suggested that the impairment of joint attention is a core deficit in autism, and that the absence of joint attention can be used as a way to distinguish individuals with autism and other developmental disabilities (Mundy \& Vaughan, 2001). According to Mundy et al. (2009) joint attention is part of an information-processing system that encodes information about other's attention, which is fundamental to human learning and the development of social cognition and social competence throughout life. Thus, deficits in joint attention early in infancy may contribute to the development of autism symptoms in early childhood, particularly in the areas of language and social cognition.

Many attempts have been made to train the component skills of joint attention (Meindl \& Cannella-Malone, 2011). In one of the first attempts to teach and reinforce 
joint attention skills in children with autism, Whalen and Schreibman (2003) used tangible reinforcers (e.g., edibles and toys) to reinforce the component skills of joint attention. While initially successful, follow-up evaluations showed that the initial increases in joint attention were not maintained, and the children were not engaging in joint attention spontaneously. A review of the literature confirms that most researcher have used nonsocial reinforcers to train joint attention, with increases in responding to bids of joint attention, but not in initiating them (Meindl \& Cannella-Malone, 2011). One possible explanation is that while the behaviors that make up joint attention can be taught using tangible reinforcers, the behavior is not likely to maintain because tangible reinforcers do not naturally occur when one initiates joint attention. Instead, a social stimulus normally follows. Successive studies in teaching joint attention skills to children with autism have attempted to use social stimuli to reinforce joint attention, and have even used conditioning procedures to enhance or establish the reinforcing effects of social stimuli prior to teaching joint attention (Dube, MacDonald, Mansfield, Holcolmb, \&Ahearn, 2004; Jones \& Carr, 2004; Isaksen \& Holth, 2009). For example, Isaksen and Holth (2009) used a discriminative stimulus procedure to condition a smile to function as a reinforcer prior to training joint attention. Their data showed an improvement in joint attention skills, as well as maintenance of training effects at a one-month follow up test.

The case of joint attention presents a perfect example of the limitations of using contrived and tangible reinforcers for behaviors that are normally maintained by social interaction, particularly when social reinforcers are ineffective. One interesting dichotomy in the joint attention behavior of children with autism that has been largely undisputed is in the difference between individuals with autism's performance in 
responding to joint attention (RJA) versus initiating joint attention (IJA). RJA is the response to a bid to look at something in the environment, while IJA is the initiation of a bid to have someone else look at something in the environment for the purpose of sharing enjoyment in the environmental event (Mundy, 1995). It has been repeatedly found that performance in RJA more closely resembles that of typically developing individuals, but that performance in IJA is markedly diminished in individuals with autism (Mundy, 1995; Mundy \& Newell, 2007; Nation \& Penny, 2008). Further, a study examining the contributions of joint attention to language development indicated that impairments specifically in the initiation of joint attention were correlated with decreased language ability at three and four years of age (Toth, Munson, Meltzoff, \& Dawson, 2006), perhaps indicating a more severe manifestation of autism.

In this dichotomy, both types of tasks include social stimuli. However in RJA there is an attentional bid to observe something in the environment, which could potentially include reinforcement in a variety of forms, including nonsocial positive reinforcement, such as an interesting toy or available treat, or negative reinforcement in the form of avoiding a potentially dangerous situation. In IJA however, the initiation of the response must come from the individual and must be for the purpose of sharing the enjoyment of an event or experience. Thus, the function of the two responses is clearly different: RJA functioning for a variety of social and nonsocial reinforcers, and IJA functioning solely for an often subtle, social interaction. These differences, again, show the specificity of the deficit in orienting and responding to social stimuli. They also highlight the importance of having social stimuli function as reinforcers. If social stimuli 
were effective reinforcers, the differences in social behaviors seen in autism may be less evident.

Are Social Stimuli Reinforcing in Autism?

Social stimuli are often complex, dynamic and unpredictable, making it difficult for individuals with autism to attend to them (Greenway \& Plaisted, 2005). Studies on visual scanning and attentional focus with individuals with autism have shown that there is a general tendency to attend to low-level perceptual information, as well as to pay attention to often-irrelevant details in a scene (O’Connor \& Kirk, 2008; Sasson, TurnerBrown, Holtzclaw, Lam, \& Bodfish, 2008). This makes the argument that it is not necessarily that social stimuli are unattractive, but that individuals with autism find other stimuli more salient. Some even argue that this attention to detail makes individuals with autism superior at processing certain types of information, making the disorder more of a difference in processing, rather than a deficit (O’Conner \& Kirk, 2008).

The exaggerated attention to detail may lead to a difficulty with processing information in context, and at a global versus local level. What has been labeled as the "weak central coherence" hypothesis (Frith \& Happe, 1994) proposes that difficulties with attention to complex and global information are a result of a general impairment in global processing, and not a specific social deficit (O’Connor \& Kirk, 2008). Visual engagement of low-level perceptual information and detail also seems to come with a difficulty with disengaging from such stimuli in order to attend to other stimuli in the environment. Using a gap-overlap task, Elsabbagh et al. (2009) demonstrated that infant siblings at risk for autism showed longer disengagement latencies when a peripheral stimulus was displayed on a screen, when compared to a control group. This inability to 
disengage from an irrelevant part of a scene may help to explain the general reduced visual exploration seen in individuals with autism (Sasson et al., 2008). However, it does not help explain why, when scanning does occur, it is less likely for individuals with autism to attend to social versus nonsocial stimuli.

In a visual array task used by Sasson et al. (2008), visual engagement with social, high autism interest (HAI, for example trains and electronics), and low autism interest (LAI, for example furniture and clothes) items was measured using eye-tracking technology. Their results showed that, although children with autism were more likely to look at nonsocial versus social stimuli, they were more likely to look at social stimuli when they were presented in tandem with LAI items versus HAI items. This finding suggests, again, that it may not be an issue of selecting nonsocial stimuli over social stimuli, but that certain stimuli in the environment can garner undue attention and thus prevent broader scanning of a scene. Interestingly however, Sasson et al. suggest that "social and nonsocial information differ in relative reward value of nonsocial information" (p. 39), which results in increased attention to nonsocial versus social stimuli. Indeed, it is likely that individuals will turn their focus towards reinforcing stimuli.

Many researchers have attempted to pinpoint why it is that individuals with autism attend more to nonsocial versus social stimuli. Some suggest that identifying the reason for this discrepancy may elucidate the most fundamental component of what causes the developmental cascade into full autism spectrum disorder (Mundy, 1995). 


\section{Social Motivation Theory}

Some studies have suggested that the neural networks involved in emotional regulation are disrupted in individuals with autism (Panskeep \& Sahley, 1987; Scott-Van Zeeland, Dapretto, Ghahremani, Poldtrack \& Bookheimer, 2010). Early neuropsychological studies using electroencephalography technology with 10-month-old infants demonstrated left pre-frontal cortex activation associated with maternal approach and positive affect, but not with stranger approach and negative affect (Fox \& Davidson, 1987; 1988). These data suggest that the left-prefrontal cortex is involved in the expression of positive affect, including facial signs of joy and vocalizations specifically related to maternal approach, particularly maternal reach. This combination of social approach and positive affect presents a specific type of social behavior, where the function, or reinforcer, is engagement with a social partner.

Developmental studies have also demonstrated an early bias for attending to social stimuli in young infants (e.g. Field, 1979; Panskeep \& Sahley, 1987; Cassia, Valenza, Simion, \& Leo, 2008; Elsabbagh et al., 2013), which may be evolutionarily and biologically important. These findings suggest that the neural networks that mediate emotion regulation and associated approach or withdrawal are present very early in development, and may contribute to social development (Mundy, 1995). Thus, the specificity of the impairment in autism to initiate social interactions seems to fit with the model that social approach behavior is a specific set of behaviors to which typically developing infants may be predisposed, and that are disrupted in autism. Sahley and Panksepp (1987) suggest that one of the neurophysiological deficits in autism is the inability of the emotional systems of the brain to mediate social affect and social intent. 
They further discuss preliminary evidence to suggest that opiod receptor blockers may increase social intent in laboratory animals. These findings present an interesting perspective of the possible roots of autism symptom presentation, in that socialemotional, rather than cognitive variables are involved. Furthermore, these findings have important implications for the treatment of autism from a social-emotional perspective.

This interesting and growing body of literature supports the notion that symptoms in autism may be caused by a general reduction in social motivation. The Social Motivation Theory (SMT; Chevallier, Kohls, Troiani, Brodkin, \& Schultz, 2012), gathering from behavioral and neuroscience research, posits that diminished social motivation, rather than social cognition, is responsible for diminished social orienting and social reward. Further, the SMT argues that the deficits in social cognition can also be explained, and are caused by the mechanisms affected in social motivation (Chevallier et al., 2012). Dawson (2008) discussed the integration of the neural systems that process social stimuli, including the fusiform gyrus and the language regions with the amygdala and related reward mechanisms, highlighting the potential connections at the neurological level. For example, functional MRI data show diminished neural responses to both social and monetary rewards in twelve-year old boys with ASD as compared to age- and IQmatched typically developing boys, with a pronounced reduction in the response to social rewards during an implicit learning task (Scott-Van Zeeland et al., 2010). However, the neurological evidence for the affectedness of the social-reward system in autism is minimal and requires further investigation.

Although the neurological evidence is limited and preliminary, there is abundant behavioral evidence that suggests that social orienting and social motivation are low in 
individuals with autism, and including social motivation as a target for therapeutic intervention should be pursued. In a review of the literature contemplating the possibility of the reduction of symptoms of autism, Helt et al. (2008) suggested directly targeting the reinforcement value of social stimuli, along with other traditional and empirically validated interventions, to increase the likelihood of recovery from symptoms of autism. The explanation for including this component in autism treatment is that following successful conditioning the child may experience emotional arousal in the presence of social stimuli, and thus "rewire" the circuitry between the amygdala and the prefrontal cortex, correcting the lacking bias for social stimuli in infants with autism. Another important component to this hypothesis is intervening early, to take advantage of the plasticity of an infant's brain systems, and to impact as much of the subsequent development of the individual as possible. Dawson (2008) proposes the same type of intervention early enough to make the prevention of autism plausible.

\section{Establishing Social Conditioned Reinforcers}

Social reinforcers are likely made up of a combination of unconditioned or evolutionarily learned stimuli (e.g., touch and facial expressions) and conditioned stimuli (e.g., praise and acceptance) (Vollmer \& Hackenberg, 2001). Early in life, unconditioned social stimuli such as warmth and touch likely make up the majority of external influences on development and behavior. However, as the child develops the list of conditioned social stimuli that function as reinforcers grows. This is likely the result of the many associations made between social stimuli and already established or unconditioned reinforcers, as well as through the discriminative value of a social stimulus for said reinforcers (Gewirtz, 1969). For example, a child receiving warmth, comfort and 
nutrition from his mother makes the mother's presence reinforcing (Gewirtz \& Pelaez, 1992). In the same vein, the presence of a young child's mother can function as a discriminative stimulus for behavior that is reinforced by maternal attention, making her presence reinforcing (Vollmer, Northup, Ringdahl, LeBlanc, \& Chauvin, 1996). By whichever process, the end result is a long list of conditioned social stimuli that help shape (for better or worse) the development of most individuals.

The fact that a stimulus can have a variety of functions across development and context is an adaptive trait that promotes the survival of individuals, and of the species (Skinner, 1953). It allows a complex set of environmental contingencies to create a context for future interactions, and allows individuals to detect and contact reinforcers in the environment. The range of conditioned social stimuli that are effective in maintaining behavior broadens with development to include less salient social stimuli, while the range of unconditioned stimuli remains about the same, making the ability for new social stimuli to become conditioned increasingly important with age (Gewirtz, 1969). In other words, for infants to develop typically, it is necessary for them to adapt to new and subtler forms of social contingencies, as social interactions become more complex.

For infants with autism, the lack of social orienting early in life may make it more difficult for these associations to be made, making it less likely that they will develop typically. In fact, the literature on pairing specifically discusses the importance of attending to a stimulus in order for the conditioning to occur (Dozier, Iwata, ThomasonSassi, Worsdell, \& Wilson, 2012). Stated differently, "restriction of early social interaction prevents social contact from acquiring reward value" (Helt et al., 2008). Further, longitudinal studies looking at the development of children with autism were 
able to predict optimal outcomes following intervention based, partly, on social interest scores prior to intervention (Helt et al., 2008), demonstrating the importance of early social reinforcement to the susceptibility of intervention.

Simply because children with autism have a diminished desire to orient to social stimuli does not mean that these stimuli cannot be conditioned to be more reinforcing, and thus provide motivation for social orienting and subsequent social behaviors. Through our understanding of learning processes, researchers in behavior analysis and related fields have been able to use conditioning procedures to change the function of neutral or ineffective stimuli (e.g., Ayllon \& Azrin, 1968; Gewirtz \& Pelaez-Nogueras, 1992; Dozier et al., 2012). One widely used and practical example from the behavior analytic literature is the use of token systems in classrooms and residential facilities (Ayllon \& Azrin, 1968). In this type of training, a neutral stimulus such as a token or a check mark is either paired with, or signals the delivery of, an already established or unconditioned reinforcer. Over time, the delivery of the token itself functions as a reinforcer, and the need to provide the established or unconditioned reinforcer decreases. Ineffective or neutral social stimuli have also been conditioned to function as reinforcers through similar techniques (Gewirtz \& Pelaez-Nogueras, 1992; Dozier et al., 2012). For example, Gewritz and Pelaez-Nogueras (1992) conditioned arbitrary maternal facial expressions to function as discriminative stimuli for reinforcement in one-year-old infants using an operant approach. In their study, the researchers covered an ambiguous object and asked the mother to either signal approach or avoidance with either a closed fist over the nose or with open palms next to the face. When the infant reached for the object either a reinforcing or a punishing stimulus was delivered. Subsequently, maternal facial 
expressions served to reinforce or punish reaching behavior in all 20 of the infants who participated.

\section{Stimulus-Stimulus Pairing}

One of the most commonly used methods to change the function of a stimulus is through stimulus-stimulus pairings (Catania, 2007). Stimulus-stimulus (S-S) pairing involves the temporal relationship of two stimuli that results in a neutral stimulus (NS) becoming a conditioned stimulus (CS) after pairings with an unconditioned stimulus (US) or an already established CS. Ivan Petrovich Pavlov first discovered the pairing effect in 1901 when he noticed that the dogs he was studying began to salivate when the sound of food presentation was heard, rather than when the food itself was presented (Pierce \& Cheney, 2008). This discovery provided tremendous insight into one of the ways that organisms learn and has been useful in many clinical applications including the reduction of phobias (Wolpe, 1958), the reduction of drinking in alcoholics (Chakravarthy, Kumaraiah, \& Mishra, 1990) and the reduction of eating in obese individuals (Frohwirth \& Foreyt, 1978).

The S-S pairing paradigm has been used in myriad experiments and has been proven effective in conditioning reflexive responses across a variety of organisms (e.g., Watson \& Rayner, 1920; Vanetsian, 1974; Gutmann, Brozek, \& Bures, 1972; Svensoon \& Ivarsson, 1999). Some common examples include conditioning the eye-blink reflex in small animals including cats (Vanetsian, 1974), rabbits (Gutmann et al., 1972) and ferrets (Svensoon \& Ivarsson, 1999), to study neural processes; as well as in humans, to study learning processes (Papka, Ivry, \& Woodruff-Pak, 1997). The desensitization (or extinction) of the fear response in humans with severe phobias including school phobia 
(Lazarus, Davison, \& Polefka, 1965), flying phobia (Vriends, Michael, Schindler, \& Margaf, 2012), and dog phobia (Glasscock \& MacLean, 1990), among others, has also been well documented and is regarded as a reasonable way to treat phobias because of the understanding that the phobias themselves come from S-S pairings in the individual's learning history (Wolpe, 1958; Schweckendiek, Klucken, Merz, Tabbert, \& Walter, 2011).

Stimulus-stimulus pairings have also been used in children with autism, in an attempt to increase the reinforcing value of vocalizations, with mixed success (Caio, Carr, \& Michael, 2001; 2002; Normand, \& Knoll, 2006; Carroll \& Klatt, 2008). This S-S procedure was intended to increase the reinforcing value of the child's own vocalizations by pairing the same vocalizations with presumed reinforcers, to create an automaticreinforcement effect. The gist of these procedures was that the experimenter emitted vocalizations that the participants currently emitted at a low rate while simultaneously delivering preferred stimuli. The rate of utterances by the participants was then compared before and after the conditioning procedure. However, each of these studies showed positive results for some, but not all participants. Clearly more work is needed to make the pairing procedure effective for more of these young participants.

Many aspects of the stimuli involved in pairing, as well as their temporal relationship, affect the likelihood of successful conditioning. Some of these variables are well known. For example, presenting the NS immediately (between $.5-1$ second) before the US and letting it overlap slightly (known as delay conditioning) is the most effective temporal relationship for establishing a new stimulus function when compared to simultaneous or backward conditioning (Catania, 2007). Increased consistency in 
pairings also increases the efficacy and durability of the conditioning effect (Catania, 2007). Some variables are less discussed but may still be important. For example, the stimuli that are used to condition the neutral stimuli should actually function as reinforcers. For example Dozier et al. (2012) used reinforcer tests to determine the reinforcing effectiveness of food as a reinforcer. Only the most effective items were used. Reinforcers are idiosyncratic, especially in children with autism, and great care must be taken to ensure that the stimuli selected for conditioning are going to have a durable effect. If the US was not particularly reinforcing, it could take many trials for conditioning to occur, or it may never occur (Catania, 2007). One possible limitation of the studies mentioned above that employ S-S pairings in children with autism was that they did not emphasize preference or reinforcer assessments, perhaps contributing to the lack of consistent effects.

Another variable that has been discussed more recently, and seems important, is making the pairings contingent on a response (Dozier et al., 2012; Miller \& Drennen, 1970; Stahl et al., 1974). For example, Dozier et al. (2012) compared S-S pairings that were non-contingent to pairings that were contingent on a simple task. In their study, neutral praise statements were paired with preferred edibles and then tested for their reinforcing effectiveness on a subsequent task. The non-contingent pairings were not successful for three of the four participants, even though thousands of pairings were presented. However, the contingent pairing procedure (response-stimulus pairing) was successful in establishing praise as a reinforcer for four of the eight participants. One explanation for the difference in results is that the process of contingent pairing may increase the attention paid to the stimuli being paired. Alternatively, there may be a 
temporary increase in the reinforcing value of the US based on an establishing operation created by successfully completing the response. Either way, presenting the S-S pair immediately following a response appears to make the procedure more effective (Dozier et al., 2012). This may also be a limitation of the S-S studies mentioned above, which did not present the S-S pairs following a response, perhaps contributing to their mixed results. The vast literature on pairing procedures highlights the implicit assumption that the classical conditioning paradigm is the best method for establishing conditioned reinforcers. Indeed, it is the most researched and most commonly used method for establishing new functions in stimuli, but it is not the only mechanism by which stimuli become conditioned.

\section{Discriminative Stimulus Procedure (Sd Procedure)}

Another potential method to change the function of a stimulus is the discriminative stimulus procedure. According to Dinsmoor's hypothesis, a stimulus will take on reinforcing properties insofar as the individual can discriminate that stimulus as a necessary concomitant of reinforcement (Dinsmoore, 1950). In this procedure, an antecedent stimulus, which consistently signals the availability of reinforcement contingent on some response becomes reinforcing in its own right. In one of the few documented examples of this procedure, Lovaas et al., (1966) established the word "good" as discriminative for approaching an experimenter by delivering an edible item only when the word "good" was presented. Once the participant approached only in the presence of the word "good," lever pressing was used to demonstrate the reinforcing effects of the training. Lever pressing following conditioning demonstrated that responding in the presence of the word "good" continued to occur for many sessions, as 
long as the word "good" continued to be presented before reinforcement was delivered. This study demonstrated the durability of such a procedure, as long as the stimulus continued to be discriminative for available reinforcement.

Isaksen and Holth (2009) used a similar method to condition social stimuli prior to training joint attention in children with autism. In their procedure, the social stimulus (an experimenter's smiling face) was attended to before an already established reinforcer was delivered. However, the procedure was only one part of a comprehensive training that included explicitly training various components of joint attention, where addressing the reinforcing value of the social stimulus was only a small part. Once their training was complete, they tested the reinforcing effectiveness of the smile in a joint attention assessment. They reported moderate success for all four of the children who participated, with improvements in joint attention scores following the training. However, it was impossible to know if the level of success following the procedure was a result of the conditioning procedure, or a result of the complete training package. What is interesting about this procedure for joint attention and other social behaviors is that, following the logic of behavior chains, stimuli that indicate reinforcement come to have reinforcing properties themselves, thus making social stimuli both the antecedent stimulus, and the reinforcer, making this procedure worth pursuing.

\section{The Current Study}

The current study aimed to use operant and respondent procedures to condition social stimuli that were empirically shown to not be reinforcing prior to using empirically identified reinforcing stimuli. Particularly, this study aimed to compare the two procedures in their effectiveness to condition social stimuli to function as reinforcers for 
a simple task, as well as in their ability to maintain effects after conditioning ended. This study also sought to determine if conditioning social stimuli to function as reinforcers had any effect on the social functioning of young children with autism. The implications for this study include the refinement and selection of procedures used to condition neutral or ineffective social stimuli, as well as the potential benefits of conditioning social stimuli in young children with autism. To provide a general sense of overall social interactions before and after the conditioning procedures were conducted, the Early Social Communication Scales (ESCS; Mundy et al., 2003) was conducted as a pre- and postmeasure. It was hypothesized that the two procedures would result in different response rates for each of the social stimuli conditioned under each paradigm immediately following conditioning, as well as in follow-up sessions conducted three weeks after conditioning ended. It was also hypothesized that general social behaviors, particularly those tested in the ESCS would improve after both conditioning procedures were completed. 


\section{METHODOLOGY}

\section{Participants}

Six participants diagnosed with autism spectrum disorder between the ages of 18 months and three years participated. A research-reliable ADOS administrator confirmed diagnoses prior to beginning the study. Although an attempt was made to balance the number of female and male participants, all of the children who participated were male. This imbalance is reflective of the gender imbalance in autism diagnoses, where, according to the Centers for Disease Control and Prevention, boys are five times more likely to be diagnosed than girls (CDC, 2008). Participants were recruited from responses to a flyer posted in the monthly UM-NSU CARD e-newsletter (Appendix A), as well as from the Early Intensive Behavioral Intervention program at the Center for Children and Families at Florida International University.

\section{Materials}

An Autism Diagnostic Observation Schedule (ADOS; Lord, Rutter, DiLavore, \& Risi, 1989) kit was used to conduct ADOS assessments prior to intervetion. A scoring sheet that includes some of the items used is available in Appendix D. An Early Social Communication Scales (ESCS; Mundy, et al., 2003) kit was used to conduct ESCS assessments before and after intervention. A materials list is available in Appendix E. A Preference Assessment Parent Interview Form (Appendix C) was created for this study and used to generate a list of preferred social and nonsocial stimuli according to parental input. Tangible items identified by the participant's parents were purchased or borrowed in order to conduct reinforcer assessments, which then determined the stimuli that were 
used to condition social stimuli. Picture cards representing the social and nonsocial stimuli were created to represent access to the stimuli during reinforcer assessments. Sample social and nonsocial stimulus cards are available in appendices F and G. Items selected for conditioning included a bubble machine, an iPad, balloons, cookies, and a car-shaped book.

Procedure

Intake: Intake sessions were the first session where the investigator and the child and caregiver met. During the intake session the investigator provided information regarding the study and its potential risks and benefits as stated in the Parental Consent Form (Appendix B). Informed consent was obtained in the session, or the form was taken home so the families could review the information independently. Once informed consent was received, parents were interviewed using using the Preference Assessment Parent Interview Form to determine the child's preferences in both social and nonsocial stimuli.

ESCS and ADOS: ESCS and ADOS assessments were conducted during the second session. The ADOS was administered by a researcher who is not directly connected to the current study, and who is considered research reliable on the assessment. All of the children who participated were already diagnosed with autism. The ADOS was used to confirm these diagnoses. The ESCS was administered by the primary investigator, who is trained in conducting these assessments. The ESCS was used to provide a standardized measure of social behavior both before and after the study. 
Reinforcer Assessment: The five nonsocial stimuli ranked highest, and the five social stimuli ranked lowest from the Preference Assessment Parent Interview Form were validated using a free-operant, concurrent-choice reinforcer assessment (Smaby, MacDonald, Ahearn, \& Dube, 2000; Gutierrez, Fischer, Hale, Durocher, \& Alessandri, in press). Picture cards of the preferred stimuli were created to represent access to the ranked stimuli (Appendices $\mathrm{F}$ and $\mathrm{G}$ ). One at a time, the picture cards were presented to test how many times the child was willing to engage in a simple task (handing or touching a picture card) to obtain access to the stimulus. Each stimulus trial began with five forced exposures, where the researcher used prompting and verbal instructions (i.e., "if you want bubbles, give me the card") to have the child engage in the task, resulting in brief access to the stimulus ( $\sim 30$ seconds). After the forced exposures, the participant was asked to engage in the task as many times as they wanted during a one-minute interval in order to receive access to the stimulus (i.e., "as many times as you want, give me the card"). Each time the participant engaged in the task, the timer was paused to allow the child to engage with the stimulus being tested without detracting from the assessment interval. This was done to control for the differeces in the duration of access to the stimuli, which varied depending on the stimulus. For example, the time it takes to eat a piece of cookie or to let all the bubbles pop may be different each time. After the one-minute interval the stimuli were reset and the procedure was repeated until all 10 stimuli were tested. This process was repeated three times in varying order of presentation to control for order effects. The nonsocial stimulus that resulted in the highest rates of responding, and the two social stimuli that resulted in the lowest rates of responding were selected for the conditioning procedure. The social stimulus "smile" was 
included in all of the assessments, and was ranked lowest or second lowest each time. However, in order to replicate the procedure conducted by Isaksen and Holth (2009), smile was used for the discriminative stimulus procedure for all participants. Results for the reinforcer assessents are available in Appendix H.

Baseline: Baseline sessions were very similar to the reinforcer assessment sessions, where, following a forced exposure, the child engaged in a simple task in order to receive the stimulus as many times as they wanted within a one-minute interval. However, in this condition the picture card had a non-specific image (a smiley face, with different colors for each condition). Baseline was broken down into two parts. The first set of baseline trials were labeled extinction because no programmed consequences were given contingent on task completion. This was done to test if the child found the task itself reinforcing, and to see if he would engage in the task without a programmed reinforcer. In the second set of baseline trials, the social stimulus to be conditioned was presented contingent on task completion. This was used as a pre-conditioning measure, to determine how many times the child would complete the task in order to receive the social stimulus prior to conditioning. Both baselines continued until stability was reached, or until there were at least three more trials in the condition than the previous participant. This was done to demonstrate experimental control in the multiple-basline design (Pierce \& Cheney, 2008).

Reversal baselines were repeated following conditioning trials to test the social stimuli after conditioning. Rather than running these trials to stability, reversals were conducted for only six trials because of the likelihood that responses would drop off after repeated trials. This decision was based on data from a pilot study that was conducted 
prior to beginning this study. These trials were labeled as post-pairing and post-Sd, but are the same as the baseline trials (pre-pairing and pre-Sd), except that they followed conditioning.

Conditioning:

Pairing: Beginning with five forced exposures, the social stimulus (NS) and the nonsocial stimulus (CS) were presented in a delay conditioning fashion (Catania, 2007) following task completion. The task was the same as in the baseline conditions, and was either handing the card to the experimenter or touching the card on a clipboad. Then, as in the reinforcer assessment and baseline conditions, the child was asked to complete the task as many times as they wanted within a one-minute interval (i.e. "as many times as you want, give me the card"). Intervals were repeated as many times as were necessary to reach 80 conditioning trials. Forced exposures were repeated any time that intervals were interrupted by breaks or the end of a session. Participants reached 80 trials in as few as two one-minute intervals (participant two), or as many as eight one-minute intervals (participant eight). Most participants finished the pairing condition within two sessions.

Discriminative Stimulus (Sd): Beginning with five forced exposures, the participant was asked to look at the experimenter in order to attend to the social stimulus (a smile) before the task could be completed. The task was the same as in all previous conditions. Verbal, gestural, and physical prompts were used as necessary during the forced exposures. After the forced exposures, attempts to engage in the task prior to attending to the social stimulus were verbally redirected (i.e., "look at me!") until the social stimulus was attended to. Once the participant looked at the experimenter's 
smiling face, the task was completed and the nonsocial stimulus was delivered. Then, as in all other conditions, the child was asked to complete the task as many times as they wanted within a one-minute interval. Intervals were repeated as many times as were necessary to reach 80 conditioning trials. Forced exposures were repeated any time that intervals were interrupted by breaks or the end of a session. Participants reached 80 trials in as few as six one-minute intervals (participant four), or as many as 18 one-minute intervals (participant six). Two participants (participant three and particpant five) never reached 80 conditioning trials. The decision to stop running condtioning trials was reached when less than 40 trials had been completed in 20 one-minute intervals. Those participants who finished the discriminative stimulus condition reached 80 trials within three to six sessions.

Half of the participants received the pairing condition first, and the other half received the discriminative stimulus condition first, in order to counterbalance for order effects. There was no programmed break in between any of these conditions. If a participant finished conditioning at the beginning of a session, the reversal baseline was conducted right away. Most of the time reversals were conducted during the next session following the last day of conditioning. There was also no programmed break in between each of the conditioning procedures. Once all post-conditioning data was collected, the next procedure was introduced. The only conditions that had a programmed break were the probes for each procedure.

Probes: Follow-up baseline trials testing for maintenance were repeated for each conditioned social stimulus at least 3 weeks after the last conditioning trial was 
completed. The procedure was identical to the original baseline procedure, except that only three one-minute intervals were completed for each stimulus. If pairing was done first, the pairing probe was conducted first, and vice-versa. In other words, probes for the pairing procedure were done at least three weeks after the pairing procedure ended and probes for the Sd procedure were done at least three weeks after the Sd procedure ended, which depended on when each participant was exposed to each condition.

ESCS - Post-Assessment: After all of the conditions were complete, another ESCS was admnistered by the same researcher, or by another trained researcher, to determine if there was a significant change in overall social interaction.

\section{Data Collection/Validity Measures}

The primary dependent variable across all phases was rate of responding, particularly, the number of times that a task was completed within each one-minute interval. Data were collected during the live sessions by a second observer who was trained in data collection, using paper and pencil. Inter-observer agreement (IOA) for frequency of responding was collected by the researcher, and another trained observer for one-third of all sessions via video recording of the sessions. IOA was calculated by dividing the smaller frequency by the larger frequency for each interval and multiplying by 100 to obtain a percentage of agreement score (Bijou, Peterson, Harris, Allen, \& Johnston, 1969). Then the scores for all the intervals were averaged to get a total IOA score. IOA was $99.94 \%$ with a range of $96-100 \%$. 
Analysis

This study used a multiple treatment with reversal, embedded in a multiplebaseline design (Pierce \& Cheney, 2008; Watson \& Workman, 1981). The conditions were as follows: baseline A (extinction), baseline $\mathrm{A}_{1}$ (pre-conditioning), reversal A (postconditioning), baseline B (pre-conditioning, second procedure), reversal B (postconditioning, second procedure), probe A, probe B. The conditioning data was left out of the graphical display to better contrast the effects of conditioning before and after each procedure and because all of the participants received the same number of conditioning trials. The order of treatment presentation was counterbalanced such that participants one through three received the pairing procedure first, and participants four through six received the Sd procedure first. This was done to control for order effects.

Because this was a single-case design, the primary dependent variable was analyzed using visual inspection, where changes in trend, level and variability indicate an effect from the independent variable. In most single-case designs, reversals or withdrawals serve as control conditions (Sidman, 1960, Barlow, Nock, \& Hersen, 2009); however, because the effects of conditioning may not reverse, the multiple-baseline design was used to demonstrate an effect from the independent variable; wherein changes in the dependent variable occur only when the independent variable is introduced, across all participants (Barlow et al., 2009). Visual inspection (or graphic data analysis) is commonly used in single-case research because in most cases "when the differences are large and the relationships are clearly apparent, there is little need for statistical tests" (Bijou et al., 1969). 
To provide additional, exploratory statistical analysis, a non-parametric test (Wilcoxon Matched Samples Test) was used to compare response rates before and after conditioning for each procedure, as well to compare response rates for each procedure after conditioning. The Wilcoxon Matched Samples Test is used when participants are measured on two occasions (before and after conditioning), or under two different conditions (after each type of conditioning procedure) (Pallant, 2010). The Wilcoxon Matched Samples Test is the non-parametric alternative to the paired-samples t-test, which would commonly be used with this type of data. However, after running the Shapiro-Wilk test for normality, the majority of the data sets analyzed were skewed. This is most likely a result of the small sample size, which is common in the behavioral intervention literature where statistical analyses are not typically used. Rather than comparing means, the Wilcoxon Matched Samples Test converts scores to ranks and compares them at the two time points (Pallant, 2010).

In order to compare the results of the ESCS before and after conditioning, the same test was used to determine if there were any significant changes in each of the assessment categories before and after conditioning. The Wilcoxon Matched Samples Test was chosen again for the same reasons: the data were skewed and they represented a repeated measure. Each assessment consisted of six categories of social behavior, including initating joint attention, responding to joint attention, initiating behvaioral requests, responding to behavioral requrests, initating social interactions and respondig to social interactions. Each category was compared individually, as well as in the aggregate, even though there is no overall score in the assessment. 


\section{$\underline{\text { RESULTS }}$}

Reinforcer Assessments

Social and nonsocial reinforcer assessment graphs are available in Appendix $\mathrm{H}$. For participant one the nonsocial stimulus that resulted in the highest response rates was a book that was shaped like a car and had wheels. The social stimuli that resulted in the lowest response rates were claps and smile. For participant two the nonsocial stimulus that resulted in the highest response rates was a video that was played on an iPad. The social stimuli that resulted in the lowest response rates were "hooray!" and smile. For participant three the nonsocial stimulus that resulted in the highest response rates was chocolate chip cookies. The social stimuli that resulted in the lowest response rates were "hooray!" and smile. For participant four the nonsocial stimulus that resulted in the highest response rates was a balloon. The social stimuli that resulted in the lowest response rates were hugs and smile. For participant five the nonsocial stimulus that resulted in the highest response rates was iPad games. The social stimuli that resulted in the lowest response rates were "yay!" and smile. For participant six the nonsocial stimulus that resulted in the highest response rates was bubbles. The social stimuli that resulted in the lowest response rates were claps and smile.

\section{Conditioning}

Results varied for each participant, and for each condition (Table 1). On average, the extinction condition had lower response rates than all other conditions. The extinction condition consisted of the participant handing the experimenter the card with no planned consequence. The purpose of the extinction condition was to demonstrate 
that there was no intrinsic reinforcer for the task itself. When looking at mean response rates across the six participants, the largest difference occurred following the pairing procedure, where the mean response rate prior to conditioning was 2.26 , and following conditioning was 9.26. In contrast to the pairing procedure, the discriminative stimulus (Sd) procedure appeared to have no effect, where the mean response rate prior to conditioning was 2.74 and following conditioning was 2.63. Probes conducted at least three weeks after conditioning ended demonstrated some maintenance of effects for pairing, and continued to show no effect for the Sd procedure.

\begin{tabular}{|c|r|r|r|r|r|r|r|}
\hline & \multicolumn{7}{|c|}{ Response Rates Per Condition } \\
\hline PP \# & \multicolumn{1}{|c|}{ BL } & Pre-Pair & $\begin{array}{c}\text { Post- } \\
\text { Pair }\end{array}$ & $\begin{array}{c}\text { Probe- } \\
\text { Pair }\end{array}$ & Pre-SD & Post-SD & $\begin{array}{c}\text { Probe- } \\
\text { SD }\end{array}$ \\
\hline 1 & 0.67 & 0.67 & 19.20 & 3.33 & 8.00 & 4.33 & \\
\hline 2 & 0.11 & 9.68 & 15.00 & 11.67 & 3.10 & 6.40 & 8.33 \\
\hline 3 & 1.33 & 0.92 & 15.83 & 0.67 & 2.75 & 1.33 & 0.00 \\
\hline 4 & 1.25 & 0.50 & 0.50 & 0.00 & 0.00 & 2.50 & 0.33 \\
\hline 5 & 0.11 & 0.44 & 2.00 & 0.33 & 0.11 & 0.00 & 2.00 \\
\hline 6 & 1.67 & 1.33 & 3.00 & 7.33 & 2.50 & 1.22 & 1.67 \\
\hline Mean & $\mathbf{0 . 8 6}$ & $\mathbf{2 . 2 6}$ & $\mathbf{9 . 2 6}$ & $\mathbf{3 . 8 9}$ & $\mathbf{2 . 7 4}$ & $\mathbf{2 . 6 3}$ & $\mathbf{2 . 4 7}$ \\
\hline
\end{tabular}

Table 1. Mean response rate per condition, across participants.

Wilcoxon Matched Samples Test was conducted as an exploratory statistical analysis for each set of conditions. Both the post-conditioning conditions and the probe conditions were compared to the pre-conditioning conditions, as well as against each other (Table 2). The only comparison that was found to be statistically significant was the pre- vs. post-pairing comparison, where $z=-2.023, p<.05$, with a large effect size $(r=$ .58) (Cohen, 1988). The two pre-conditioning conditions were also compared to demonstrate that there was no difference between each of the conditions prior to intervention. None of the other relationships were found to be statistically significant. A 
False Discovery Rate (FDR) correction was conducted to control for multiple hypothesis testing using single hypothesis procedures (Benjamin \& Hochberg, 1995). Following the correction none of the significant relationships remained. However, because this is a single-case design, analysis is best performed by graphical analysis.

\begin{tabular}{|c|c|c|c|}
\hline Comparison & $\boldsymbol{z}$ & $\boldsymbol{p}$ & $\boldsymbol{r}$ \\
\hline Pairing: pre vs. post & -2.023 & .043 & .58 \\
\hline Pairing: pre vs. probe & -.943 & .345 & .30 \\
\hline Sd: pre vs. post & -.314 & .753 & .09 \\
\hline Sd: pre vs. probe & -.405 & .686 & .13 \\
\hline Pairing pre vs. Sd pre & -.524 & .600 & .17 \\
\hline Pairing post vs. Sd post & -1.682 & .093 & .48 \\
\hline Pairing probe vs. Sd probe & -.944 & .345 & .30 \\
\hline
\end{tabular}

Table 2. Wilcoxon Matched Samples Test $\alpha=.05$ for response rates in each condition. 
Response Rates Before and After Each Conditioning Procedure

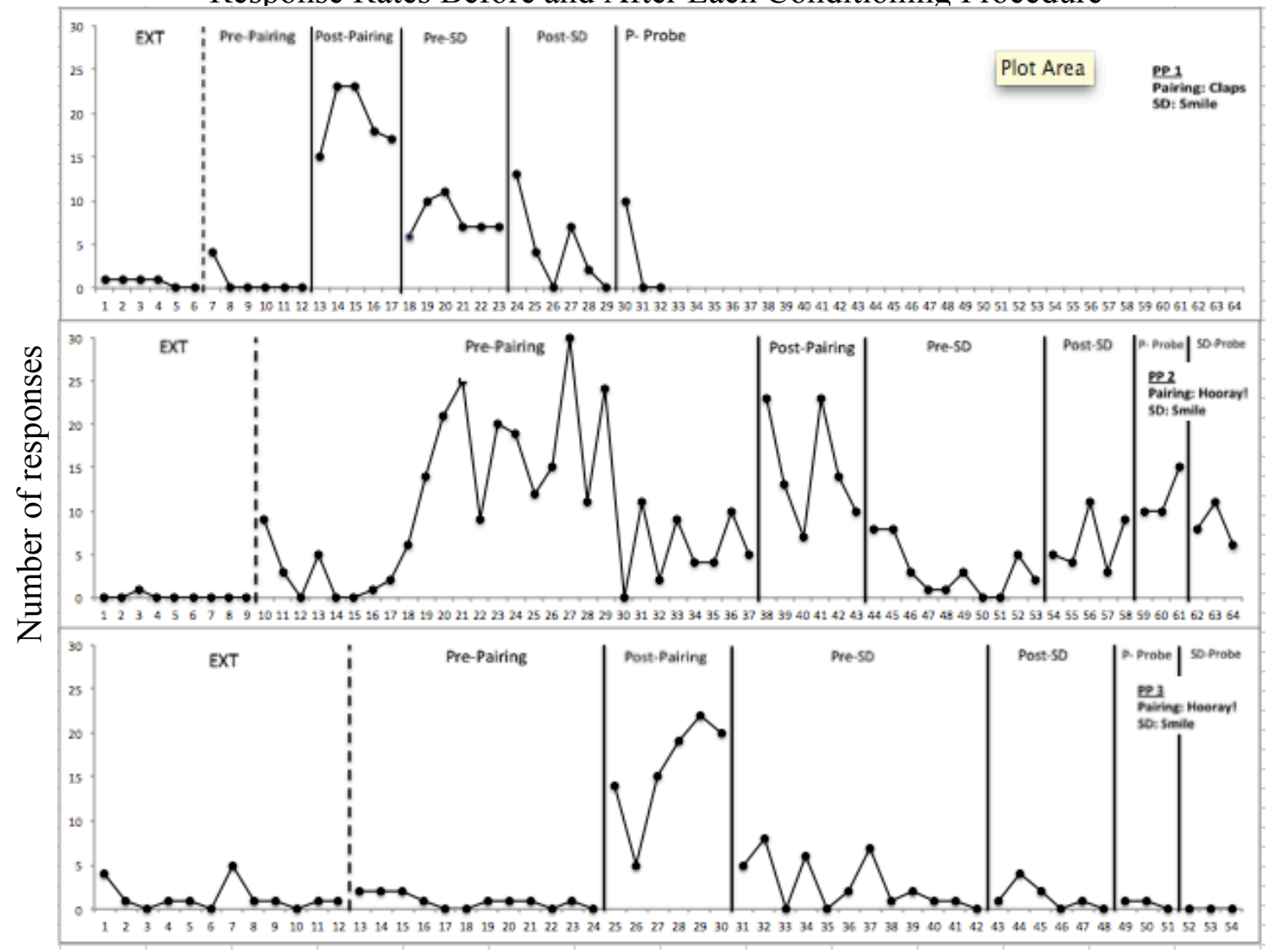

One-minute intervals

Figure 1. Response rates across conditions, pairing presented first (participants 1-3).

Participants one through three had the pairing condition presented first, immediately following extinction. Participant one was exposed to the pairing procedure to condition clapping as a reinforcer, while participants two and three were exposed to the pairing procedure to condition the word "Hooray!" as a reinforcer. All participants received the $\mathrm{Sd}$ procedure to condition a smile as a reinforcer.

Participant one increased in the number of responses following the pairing procedure, and although the data show a decreasing trend, the level of response rates is higher than in the pre-pairing condition. Response rates in the pre-Sd condition, although 
stable, were not as low as in the pre-pairing condition. However, response rates in the post-Sd condition were even lower than in the pre-Sd condition. The probe, conducted three weeks after the pairing procedure, resulted in one trial of relatively high response rates, but immediately dropped off to zero after the first trial. Participant one was not available for testing in the Sd-probe condition.

Despite participant two's unusually high response rates in the pre-pairing condition, the post-pairing condition still had higher response rates on average, and although the data were variable, they were noticeably higher than the stable portion at the end of the pre-pairing condition (data points 30-37). Median response rates reflected similar results, where the median response rate in the pre-pairing condition was 7.5 , and 13.5 in the post-pairing condition. The Sd procedure also had a positive conditioning effect, although the increase in response rates was not as high as with the pairing procedure. The probes, conducted four weeks after conditioning, reflected the initial post-conditioning results, with higher rates of responding in the pairing probes than in the Sd probes.

Participant three only had an effect from the pairing procedure. After a long, low and very stable pre-pairing condition, his response rates were much higher in the postpairing condition, and were beginning to stabilize at a high rate, after an ascending trend. The pre-Sd condition had higher response rates than the pre-pairing condition but the data stabilize at a low rate after seven trials. Because of this instability in the initial portion of the pre-Sd condition, the mean response rates are lower in the post-Sd condition. However, even without this effect, the descending trend indicates that any effects from the Sd procedure quickly faded out. It should be noted again here that participant three 
did not finish the Sd procedure. For participant three, both sets of probes demonstrate a lack of maintenance of effects.

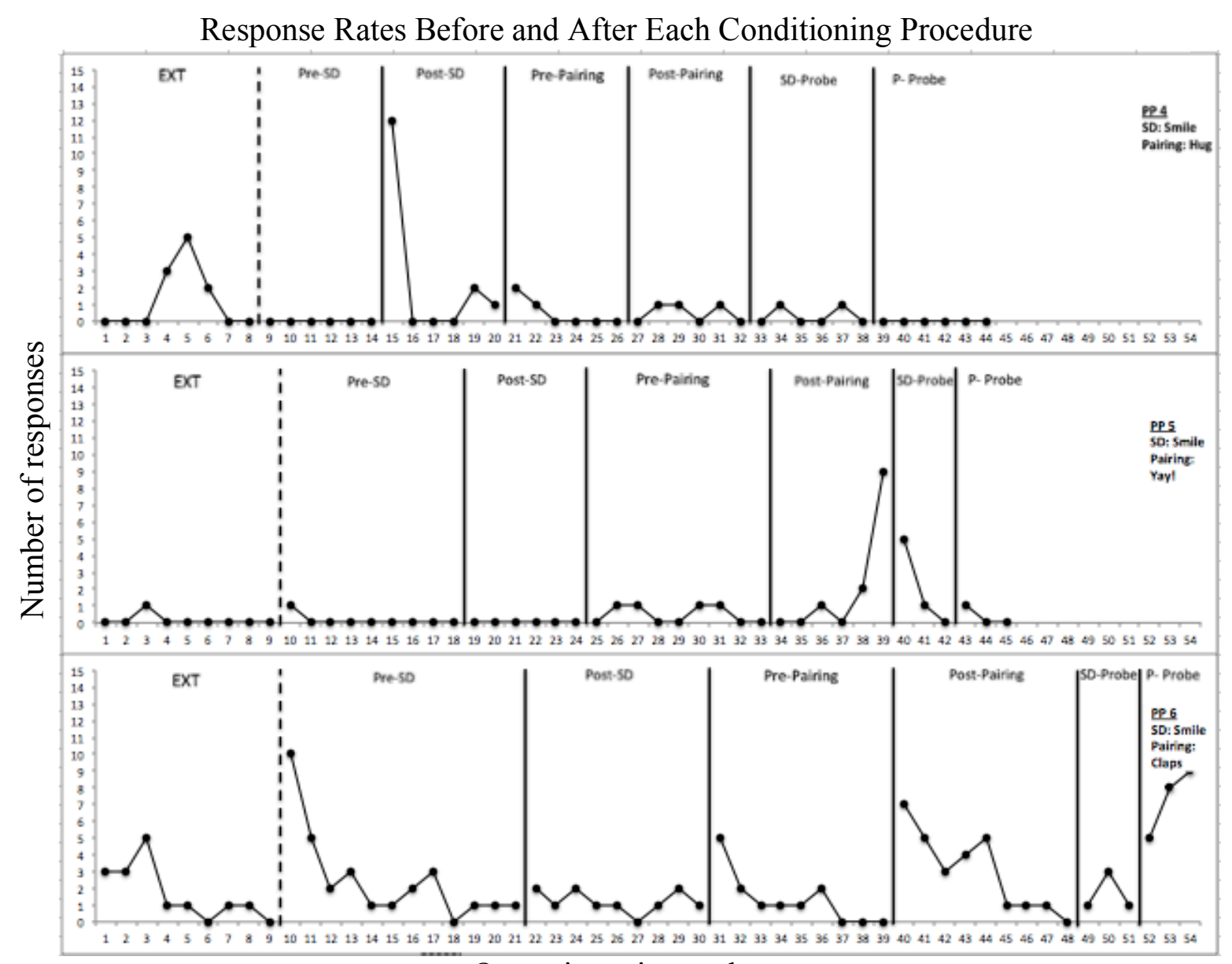

One-minute intervals

Figure 2. Response rates across

conditions, discriminative stimulus procedure presented first (participants 4-6).

Participants four through six had the Sd condition presented first, immediately following extinction. Participant four received the pairing procedure to condition a hug as a reinforcer, participant five received the pairing procedure to condition the word "Yay!" as a reinforcer, and participant six received the pairing procedure to condition 
clapping as a reinforcer. All participants received the Sd procedure to condition a smile as a reinforcer.

Participant four had almost identical median response rates in the post-Sd and preSd conditions, with a median rate of zero in the pre-Sd condition and a median rate of .5 in the post-Sd condition. Although mean response rates show a greater difference, this is primarily because of a single data point. The pre- and post-pairing conditions have the same mean response rates. Graphical analysis confirms that there is no obvious change in trend or level across these conditions, demonstrating a lack of an effect. Both probe conditions, conducted three weeks later, also showed very low or no responding, confirming the lack of an effect for this participant.

Participant five had response rates of zero across almost all of the pre-Sd and all of the post-Sd conditions, demonstrating no effect from the Sd procedure. It should be noted again that participant five did not complete the Sd procedure because his response rates were so low during conditioning that it would have taken too long to finish. Response rates during the post-pairing condition were higher, on average, than in the prepairing condition, and end on an increasing trend. However, median response rates show a much smaller difference, with a median of zero responses in the pre-pairing condition and .5 responses in the post-pairing condition. While the probe for the $\mathrm{Sd}$ procedure is slightly higher on average, both probes, which were conducted three weeks later, ended on zero response rates following a decreasing trend.

Participant six had relatively high pre-conditioning response rates. However, preconditioning conditions were run until stability was reached, and doing so produced low response rates in both conditions. The post-Sd condition had lower response rates than 
the pre-Sd condition, with fairly stable rates of responding. The post-pairing condition had higher rates of responding than the pre-pairing condition, but still had a decreasing trend and ended on a zero response rate trial. However, the probes for participant six, which were conducted three weeks later, showed a fairly different set of results, with the pairing procedure demonstrating much higher response rates than the $\mathrm{Sd}$ procedure. The increasing trend also demonstrated that the maintenance of effects was more robust for the paired stimulus than for the $\mathrm{Sd}$ stimulus.

For most participants, the pairing procedure had more robust and enduring effects. However, maintenance of effects is not clear, and while it is more evident with the pairing procedure, response rates were not nearly as high as they were immediately following pairing. The $\mathrm{Sd}$ procedure did not result in response rates that were as high as those achieved following pairing, and the long-term effects were essentially nil. ESCS

All participants had some improvement in their ESCS scores, and on average, all participants improved in every category of the ESCS, except for initiating social interactions, which remained the same (Figure 3). The biggest improvements were seen in both initiating and responding to joint attention (IJA, RJA). However, modest improvements were also seen in initiating behavior requests (IBR). Wilcoxon Matched Samples Tests were conducted as an exploratory statistical analysis for an aggregate ESCS score, as well as for each test category (Table 3). 


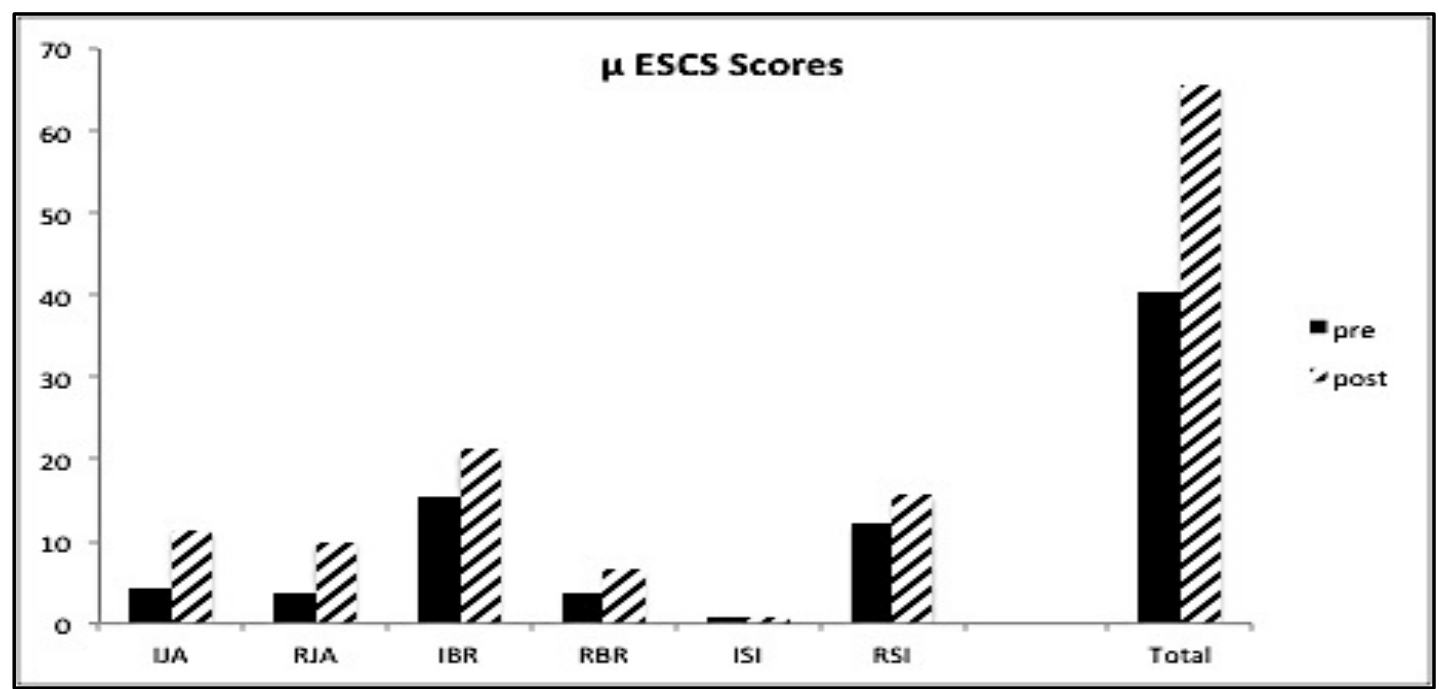

Figure 3. Mean ESCS scores across test categories

\begin{tabular}{|c|c|c|c|}
\hline Comparison & $\boldsymbol{z}$ & $\boldsymbol{p}$ & $\boldsymbol{r}$ \\
\hline ESCS pre vs. post & $\mathbf{- 2 . 2 0 1}$ & $\mathbf{. 0 2 8}$ & $\mathbf{. 6 4}$ \\
\hline IJA pre vs. post & -1.992 & .046 & .58 \\
\hline RJA pre vs. post & -2.032 & .042 & .59 \\
\hline IBR pre vs. post & -1.363 & .173 & .39 \\
\hline RBR pre vs. post & -1.633 & .102 & .47 \\
\hline ISI pre vs. post & 0.000 & 1.000 & 0 \\
\hline RSI pre vs. post & -1.051 & .293 & .30 \\
\hline
\end{tabular}

Table 3. Wilcoxon Matched Samples Test $\alpha=.05$ for pre- post-ESCS scores

Wilcoxon Matched Samples Test results reveal a significant difference between the aggregate pre- and post-ESCS scores, $z=-2.201, p<.05$, with a large effect size $(r=.64)$ (Cohen, 1988, Cited in Pallant, 2010). While the test categories represent different behavioral and social domains, the aggregate score reflects the sum of all the scores within the test. Wilcoxon Matched Samples Tests were also conducted for each test category. Two of the six categories appear to have a significant difference: IJA $(z=-$ 
$1.992, p<.05, r=.58)$ and RJA $(z=-2.032, p<.05, r=.59)$. The remaining categories did not appear to be statistically different. A False Discovery Rate (FDR) correction was conducted again to control for multiple hypothesis testing using single hypothesis procedures (Benjamin \& Hochberg, 1995). Following the correction none of the significant relationships remain. 


\section{DISCUSSION}

\section{Pairing}

Results from the pairing procedure demonstrated that, for some participants, the procedure was more effective in conditioning social stimuli to function as reinforcers than the Sd procedure. In some cases, the response rates following pairing were much higher than they were before conditioning, and in most cases they were at least slightly higher following pairing. However, graphic analysis of the data for the pairing procedure only demonstrated clear effects from the intervention for two of the participants. Participants one and three had very stable and low response rates prior to the pairing procedure, and much higher, and relatively stable response rates following intervention, demonstrating a substantial effect. Participant two had a very unstable and long prepairing condition. This may have been a result of some previous pairing conducted for another set of stimuli that had to be discontinued because of a change in dietary restrictions prohibiting the use of cookies as a reinforcer. Regardless of this confounding data, his post-pairing response rates were still relatively high, though they were variable. Participants five and six had moderate increases in mean response rates between the preand post-pairing conditions, however, those data were not stable when the condition was ended. Participant four was the only participant who had no effect from the pairing procedure. It should be noted that this participant was more verbal than the rest of the participants. For one of the sessions, when the participant was asked to hand the card to the experimenter as many times as he wanted, the participant replied "I don't want to." This participant was instructed to wait nicely through the interval if he did not want to 
hand the card. None of the other participants received verbal instructions on what to do if they did not want to engage in the task.

The moderate success from the pairing procedure was similar to the data reported by Dozier et al. (2012), where contingent pairing resulted in an increase in responding for the social stimulus. These data were also reflective of the importance of having the pairing procedure include contingent pairing, rather than just presenting the S-S pairs non-contingently. Although the direct comparison was not made in this study, one possible explanation is that the contingency of presenting the paired stimuli following a simple task increases the saliency of the stimuli. Future studies using pairing should consider including the contingency, as it may increase the likelihood that pairing would be effective. For example, a study looking to increase the reinforcing effectiveness of praise should present praise and a known reinforcer contingent on some response.

The literature on pairing suggests that the number of trials is important for successful conditioning (Catania, 2007). The number of conditioning trials may have had an effect on the overall success of each of the conditioning procedures. The number of conditioning trials conducted was selected based on the results of pilot data gathered prior to beginning this study, and was the same for both procedures. The number selected was considered just high enough to have an effect without detracting from the child's daily intervention schedule. However, many conditioning studies reported much higher total conditioning trials. Dozier et al. (2012) used thousands of pairings in the S-S condition, where the pairings were non-contingent, without success. However, it seemed that they used substantially fewer trials in the contingent pairing procedure, although it is unclear how many pairing trials occurred, or if they were equated for all participants. 
More research needs to be done to determine how many trials of pairing are optimal for conditioning. In this study, it may be the case that the total number of contingent pairings was sufficient to have an effect. Additionally, the number of pairing trials may depend on the individual's learning history with the particular stimulus being paired. Although great care went into selecting stimuli that were neutral in terms of their reinforcing effects (as demonstrated in the baseline pre-conditioning conditions, and in the reinforcer assessment results; see Appendix H), these stimuli are by no means novel, and each participant is likely to have a unique learning history with the stimuli selected for conditioning. Perhaps future studies should control for learning histories by using social stimuli that are uncommon.

Another potential factor that may have affected the outcome of the pairing procedure is the type of stimulus conditioned. The stimuli that were conditioned using pairing, particularly cheers, claps and hugs, can all be classified as stimuli that are multimodal. In other words, these stimuli can be detected via more than one sensory modality, primarily visual and auditory, with the exception of hugs, which is not audible, but rather tactile. This may be important because of the increased likelihood that the stimuli were in fact attended to during the pairing procedure. Again, increasing the saliency of the paired stimuli, or increasing the attention paid to the paired stimuli, may make the pairing procedure more robust (Dozier et al., 2012). Thus, perhaps part of the effect from the pairing procedure may be attributed to the fact that these stimuli were more salient than a smile, which was the only stimulus conditioned under the Sd procedure. Although conditioning the same stimuli using both procedures excludes them from being 
compared, future research should ensure that the stimuli being compared under each procedure are equally salient.

The pairing procedure seemed to have slightly better maintenance of effects, but the differences were not large enough to be statistically significant, and those effects were only present for two of the six participants. One possible explanation for the maintenance of effects for the two participants for whom response rates maintained is that the procedure may have functioned as a way to boost the reinforcing effects of these stimuli, which then continued to be intermittently paired in the natural environment. Cheers and claps are often presented contingent on correct responding during ABA interventions, making this a distinct possibility. The post-conditioning conditions were essentially brief respondent extinction sessions, where the newly conditioned stimuli may have started to loose some of their reinforcing qualities. Respondent extinction is the presentation of the CS (in this case the social stimulus) continually without the US, resulting in a decrease and eventual termination of the effects from the CS (Catania, 2007). In other words, the CS becomes de-conditioned and once again functions as an NS. This may be one explanation for why conditioning did not maintain for most participants. This is also why the post-conditioning conditions were not presented until stability was reached. It was assumed that if the social stimulus continued to be presented independently of the reinforcer, response rates would have dropped to zero, reversing the effects of conditioning.

Another reason that maintenance may have suffered is that the contingency of handing the experimenter the card that resulted in access to the reinforcer was on a continuous schedule of reinforcement (CRF), where every response was reinforced. The 
literature on schedules of reinforcement indicates that behaviors that are reinforced on a CRF schedule are more likely to extinguish quickly and cleanly following continuous, rather than intermittent schedules of reinforcement (Catania, 2007). It may be worthwhile to test whether the effects of pairing are more likely to maintain if pairing trials are interspersed with non-pairing trials (where the social stimulus is presented alone), to mimic an intermittent schedule of reinforcement. Another alternative could be to use schedule thinning, where the pairings are continuous at first, and are gradually interspersed until the US is no longer presented (Hopkins, 1968).

\section{Discriminative Stimulus Procedure}

The Sd procedure was not found to be very effective in conditioning social stimuli to be reinforcing. In some cases, it was difficult to compare response rates because some pre-Sd conditions had higher response rates than pre-pairing conditions as a result of carry-over effects. Because data are collected sequentially in single-case designs, the potential for carry-over effects is always present (Barlow et al., 2009). This is why the order of conditioning procedures was counterbalanced for half of the participants. The first three participants had the pairing procedure presented first, creating the potential for carry-over effects on the pre-Sd condition. For example, participant one had higher response rates in the pre-Sd condition, than in the pre-pairing condition, occluding the difference in response rates across conditions. However, the post-Sd response rates were lower than the post-pairing response rates demonstrating less of an effect. Participant two also had relatively high and variable pre-Sd response rates that did not increase substantially in the post-Sd condition. Participant three had higher and more variable response rates that eventually decreased and stabilized in the pre-Sd condition, reflecting 
potential carry-over effects from pairing. However, response rates in the post-Sd condition are even lower than response rates prior to conditioning, reflecting a weak or nonexistent effect. The presence of carry-over effects was particularly challenging for the first three participants because the procedure that seems to have been more effective was presented first. Participants four and five had very low and stable pre-Sd conditions that had little evidence of carry-over effects to the pre-pairing condition.

The only two participants that had higher mean response rates in the post-Sd condition as compared to the pre-Sd condition were participants two and four. Again, participant two had very unstable data that were relatively high in the pre-Sd condition, probably as a result of carry-over effects, so it is noteworthy that he still had some increase in his response rates following conditioning. If mean response rates were the primary dependent variable, participant four would have appeared to have a substantial effect from the Sd procedure. However, graphical analysis reveals that this increase in response rates was a result of a single data point. One distinct possibility is that this data point is reflective of an extinction burst, known in the literature as a momentary increase in the rate and intensity of a behavior that is placed under extinction (Catania, 2007). To clarify, during the conditioning portion of the procedure, participant four was presented a balloon, along with the hug, each time he handed the experimenter the card. During the post-Sd condition, only the hug was delivered for the card, essentially placing the behavior on extinction if the social stimulus did not function as a reinforcer. The data points following the first trial are probably more reflective of any conditioning effect that may have occurred. 
There are a few variables that may have contributed to the procedure being less effective, including the number of trials conducted, although they were equated across procedures and for all participants in the current study, and the type of stimulus conditioned in this procedure. Lovaas et al. (1966) conditioned the word "good" to function as a reinforcer using the same procedure, however in their study Participant 1 received 1530 trials of conditioning and Participant 2 received 900 trials. These participants were institutionalized and were likely available for longer sessions with minimal time constraints. Although it was possible to provide more conditioning trials, it could have potentially taken upwards of six months to complete that many trials of conditioning under this procedure. Further, it is evident that this many trials were not required for the pairing procedure. One of the important findings of this study is that even if both procedures are effective, the contingent pairing procedure was more efficient than the Sd procedure, in that the children were able to complete the requisite number of conditioning trials faster.

Isaksen and Holth (2009) used a similar procedure to condition a smile as a social stimulus, making it a more direct comparison. They only conducted between 35-75 trials of the Sd procedure. However, they conducted nine other trainings before conducting their final assessment. These researchers did not independently test smile to determine if it was indeed reinforcing. Therefore, it was difficult to determine if their procedure was effective, or if it was the complete training package that contributed to the gains in joint attention they observed.

Another potential variable affecting the difference in results could be the difference in the type of stimuli conditioned. As mentioned above, the Sd procedure was used to 
condition smile only, which is a unimodal stimulus. Even though the child was required to orient towards the smile and essentially observe the smile before the reinforcer was delivered, it is still possible that the smile was less salient than the stimuli conditioned under pairing. A smile is a subtle social stimulus that is likely to function as a reinforcer for adults and older children (Skinner, 1953), but it is unclear if a smile functions as a reinforcer in younger, typically developing children. Isaksen and Holth (2009) used a smile in their Sd procedure, but they never tested the reinforcing effectiveness of the stimulus itself. Therefore, it is still unclear if the Sd procedure is an effective way to condition a smile to function as a reinforcer. Future studies in this line of research should include conditioning stimuli that are equally salient across both procedures.

One final consideration related to the type of stimulus used with the $\mathrm{Sd}$ procedure is that there was an additional response requirement that was not present with the pairing procedure. Because the stimulus to be conditioned was a smile, and because the smile had to be attended to prior to the reinforcer being delivered, the child was required to look at the experimenter's face before touching or handing the card. Sd trials took longer and required more prompting and redirection than the pairing procedure, providing further evidence that this procedure required more response effort. As mentioned in the literature review, children with autism are less likely to orient to faces, making this response even less likely (Dawson et al., 1998). For the two participants that did not complete the Sd procedure, it seemed as though the reinforcer available was simply not enough to evoke the response. After the procedure was officially ended for purposes of this study, a reinforcer manipulation was made for one of the participants, which resulted in much higher response rates during the Sd procedure. Though those data were not 
reported, there was sufficient evidence to show that, had the reinforcer been more valuable, the Sd procedure would have likely been completed. This, however, does not speak to whether or not his response rates would have increased following conditioning.

Four of the six participants did, however, complete the Sd procedure, demonstrating that it was possible to garner orienting to the experimenter's face. In fact, for those participants that completed the Sd procedure, very little prompting and redirecting was needed after the first few trials. Although data was not collected on the amount and type of prompting used, it seemed that the participants became fluent in the procedure and complied with the requirement to look at the experimenter prior to handing or touching the card. The Sd procedure still holds promise and should continue to be pursued. Future studies should consider increasing the magnitude of reinforcement provided for completing responses under this paradigm in order to better match the response effort required.

ESCS

Results of the ESCS pre- and post-assessments demonstrated that conditioning social stimuli to function as reinforcers had an effect on general social behaviors including joint attention. Although it is impossible to determine if the changes in ESCS scores are entirely a result of the conditioning procedures, it is feasible that the conditioning had some impact. Some of the behaviors tested in the ESCS are directly taught in many ABA programs, primarily IBR and RBR. "Initiating behavior requests" is targeted in most early intervention programs under the label of mand training (Michael \& Sundberg, 2001), where children are taught to request preferred or desired items using a variety of socially acceptable forms of communication, including reaching and pointing, 
which are scored as bouts of IBR in the ESCS. "Responding to behavioral requests" is also often taught in early intervention programs under the labels of compliance, sharing or turn-taking (e.g. Barton \& Ascione, 1979). Interestingly though, these were not the areas where the largest gains were observed. In fact, based on the results of the Wilcoxon Matched Samples Test, the biggest gains were observed in IJA and RJA, with gains in RJA being (only slightly) bigger. This is one of the more interesting results of this study, primarily because these responses were not trained explicitly during our study, and were unlikely to be explicitly trained in the early intervention program that most of the participants were enrolled in. As discussed earlier, joint attention behaviors have been particularly difficult to train in children with autism, and many training programs have demonstrated noticeable differences between improvements in RJA and IJA.

Five of the six participants improved in their RJA scores (see Appendix I) in the post-test. Scores in the RJA domain represent the number of times the child was observed engaging in behavior that is coded as RJA and included behaviors such as following a point when the experimenter called the child's name (without saying "look"). The range of improvement in this domain was 0 to 9 , with every participant increasing their scores by at least six points, except for Participant one. Improvements in this domain could be attributed to the reinforcement of looking behavior during the Sd procedure, because in order to follow a point the child must first attend to the experimenter. Although the reinforcer in RJA can be social and nonsocial (and is often both social and nonsocial), the requirement of looking makes it a difficult response for many children with autism. Even though this response was not explicitly trained, one of 
the major components of this skill was explicitly trained and likely contributed to the improvement in this domain.

Five of the six participants improved their IJA scores (see Appendix I) in the posttest. Scores in the IJA domain represent the number of times the child was observed engaging in behavior that is coded as IJA and included behaviors such as looking up at the experimenter when the toy was in the child's hand (indicating that he did not want anything, but instead was sharing in the enjoyment of the toy). The range of improvement in this domain was -2 to 17 , with participants one, four and six improving by 9,17 , and 11 points, respectively. Participants three and five had no bouts of IJA prior to intervention, and had three and four bouts, respectively, after intervention. The small sample size prevents any major conclusions to be drawn about how the general population of children with autism would respond to this intervention, but the differences were large enough to be statistically significant. Therefore, it is noteworthy that significant gains were observed in these domains, especially over such a short period. The areas of ISI and RSI did not have any significant changes. This lack of effect is at least partly a result of the design of the assessment itself. There are only two opportunities to initiate social interaction, making it less likely that any changes would be observed. Four of the participants had no change in their ISI score, one improved and one did not. The number of responses under RSI is also quite variable and comes primarily from the number of times that a child engages in a turn taking game, which is mostly controlled by the experimenter. Despite this, four of the six participants had improvements in their RSI scores. 


\section{General Discussion}

Conditioning social stimuli to function as reinforcers is a promising and different way to intervene with young children with autism. Many intervention programs target behavioral skills deficits, such as verbal behavior and social skills directly (e.g., VBMAPP, Sundberg, 2008, ABLLS-R, Partington, 2006), without addressing the socialemotional aspect of the autism diagnosis. While many skills are successfully taught without social reinforcers, it may be worthwhile to include a component that targets specifically how social stimuli function. While it is likely that many associations, or pairings, between social and nonsocial stimuli do occur during typical ABA interventions, it is unknown if they are made in a systematic and programmatic fashion. Even basic textbooks recommend the use of pairing to increase the likelihood that social reinforcers are effective in increasing or maintaining novel responses (Kazdin, 2012), but the literature is sparse on how to do so effectively. While the concept of classical conditioning is well established, using it systematically and in an applied setting to increase the reinforcing effectiveness of social stimuli, especially in young children with autism, is not part of clinical best practice. The current study showed that conditioning social stimuli to become reinforcing is not as straightforward as it might seem, and that the methods chosen for conditioning may have an impact on the effectiveness and success of such procedures. Therefore it is important to continue to investigate what makes these procedures more efficient, since they have very important implications for clinical practice. 


\section{Limitations}

Although the findings of the current study are consistent with previous literature, some possible limitations should be considered when interpreting the results. Some possible limitations of this study include the use of only one stimulus to function as the conditioning stimulus, the difference in the type of stimuli selected to be conditioned, the termination of experimental conditions prior to achieving stability in the data, and the inability to control for extraneous forms of conditioning.

First, the fact that only one stimulus was used to condition social stimuli in both conditions increases the likelihood that the reinforcing effectiveness of those stimuli was affected by satiation (Kazdin, 2012). Although edible items were only used for one participant, other tangible and non-tangible reinforcers are also susceptible to satiation by virtue of repeated exposures (Hagopian, Crockett, Van Stone, De Leon, \& Bowman, 2000). The reason only one stimulus was used was to reflect the results of the reinforcer assessments conducted prior to intervention, and to use only the most reinforcing stimulus. However, different versions of the same stimulus could have been used to diminish the effects of satiation. For example, Dozier et al. (2012) used a variety of preferred edibles as the conditioning stimulus in a quasi-random order to prevent satiation.

The next limitation is in the potential inability to compare the procedures because of the difference in the types of stimuli conditioned. Indeed, great care was taken to make sure that the social stimuli in both conditions were attended to, however, as was mentioned before, there is likely a difference in the saliency of each of the stimulus types, particularly between smile (conditioned under the Sd procedure) and the other stimuli 
conditioned under the pairing paradigm. As discussed in the literature review, children with autism are less likely to orient to faces (Dawson et al., 1998). Although training was conducted in the form of prompting during the forced exposures, prior to conditioning, it is possible that more training trials were required to achieve a consistent orienting response. Further, it is possible that a higher magnitude reinforcer was necessary for the smile to become conditioned. In other words, the reinforcer that was presented following task completion was not sufficient to make a smile discriminative for reinforcement. It is possible that these procedures cannot be compared in this study because of the difference in the stimuli used for conditioning. A replication of this study should use equally salient stimuli for each condition. For example, a smile and a head nod could be compared under each procedure, counterbalancing the stimuli across participants.

Another limitation is that the post-conditioning conditions were not conducted until stability was reached. Typically in single-case designs, conditions are not ended until there is stability in the data (Barlow et al., 2009). Stability was achieved in the preconditioning conditions in order to clearly demonstrate the effects of intervention in the multiple-baseline design, where reversal are not necessary to demonstrate experimental control (Barlow et al., 2009). With this design, if data in the pre-conditioning (baseline) conditions are variable, or show an increasing trend, increases in the post-conditioning (reversal) conditions cannot be attributed to the intervention. As required by the design, none of the pre-conditioning conditions had ascending trends and trials were run to stability, demonstrating a valid effect from the intervention, when it occurred. However, the post-conditioning conditions were not run to stability, which may occlude some of the effects from the procedure. Post-conditioning conditions were run for six trials for all 
participants to examine the effects of conditioning immediately after the procedures, without completely de-conditioning the social stimuli, since the reversal condition was essentially an extinction procedure. Future studies may consider running the postconditioning conditions to stability to gather information about the durability of conditioning effects under extinction.

Finally, it is difficult to determine if there were any external influences affecting the outcome of this intervention. Because of the nature of the stimuli, it is possible that associations were made with the stimuli under conditioning outside of the study. The stimuli selected for conditioning were common, and by no means novel to the participants involved. However, because of the evidence from the repeated baseline measures prior to conditioning, it is likely that these stimuli did not function as reinforcers prior to intervention for most of the participants. What is more difficult to determine is if, once conditioning began, those same stimuli were subject to extraneous pairings by caregivers or therapists. Although the multiple-baseline design was used to demonstrate experimental control in this study, it is possible that extraneous factors intervened. Along this vein, there is also the possibility of a carry-over of effects from one conditioning procedure to the next. Indeed, it seems that in some cases, the preconditioning phase that followed another conditioning procedure had higher rates of responding than what was expected based on the reinforcer assessments. This was particularly evident in the first three participants, where the more effective pairing procedure was presented first. It is possible that the experimenter became a generalized conditioned reinforcer following 15 sets of reinforcer assessments with various preferred nonsocial stimuli, and 80 trials of an effective pairing procedure. Future studies may 
want to consider using different confederates to implement the reinforcer assessments, and each of the conditioning procedures, to ensure a more distinct set of stimuli.

\section{Future Directions}

This study represents the beginning of an interesting and long line of research. Many more studies need to be conducted to determine the ways to refine and improve each of these procedures. Specifically, studies should be done to determine if the stimulus type affects the effectiveness of the procedures, and for which stimulus types each procedure is best. For example, the $\mathrm{Sd}$ procedure may only be effective for stimuli that need to be actively attended to, or it may be more effective if the stimulus is multimodal. Future studies should also test the number of pairing and Sd trials to determine the range of effective trials. There may be a minimum number of trials required for conditioning to be effective, or it may depend on the stimulus itself, and the individual's learning history with the stimulus. Another extension that may be useful would be in testing the reinforcing effectiveness of the newly conditioned stimuli on other behaviors, such as those typically trained in ABA interventions. It would be interesting to compare the reinforcing effectiveness of social stimuli after conditioning and nonsocial stimuli on the same type of response, as well as evaluate the maintenance and generalization of effects.

\section{Summary}

In summary, an operant and a respondent procedure were tested in their ability to condition social stimuli to function as reinforcers. After 80 trials of conditioning under each paradigm, the respondent (pairing) procedure, where pairings were presented contingent on a simple task, was found to be more effective. The pairing procedure also 
had slightly more durable effects, but overall, the maintenance of both procedures was limited. Results of a social communication assessment (ESCS) before and after conditioning demonstrated improvements in almost all categories, with the biggest gains in responding to and initiating joint attention. These results show promise for the viability and practicality of a conditioning procedure to improve the reinforcing effectiveness of social stimuli in children with autism. Improving the effectiveness of social stimuli to function as reinforcers in children with autism has far-reaching implications for clinical work as well as for research on the social motivation theory of autism. 


\section{REFERENCES}

Agras, S., Leitenber, H. \& Barlow, D. H. (1968). Social reinforcement in the modification of agoraphobia. Archives of General Psychiatry, 19(4), 423-427.

American Psychiatric Association (2000). Diagnostic and Statistical Manual of Mental Disorders ( $4^{\text {th }}$ ed., text rev.). Washington, DC.

Ayllon T. \& Azrin N. (1968). The token economy: A motivational system for therapy and rehabilitation. East Norwalk, CT, US: Appleton-Century-Crofts.

Barlow, D.H., Nock, M.K., \& Hersen, M. (2009). Single Case Experimental Designs: Strategies for Studying Behavior Change, $3^{\text {rd }}$ ed. Boston, MA: Pearson Education.

Barton, E.J. \& Ascione, F.R. (1979). Sharing in preschool children: facilitation, stimulus generalization, response generalization, and maintenance. Journal of Applied Behavior Analysis, 12, 417-430.

Benjamin, Y. \& Hochberg, Y. (1995). Controlling the false discovery rate: A practical and powerful approach to multiple testing. Journal of the Royal Statistical Society, series B (Methodological), 57(1), 289-300.

Bijou, S.W. (1969). Methodology for experimental studies of young children in natural settings. The Psychological Record, 19(2), 177-210.

Borrego, J. \& Urquiza, A.J. (1998). Importance of therapist use of social reinforcement with parents as a model for parent-child relationships: an example with parent-child interaction therapy. Child and Family Behavior Therapy, 20(4), 27-54.

Brooks, R. \& Meltzoff, A.N. (2005). The development of gaze following and its relation to language. Developmental Science, 8(6), 535-543.

Brooks, R. \& Meltzoff, A.N. (2008). Infant gaze following and pointing predict accelerated vocabulary growth through two-years of age: a longitudinal, growth curve modeling study. Journal of Child Language, 35, 207-220.

Catania, C.A., (2007). Learning: Interim $4^{\text {th }}$ Edition. New York: Sloan Publishing.

Cassia, V.M., Valenza, E., Simion, F. \& Leo, I (2008). Congruency as a nonspecific perceptual property contributing to newborns' face preference. Child Development, 79 (4), 807-820.

Centers for Disease Control and Prevention (2008). National Center on Birth Defects and Developmental Disabilities. Retrieved from http://www.cdc.gov/ncbddd/autism/data.html. 
Chakravarthy, S., Kumaraiah, V., \& Mishra, H. (1990). Aversion therapy in alcoholism. Journal of Personality and Clinical Studies, 6(1), 57-61.

Charman, T., Swettenham, S., Baron-Cohen, A., Cox, A., Baird, G. \& Drew, A. (1997). Infants with autism: an invesitgation of empathy, pretend play, joint attention and imitation. Developmental Psychology, 33, 781-789.

Chavallier, C., Kohls, G., Troiani, V., Brodkin E.S. \& Schultz, R.T. (2012). The social motivation theory of autism. Trends in Cognitive Sciences, 16 (4), 231-239.

Clifford, S.M., \& Dissanayake, C. (2008). The early development of joint attention in infants with autistic disorder using home video observations and parental interview. Journal of Autism and Developmental Disorders, 38, 791-805.

Cohen, J. (1998). Statistical Power Analysis for the Behavioral Sciences, Second Edition. Hillsdale, NJ: Lawrence Erlbaum Associates, Inc., Publishers.

Cooper, J.O., Heron, T.E., \& Heward, W.L. (2007). Applied Behavior Analysis, Second Edition. Upper Saddle River, NJ: Pearson Education Inc.

Cunningham, A.B. \& Schreibman, L. (2008). Stereotopy in autism: The importance of function. Research in Autism Spectrum Disorders, 2(3), 469-479.

Davis, M. (1988). The potentiated startle response as a measure of conditioned fear and its relevance to the neurobiology of anxiety. In Simon, P., Soubrie, P., Widlocher, D. (Ed.). Selected Models Of Anxiety, Depression And Psychosis. Basel, Switzerland: Karger.

Dawson, G., Meltzoff, A.N., Osterling, J., Rinaldi, J., \& Brown, E. (1998). Children with autism fail to orient to naturally occurring stimuli. Journal of Autism and Developmental Disorders, 28 (6), 479-486.

Dawson, G., Toth, K., Abbott, R., Osterling, J., Munson, J., Estes, A. \& Liaw, J. (2004).

Early social attention impairments in autism: social orienting, joint attention, and attention to distress. Developmental Psychology, 40(2), 271-283.

Dawson, G. (2008). Early Behavioral Intervention, Brain Plasticity, and the Prevention of autism Spectrum Disorder. Development and Psychopathology, 20, 775-803.

Dozier, C., Iwata, B.A., Thomason-Sassi, J., Worsdell, A.S. \& Wilson, D.M. (2012). A comparison of two pairing procedures to establish praise as a reinforcer. Journal of Applied Behavior Analysis, 45, 721-735. 
Dube, W.V., MacDonald, R.P.F., Mansfield, R.C., Holcomb, W.L., \& Ahearn, W. H. (2004). Toward a behavioral analysis of joint attention. The Behavior Analyst, 27(2), 197207.

Durkin, M.S., Maenner, M.J., Newschaffer, C.J., Lee, L.C., Cunniff, C.M., Daniels, J.L....Schieve, L.A. (2008). Advanced parental age and the risk of autism spectrum disorder. American Journal of Epidemiology, 168(11), 1268-1276

Ebner, E. (1965). Verbal conditioning in schizophrenia as a function of degree of social interaction. Journal of Personality and Social Psychology, 1(5), 528-532.

Eldevik, S., Hastings, R.P., Hughes, J.C., Jahr, E., Eikeseth, S. \& Cross, S. (2009). Metaanalysis of early intensive behavioral intervention for children with autism. Journal of Clinical Child \& Adolescent Psychology, 38(3), 439-450.

Elison, J.T., Sasson, N.J., Turner-Brown, L.M., Dicther, G.S., \& Bodfish, J.W. (2012). Age trends in visual exploration of social and non-social information in children with autism. Research in autism Spectrum Disorders, 6, 842-851.

Elsabbagh, M., Volein, A., Holmboe, K., Tucker, L., Csibra, G., Baron-Cohen, S...\& Johnson, M.H. (2009). Visual orienting in the early broader autism phenotype: disengagement and facilitation. Journal of Child Psychology and Psychiatry, 50(5), 637642.

Elsabbagh, M., Gigla, T., Pickles, A., Hudry, K., Charman, T. \& Johnson, M.H. (2013). The development of face orienting mechanisms in infants at-risk for autism. Behavioural Brain Research, 251(15), 147-154.

Esch., B., E., Carr, J.E., \& Michael, J. (2005). Evaluating stimulus-stimulus pairing and direct reinforcement in the establishment of an echoic repertoire of children diagnosed with autism. The Analysis of Verbal Behavior, 21, 43-58.

Esch, B.E., Carr, J.E., \& Grow, L.L. (2009). Evaluation of an enhanced stimulus-stimulus pairing procedure to increase early vocalizations of children with autism. Journal of Applied Behavior Analysis, 42(2), 225-241.

Field, T.M. (1979). Infant behavior directed toward peers and adults in the presence and absence of mother. Infant Behavior and Development, 2(1), 47-54.

Fisher, D.C. \& Wollersheim, J.P. (1986). Social reinforcement: a treatment component in verbal self-instructional training. Journal of Abnormal Child Psycholgy, 14(1), 41-48.

Fisher W., Piazza C. C., Bowman L.G., Hagopian L.P. (1992). A comparison of two approaches for identifying reinforcers for persons with severe profound disabilities. Journal of Applied Behavior Analysis, 25(2), 491-498. 
Fox, N.A. \& Davidson, R. J. (1987). Electroencephalogram asymmetry in response to the approach of a stranger and maternal separation in 10-month-old infants. Developmental Psychology, 23(2), 233-240.

Foxx, R.M. (2008). Applied behavior analysis treatment of autism: The state of the art. Child and Adolescent Psychiatric Clinics of North America, 17, 821-834.

Frith, U., \& Happé, F. (1994). Autism: Beyond "theory of mind.". Cognition, 50(1-3), 115-132.

Frith, U. (1997). The neurocognitive basis of autism. Trends in Cognitive Sciences, 1(2), 73-77.

Gewirtz, J. L. (1969). Mechanisms of social learning: Some roles of stimulation and behavior in early human development. In D. A. Joslin (Ed.), Handbook of socialization theory and research (pp. 57-212). Chicago: Rand-McNally.

Gewirtz, J. L., \& Pelaez-Nogueras, M. (1992). Infant social referencing as a learned process. In S. Feinman (Ed.), Social Referencing And The Social Construction Of Reality In Infancy (pp. 151-173). New York: Plenum.

Gewirtz, J.L., \& Pelaez-Nogueras, M. (1992). B.F. Skinner's legacy to human infant behavior and development. American Psychologist, 47(11), 1411-1422.

Gewirtz, J.L. \& Pelaez-Nogueras, M. (2000). Infant emotions under the positivereinforcer control of caregiver attention and touch. In Leslie, J.C. \& Blackman, D. (Eds.), Issues in Experimental and Applied Analyses of Human Behavior, (pp. 271-291). Reno, NV: Context Press.

Glasscock, S.E. \& MacLean, W.E. (1990). Use of contant desensitization and shaping in the treatment of dog phobia and generalized fear of the outdoors. Journal of Clinical Child Psychology, 19(2), 169-172.

Goodhart, F., \& Baron-Cohen, S. (1993). How many ways can the point be made? evidence from children with and without autism. First Language, 13(38), 225-233.

Green, C. \& Zigler, E. (1962). Social deprivation and the performance of retarded and normal children on a satiation type task. child development, 33(3), 499-508.

Gutierrez, A., Vollmer, T.R., Dozier, C. L., Borrero, J.C., Rapp, J.T., Bourret, J.C. \& Gadaire, D. (2007). Manipulating establishing operations to verify and establish stimulus control during mand training. Journal of Applied Behavior Analysis, 40, 645-658.

Guttman, W., Brozek, G. \& Bures, J. (1972). Cortical representation of conditioned eye 
blink in the rabbit studied by a functional ablation technique. Brain Research, 40(2), 203213.

Hagopian, L.P., Crockett, J.L., Van Stone, M., DeLeon, I.G. \& Bowman, L.G. (2000). Effects of non-contingent reinforcement on problem behavior and stimulus engagement: the role of satiation, extinction, and alternative reinforcement. Journal of Applied Behavior Analysis, 33, 433-449.

Hagopian, L.P., Wilson, D.M., Wilder, D.A. (2001). Assessment and treatment of problem behavior maintained by escape from attention and access to tangible items. Journal of Applied Behavior Analysis, 34(2), 229-232.

Hayes, L.J. \& Rehfeldt, R.A. (1998). The operant-respondent distinction revisited: Toward an understanding of stimulus equivalence. The Psychological Record, 48(2), $187-210$

Helt, M., Kelley, E., Kinsbourne, M., Pandey, J., Boorstein, H., Herbert, M., \& Fein, D. (2008). Can children with autism recover? If so, how? Neuropsychological Review, 18, 339-366.

Holth, P. (2005). An operant analysis of joint attention skills. Journal of Early and Intensive Behavior Intervention, 2(3), 160-175.

Hopkins, B. L. (1968). Effects of candy and social reinforcement, instructions, and reinforcement schedule leaning on the modification and maintenance of smiling. Journal of Applied Behavior Analysis, 1, 121- 129.

Hudry, K., Leadbitter, K., Temple, K., Slonims, V., McConachie, H., Aldred, C., . . . Charman, T. (2010). Preschoolers with autism show greater impairment in receptive compared with expressive language abilities. International Journal of Language \& Communication Disorders, 45(6), 681-690.

Isaksen, J. \& Holth, P. (2009). An operant approach to teaching joint attention skills to children with autism. Behavioral Interventions, 24, 215-236.

Jaccard, J., \& Becker, M.A., (2002). Statistics for the Behavioral Sciences 4th ed. Belmont, CA: Wasdworth/Thomson Learning.

Johnston, J.M. \& Pennypacker, H.S., (2008). Strategies and Tactics of Behavioral Research. Hillside, NJ, Lawrence Erlbaum Associates.

Jones, E. A. \& Carr, E.G. (2004). Joint attention in children with autism: theory and intervention. Focus on autism and Other Developmental Disabilities, 19(1), 13-26. 
Jones, E. A. \& Carr, E.G. (2006). Multiple effects of joint attention intervention for children with autism. Behavior Modification, 30, 782-834.

Kale, R.J., Kaye, J.H., Whelan, P.A., \& Hopkins, B.L. (1968). The effects of reinforcement on the modification, maintenance, and generalization of social responses of mental patients. Journal of Applied Behavior Analysis, 1(4), 307-314.

Kanner, L. (1944). Early infantile autism. The Journal of Pediatrics, 25, 211-217.

Kazdin, A.E. (2012). Behavior Modification in Applied Settings. Long Grove, IL: Waveland Press, Inc.

Kelleher, R. T., \& Gollub, L. R. (1962). A review of positive conditioned reinforcement. Journal of the Experimental Analysis of Behavior, 5, 543-597.

Klin, A , Lin, D., Gorrindo, P., Ramsay, G., \& Jones, W. (2009). Two-year-olds with autism orient to non-social contingencies rather than biological motion. Nature, 459, 257261.

Klin, A., Jones, W., Schultz, R., Volkmar, F., \& Cohen, D. (2002). Visual fixation patterns during viewing of naturalistic social situations as predictors of social competence in individuals with autism. Archives of General Psychiatry, 59. 809-816..

Lamberth, J., Gay, R. A., Dyck, D. G. (1972). Differential reward magnitude and human conditioning with social reinforcers. Psychonomic Science, 28(4), 231-233.

Lazarus, A.A., Davison, G.C. \& Polefka, D.A. (1965). Classical and operant factors in the treatment of school phobia. Journal of Abnormal Psychology, 70(3), 225-229.

Leekam, S.R., Lopez, B., Moore, C. (2000). Attention and joint attention in preschool children with autism. Developmental Psychology, 32(2), 261-273.

Lalli, J. S., Casey, S., \& Kates, K. (1995). Reducing escape behavior and increasing task completion with functional communication training, extinction, and response chaining. Journal of Applied Behavior Analysis, 28, 261-268.

Lohrmann-O'Rourke, S.,\&Browder, D.M. (1998). Empirically based methods to assess the preferences of individuals with severe disabilities. American Journal of Mental Retardation, 103, 146-161.

Lord, C., Risi, S., DiLavore, P.S., Shulman, C., Thurm, A. \& Pickles, A. (2006). Autism from 2 to 9 years of age. Archives of General Psychiatry, 63(6), 694-701. 
Lovaas, I. O., Freitag, G., Kinder, M.I., Rubenstein, B.D., Schaeffer, B., \& Simmons, J., (1966). establishment of social reinforcers in two schizophrenic children on the basis of food. Journal of Experimental Child Psychology, 4, 109-125.

Loveland, K.A., \& Landry, S.H. (1986). Joint attention and language in autism and developmental language delay. Journal of autism and Developmental Disorders, 16(3), 335-349.

Malott, R.W. (2008). Principles of Behavior, Sixth Edition. Upper Saddle River, NJ: Pearson Education Inc.

McArthur, L.A., \& Zigler, E. (1969). Level of satiation on social reinforcers and valence of the reinforcing agent as determinants of social reinforcer effectiveness. Developmental Psychology, 16(1), 739-746.

Meindl, J.N. \& Cannella-Malone, H.I. (2011). Initiating and responding to joint attention bids in children with autism: a review of the literature. Research in Developmental Disabilities, 32(5), 1441-1454.

Miller, P.M. \& Drennen, W.T. (1970). Establishment of social reinforcement as an effective modifier of verbal behavior in chronic psychiatric patients. Journal of Abnormal Psychology, 76(3), 392-395.

Miller, P.H. (2002). Theories of Developmental Psychology, $4^{\text {th }}$ ed. New York, NY: Worth Publishers.

Miltenberger, R.G. (2008). Behavior Modification: Principles and Procedures, Fourth Edition. Belmont, CA: Thomson Higher Education.

Mitchell, S., Brian, J., Zwaigenbaum, L., Roberts, W., Szatmari, P., Smith, I., \& Bryson, S. (2006). Early language and communication development of infants later diagnosed with autism spectrum disorder. Journal of Developmental and Behavioral Pediatrics, 27, S69-S78

Morales. M., Mundy, P., Delgado, C.E.F., Yale, M., Messinger, D., Neal, R., \& Schwartz, H.K. (2000). Responding to joint attention across the 6- through 24- month age period and early language acquisition. Journal of Applied Developmental Psychology, 21(3), 283-298.

Mundy, P. (1995) Joint attention and social-emotional approach behavior in children with autism. Development and Psychopathology, 7, 63-82.

Mundy, P. \& Vaughan, A. (2001). Joint attention and its role in the diagnostic assessment of children with autism. Assessment for Effective Intervention, 27(1-2), 57-60. 
Mundy, P., Delgado, C., Block, J., Venezia, M., Hogan, A., \& Seibert, J. (2003). A Manual for the Abridged Early Social Communication Scales. Coral Gables: University of Miami.

Mundy, P. \& Newel, L. (2007). Attention, joint attention, and social cognition. Current Directions is Psychological Science, 16(5), 269-274.

Mundy, P., Sullivan, L. \& Mastergeorge, A.M. (2009). A parallel and distributedprocessing model of joint attention, social cognition, and autism. Autism Research, 2, 221.

Nation, K. \& Penny, S. (2008). Sensitivity to eye gaze in autism: is it normal? Is it automatic? Is it social? Development and Psychopathology, 20, 79-97.

O'Connor, K. \& Kirk, I. (2008). Brief report: atypical social cognition and social behaviours in autism spectrum disorder: a different way of processing rather than an impairment. Journal of autism and Developmental Disorders, 38, 1989-1997.

Ohta, A. (1988) Conditioned reinforcement by conditional discriminative stimuli. Journal of the Experimental Analysis of Behavior, 49(2), 239-247.

Paclawskj, T.R., \& Vollmer, T.R., (1995). Reinforcer assessment for children with developmental disabilities and visual impairments. Journal of Applied Behavior Analysis, 28, 219-225.

Pallant, J. (2010). SPSS Survival Manual: A Step by Step Guide to Data Analysis Using SPSS (4 $4^{\text {th }}$ US Edition). Maidenhead, United Kingdom. McGraw-Hill Education.

Papka, M., Ivry, R.B. \& Woodruff-Pak, D.S. (1997). Eyeblink classical conditioning and awareness revisited. Psychological Sciences, 8(5), 404-408.

Partington, J. (2006). The Assessment of Basic Language and Learning Skills. Walnut Creek, CA: Behavior Analysts, Inc.

Pelaez-Nogueras, M. \& Gewirtz, J.L. (1995). The learning of moral behavior: a behavior analytic approach. In W.M. Kurtines \& J.L. Gewirtz (Eds.), Moral Behavior: An Introduction, 173-199). Boston: Allyn \& Bacon.

Piazza, C.C., Fisher, W.W., Hagopian, L.P., Bowman, L.G., \& Toole, L. (1996). Using a choice assessment to predict reinforcer effectiveness. Journal of Applied Behavior Analysis, 29(1), 1-9.

Pierce, D.W. \& Cheney, C.D. (2008). Behavior Analysis and Learning, Fourth Edition. New York, NY: Psychology Press. 
Plavnick, J.B., \& Ferreri, S.J. (2012). Collateral effects of mand training for children with autism. Research in Autism Spectrum Disorders, 6(4), 1366-1376.

Pryor. K., (2002). Clicker Training for Dogs. Dorking, Surrey, RH4 3YX, UK, Interpret Publishing.

Rescorla, R.A \& Solomon, R.L. (1967). Two-process learning theory: Relationships between Pavlovian conditioning and instrumental learning. Psychological Review, 73(3), 151-182.

Sahley, T.L. \& Panksepp, J. (1987). Brain opioids and autism: an updated analysis of possible linkages. Journal of Autism and Developmental Disorders, 17(2), 201-216.

Sasson, N.J., Turner-Brown, L.M.,, Holtzclaw, T.N., Lam, K.S.L. \& Bodfish, J.W. (2008). Children with autism demonstrate circumscribed attention during passive viewing of complex social and nonsocial picture arrays. Autism Research, 1, 31-42.

Schendel, D. \& Bhasin, T.K. (2008). Birth weight and gestational age characteristics of children with autism, including a comparison with other developmental disabilities. Pediatrics, 121(6), 1155-1164

Schlinger, H.D. (1995). A Behavior Analytic View of Child Development. New York, NY: Prenum Publishing Corporation.

Schweckendiek, J., Klucken, T., Merz, C.J., Tabbert, K. \& Walter, B. (2011). Weaving the (neuronal) web: fear learning in spider phobia. NeuroImage, 54(1), 681-688.

Scott-Van Zeeland, A.A., Dapretto, M., Ghahremani, D.G., Poldrach, R.A. \& Bookheimer, S.Y. (2010). Reward processing in autism. Autism Research, 3, 53-67.

Sidman, M. (1960). Tactics of Scientific Research: Evaluating Experimental Data in Psychology. New York, NY, Basic Books.

Skinner, B.F. (1953) Science and Human Behavior, New York, NY: The Free Press.

Smith, T. \& Eikseth, S. (2011). O. Ivar Lovaas: Pioneer of applied behavior analysis and intervention for children with autism. Journal of Autism and Developmental Disorders, 41(3), 375-378.

Stahl, J.R., Thompson, L.E., Leitenberg, H., \& Hasazi, J.E. (1974). Establishment of praise as a conditioned reinforcer in socially unresponsive psychiatric patients. Journal of Abnormal Psychology, 83(5), 488-496.

Stein, A.H. (1969). The influence of social reinforcement on the achievement of behavior of fourth-grade boys and girls. Child Development, 40(3), 727-736. 
Stone, W. L., \& Yoder, P. J. (2001). Predicting spoken language level in children with autism spectrum disorders. Autism, 5(4), 341-361.

Striano, T., Chen, X., Cleveland, A., \& Bradshaw, S. (2006). Joint attention social cues influence infant learning. European Journal of Developmental Psychology, 3, 289-299.

Sundberg, M. L. (2008) Verbal behavior milestones assessment and placement program: The VB-MAPP. Concord, CA: AVB Press.

Sundberg, M. \& Michael, J. (2001). The benefits of skinner's analysis of verbl behavior for children with autism. Behavior Modification, 25(5), 698-724.

Svensson, P. \& Ivarsson, M. (1999). Short-lasting conditioned stimulus applied to the middle cerebellar peduncle elicits delayed conditioning eye blink response in decerebrate ferret. European Journal of Neuroscience, 11(12), 4333-4340.

Tarabulsy, G. M., Tessier, R., \& Kappas, A. (1996). Contingency detection and the contingent organization of behavior in interactions: Implications for socioemotional development in infancy. Psychological Bulletin, 120(1), 25-41.

Taylor, J.C., Carr, E.G. (1992). Severe problem behaviors related to social interaction: attention seeking and social avoidance. Behavior Modification, 16(3), 305-335.

Toth, K., Munson, J., Meltzoff, A. \& Dawson, G. (2006). Early predictors of communication development in young children with autism spectrum disorder: Joint attention, imitation, and toy play. Journal of Autism and Developmental Disorders, 36(8), 993-1005.

Vanetsian, G.L. (1974). Conditioned blink reflex and neuronal activity in the auditory cortex of the cat. Acta Neurobiologias Experimentalis, 34(3), 339-352.

Virues-Ortega, J. (2010). Applied behavior analytic intervention for autism in early childhood: Meta-analyis, meta-regression and dose-response meta-analysis of multiple outcomes. Clinical Psychology Review, 30(4), 387-399.

Vollmer, T.R. \& Hackenberg, T.D. (2001). Reinforcement contingencies and social reinforcement: some reciprocal relations between basic and applied research. Journal of Applied Behavior Analysis, 34, 241-253.

Vollmer, T.R., Northup, J., Ringdahl, J.E., LeBlanc, L.A. \& Chauvin, T.M. (1996). Functional analysis of severe tantrums displayed by children with language delays: an out-clinic assessment. Behavior Modification, 20(1), 97-115.

Vriends, N., Michael, T., Schindler, B. \& Margraf, J. (2012). Associative learning in 
flying phobia. Journal of Behavior Therapy and Experimental Psychiatry, 43(2), 838843.

Watson, J.B. \& Watson, R.R (1920). Conditioned emotional reactions. Journal of Experimental Psychology, 3(1), 1-14.

Watson, L.R., Baranek, G.T., Crais, E.R., Reznick, J.S., Dykstra, J., \& Perryman, T. (2007). The first year inventory: retrospective parent responses to a questionnaire designed to identify one-year-olds at risk for autism. Journal of autism and Developmental Disorders, 37, 49-61.

Watson, P.J., \& Workman, E.A. (1981). The non-concurrent multiple baseline acrossindividuals design: An extension of the traditional multiple baseline design. Journal of Behavior Therapy and Experimental Psychiatry, 12(3), 257-259.

Whalen, C., \& Schreibman, L. (2003). Joint attention training for children with autism using behavior modification procedures. Journal of Child Psychology and Psychiatry, 44(3), 456-468.

Wolpe, J. (1958). Psychotherapy by Reciprocal Inhibition. Palo Alto, CA: Stanford University Press.

Zigler, E., \& Balla, D. (1972). Developmental course of responsiveness to social reinforcement in normal children and institutionalized retarded children. Developmental Psychology, 6(1), 66-73. 


\section{APPENDICES}
A. Recruitment Flyer
B. Letter of Informed Consent
C. Preference Assessment Parent Interview Form
D. ADOS Manual
E. ESCS Manual
F. Sample social stimuli cards
G. Sample nonsocial stimuli cards
H. Reinforcer Assessments Results
I. ESCS Individual Results 
Appendix A: Recruitment Flyer 
FLORIDA

INTERNATIONAL

UNIVERSITY

Department of Psychology

\title{
Behavior Analysis and Autism Research Lab
}

\section{Early Intervention Research: Conditioning Social Stimuli to Function as Reinforcement}

IRB Approval \#: 041912-02

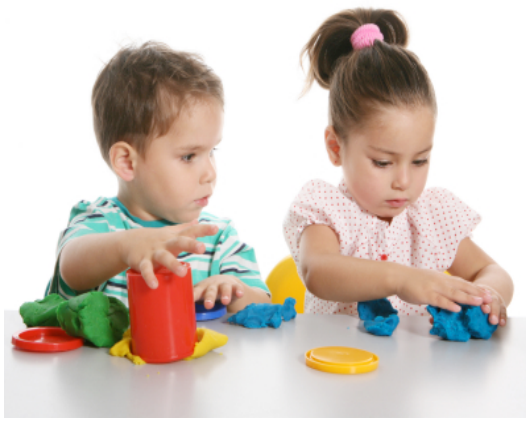

\begin{abstract}
Eligibility: This study is designed for children under three years of age who have, or are at risk for autism and related disabilities.
\end{abstract}

Goals of the study:

- Improve orienting and responding to social stimuli

- Improve effectiveness of social stimuli as reinforcers

- Demonstrate effectiveness of conditioning procedures for social stimuli

Location: FIU Modesto Maidique Campus

Center for Children and Families

11200 S.W. 8th Street, AHC1, Miami, FL 33199

Please call Paloma Pedraza at 305-348-6059 or e-mail ppedraza@fiu.edu for more information. 
Appendix B: Letter of Informed Consent 


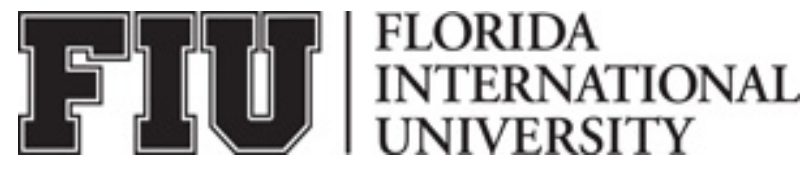

\author{
PARENTAL CONSENT TO PARTICIPATE IN A RESEARCH STUDY \\ Operant and Respondent Procedures to Establish Social Stimuli as Reinforcers in \\ Children with autism
}

\title{
PURPOSE OF THE STUDY
}

You are being asked to give your permission for your child to be in a research study. The purpose of this study is to determine if making social events more reinforcing to children with autism makes joint attention behavior more likely.

\section{NUMBER OF STUDY PARTICIPANTS}

If you agree to allow your child to participate in this study, he/she will be one of 10 people in this initial research study.

\section{DURATION OF THE STUDY}

Your child's participation will require 2-3, 1-hour visits per week (depending on availability) for approximately 6 weeks (depending on how often the child is able to come per week). There will also be a single, 1-hour post-treatment follow-up 4 weeks after the last session.

\section{PROCEDURES}

If your child participates in this study, we will ask your child to do the following things:

1. Select items and activities when given a choice of several preferred items or activities such as toys, edibles, high-fives and tickles.

2. Engage in a simple task in order to receive access to preferred items or activities such as toys, edibles, high-fives and tickles.

3. Receive preferred and non-preferred items or activities at the same time, to make the non-preferred items or activities more appealing.

4. Respond to, or initiate eye contact and/or looking at interesting events in the room, such as a toy that makes sounds and/or move, to test for Joint Attention skills.

\section{RISKS AND/OR DISCOMFORTS}

The following risks may be associated with your child's participation in this study:

- First, we may use edibles, if they are found to be preferred, and may do so across most of the sessions. Any edibles used, regardless of their health value, will be limited to one serving per session.

- Second, the tasks used may become boring or repetitive for the individual. However, getting access to the preferred items or activities should reduce the likelihood of boredom or fatigue. 


\section{BENEFITS}

The following benefits may be associated with your child's participation in this study:

- Task compliance will be targeted and strengthened.

- Preference for social and nonsocial items or activities will be identified, which can be applied to other therapies received.

- Joint attention skills will be assessed, which will provide valuable information about this skill.

- If effective, social events will be more preferred after the intervention than they were before the intervention.

\section{ALTERNATIVES}

There are no known alternatives available to your child other than not taking part in this study. However, any significant new findings developed during the course of the research which may relate to your child's willingness to continue participation will be provided to you. Many Behavior Analysis interventions use the pairing of new or neutral items or events with items or events that are interesting or exciting to the individual. However, they often do so in a less systematic manner. Further, the possibility of Joint Attention skills increasing as a result of this intervention has not been studied.

\section{CONFIDENTIALITY}

The records of this study will be kept private and will be protected to the fullest extent provided by law. In any sort of report we might publish, we will not include any information that will make it possible to identify your child as a subject. Research records will be stored securely and only the researcher team will have access to the records. However, your child's records may be reviewed for audit purposes by authorized University or other agents who will be bound by the same provisions of confidentiality.

If we learn about serious harm to you or someone else, we will take steps to protect the person endangered even if it requires telling the authorities without your permission. If we have reason to believe that your child is being abused, we will report this to the Florida Abuse hotline. In these instances, we would only disclose information to the extent necessary to prevent harm.

\section{COMPENSATION \& COSTS}

Your child will not be responsible for any costs to participate in this study. However, you are responsible for transportation to the lab and parking once you have arrived. Parking passes will be provided, if and when they are available, but are not guaranteed.

\section{RIGHT TO DECLINE OR WITHDRAW}

Your child's participation in this study is voluntary. Your child is free to participate in the study or withdraw his/her consent at any time during the study. Your child's withdrawal or lack of participation will not affect any benefits to which he/she is 
otherwise entitled. The investigator reserves the right to remove your child from the study without your consent at such time that they feel it is in the best interest.

\section{RESEARCHER CONTACT INFORMATION}

If you have any questions about the purpose, procedures, or any other issues relating to this research study you may contact Paloma Pedraza at 305-348-6059, or email at ppedraza@fiu.edu.

\section{IRB CONTACT INFORMATION}

If you would like to talk with someone about your child's rights of being a subject in this research study or about ethical issues with this research study, you may contact the FIU Office of Research Integrity by phone at 305-348-2494 or by email at ori@fiu.edu.

\section{PARTICIPANT AGREEMENT}

I have read the information in this consent form and agree to allow my child to participate in this study. I have had a chance to ask any questions I have about this study, and they have been answered for me. I understand that I am entitled to a copy of this form after it has been read and signed.

Signature of Parent/Guardian

Date

Printed Name of Parent/ Guardian

Printed Name of Child Participant

Signature of Person Obtaining Consent

Date 
Appendix C: Preference Assessment Parent Interview Form 


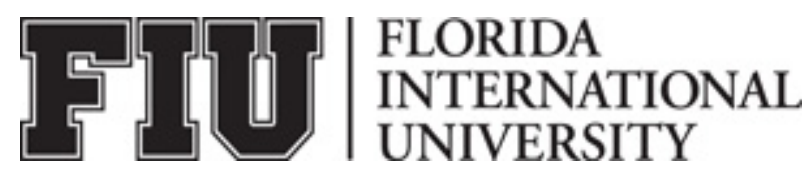

Please read the list of potentially reinforcing stimuli listed below. They are separated into social and nonsocial stimuli. For each section, please rank the stimuli in order of presumed preference. If there are stimuli that are not listed, feel free to add them into the ranking.

Social Preference Assessment

Tickles •

High-fives

Hugs/squeezes

Cheers (Yay!)

Praise (good job!)

Singing

Back pat

Smile
Head nod

Thumbs-up

Clapping

Pick-up

Social game (i.e., peek-a-boo)

Other:
Non-Social Preference Assessment Sweet edibles:

Salty edibles:

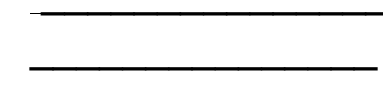

Ball

Figurines (Barbies, G.I. Joe)

Puzzles

Video games

Balloons
Sensory interests (lights, sounds, vibrations)

Musical instrument

Books

Bubbles

Blocks

Lego toys

Movies/video clips

Music

Play-doh 
Appendix D: ADOS Manual 


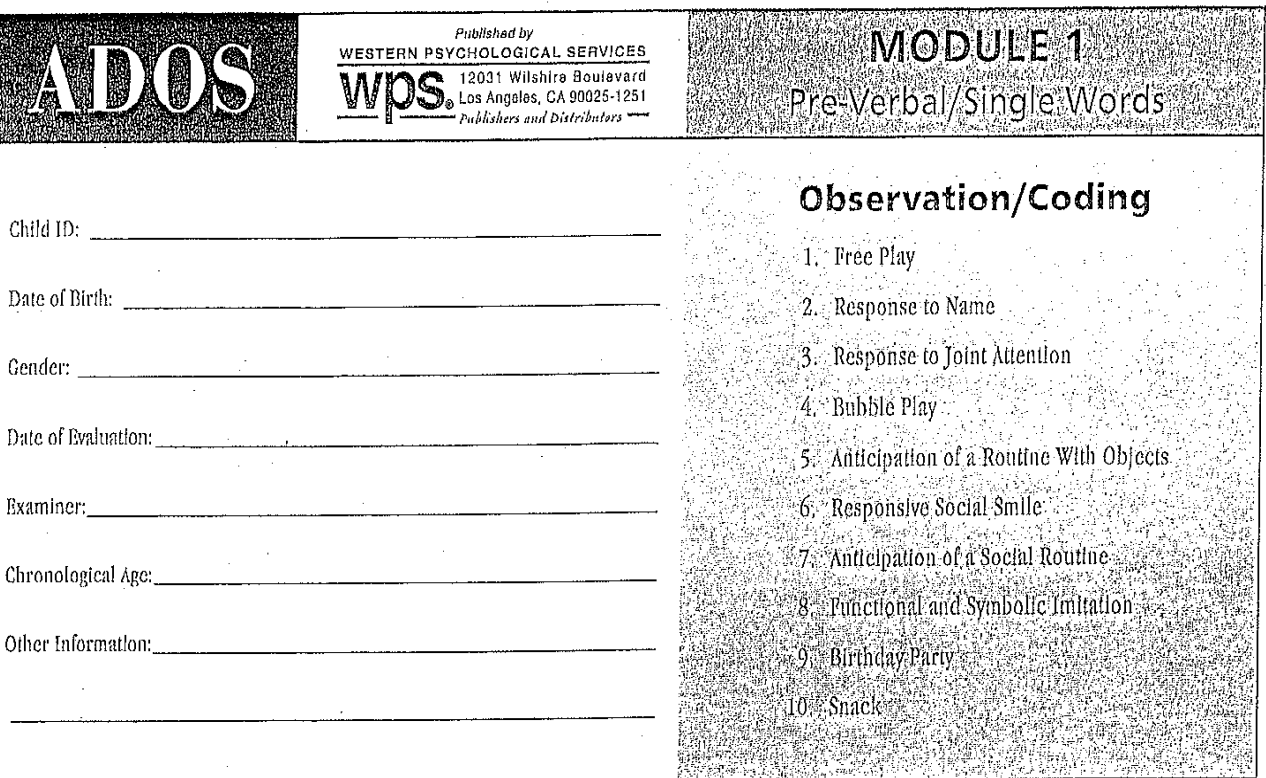

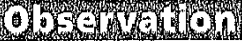

NOTES

\section{Frec Play}

Focus of Observation: The focus of observation is threefold. The filst issue is whether the child spontaneously'y seeks engagement with the parent/caregiver.

If so, how does he/sle do this, and does it involve joint reference to objects, such as giving and showing, or is it limited to seeling affection or help? The second issue is the extent to which the child explores materials either symbolically or functlonally. The third issue is the extent to which he/she stays with an activity for tn appropriate length of time, flits from object to object, or engages in repetitive actions.

Conmunication Sample: 


\section{Response to Naune}

Loctus of Observation: 'the goal of this thask is to obserye the consistency of the child's response to a hierarchy of atuditory slinuli, from (il) the cxaminer calling his/her motne, to (b) the parchl/categiver calling his/her nathe, to (c) the parent/caregiver malking a Faniliar noise or calling in a way daat implies physicial contact (c.g., "'H'm gonna get you!"), to (d) touching the child. "The focus of obscryalion is both on the sounds that the eximiner or parent/caregiver needs to make to get the child's atcention and on how the child responds.

37. Response to Joint Attention

Focus of Observation: 'the focus of obsetvation is on whether the child follows a shift in gaze alone or follows a shillt in gaze when it is accompanied by pointing.

3uble play

Focus of Observalion: 'This task provides a context for obseryation of the child's affect, iniliation of joint altention, shated enjoynent, recquesting, and motor behavior while the bubbles are present. Iniliation of joint attention requires a spontaneous shift in gaze from object to person to object with no apparent pulpose other that to share interest or pleasure.

5. Anticipation of a Routine Witl Objects

Focus of Observation: 'llis lask provides another contcxt for observatlon of the child's affect, initiation of joint attention, shared cujoynent, requesting, and motor belativior during the activity.

\section{Responsive Social Smile}

Foctis of Observation: 'the focus of observation is the consisicency of the child's smile in response to (a) the examiner suiling, (b) the paren/caregiver sniling, (c) the parenveregeger smiling and making a familiar nosse or calling in a waty that implies physical contact (e.g, "l'n gonna get you!"), or (d) being touched. 
Anticipation of a Social Routine

Focus of Observation: 'The focls of observition is on the child's allect and his/her altempts to intinte he repetition of the routtine. Particular attention should be given to the social dircetedness of the child's behaviors and the extent to which lec/sic integrates gazc, facial expression, vocalization, and gesture in aclions

dirceted to the examiner or the parent/caregiver.

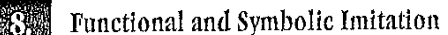

Pocts of Observation: The focus of observation is on the child's use of miniature objects and a phaceloolder in imitation of familiar actions, including whether these acts ate carried out with social awareness and shared enjoyment.

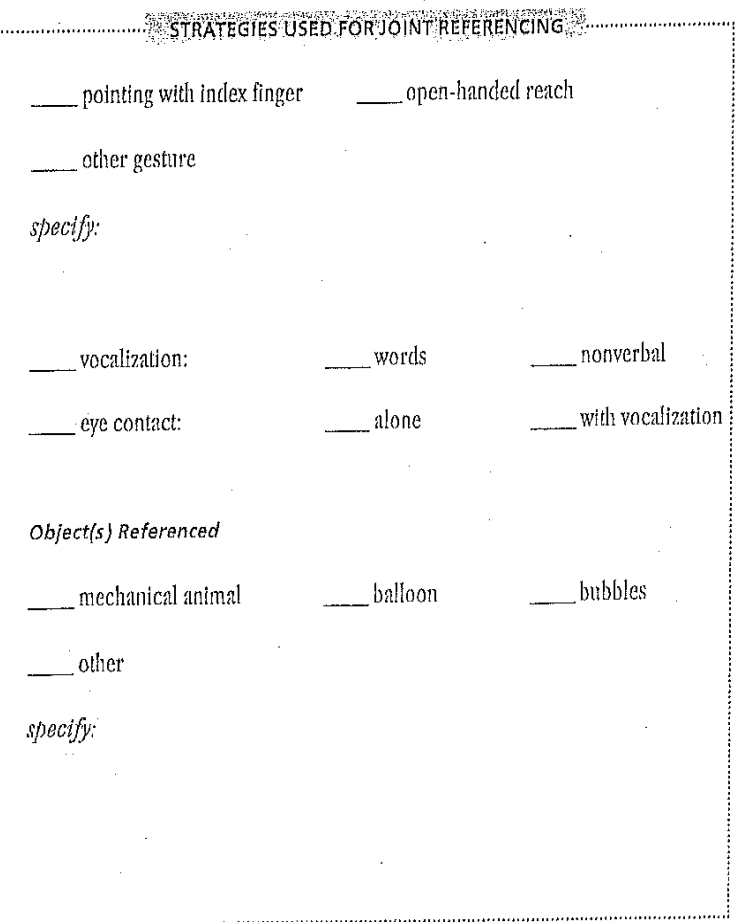


16) Birthday larty

fiocus of Obseryalion: "hline focus of observation is on the child's interest and ability to join in the "scriple" of a doll's bisthatay party. Allention should be clirected to

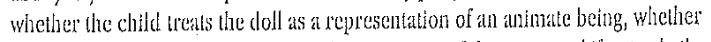
he/she spontuneously contributes to the entathent of the party, and if nol, whether he/sle will imitate the exanniner's actions spontineously or participate when asked or directed to do so.

\section{政10.}

focus of Obscrvatton: 'this thask provides the opportunily to determine if and how the child indlicatcs a preference and requests food in al familiar context. Atention is directed to lrow the child uses gate, gesture, reacling, factial expression, and wocalization to conmunicate a request to the examiner.

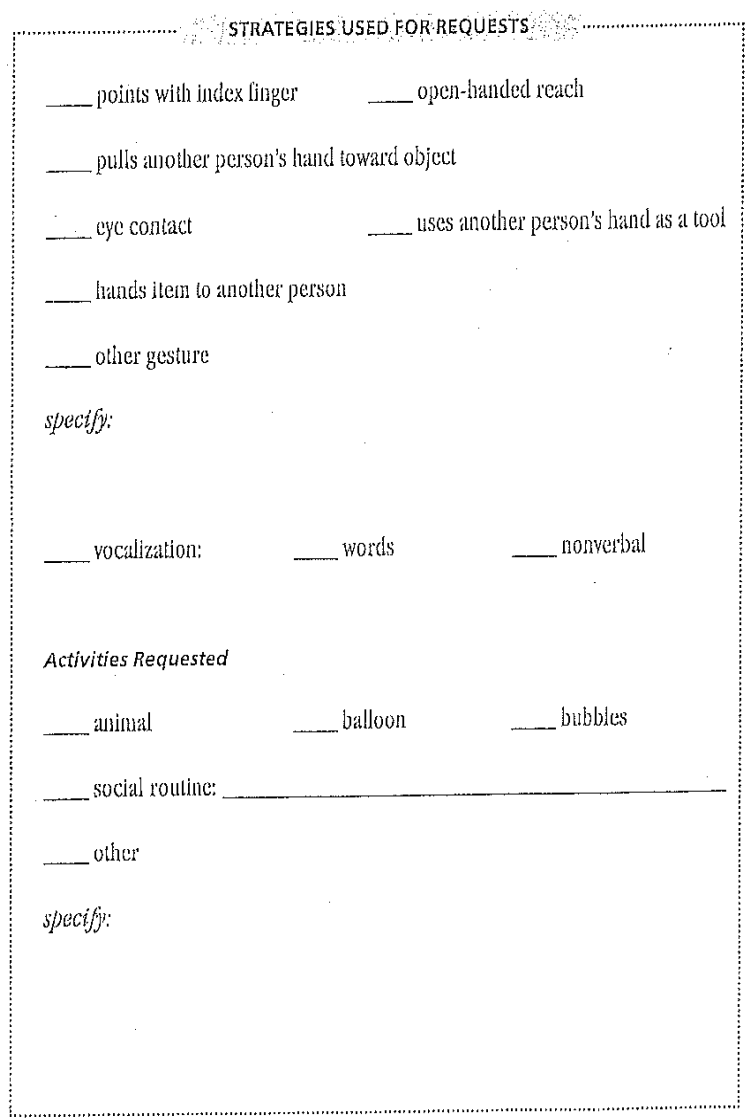




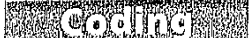

The overall ratings that you assign in this section should be matle on the basis of the chifl's behivior throughout the entire

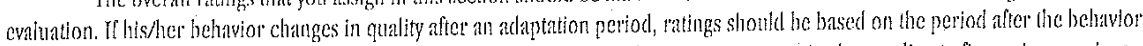
stabilizes. Ratings should be assigned inmediately after the assessment. "The ratings ate organized according to five main groupings: "A. Language and Communication," "B. Reciprocal Soctal friteraction," "C. Play," "D. Stercolyped Behaviors nud Restricted Intercests," atul "f, Oher Almormal Behaviors."

8 LANGUAGE AND COMMUNICATION.

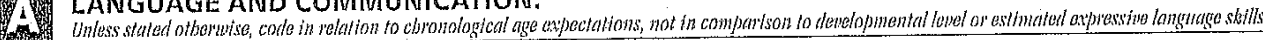

1. Overall level of Non-Echoet Language. This item is coded for the complexity of spontineous expressive langlage produced during the session. This rating should reflect the majority of utterances, not the most complex.

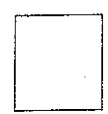

$0=$ Regular use of utterances with two or more worts.

$1=0$ ocasional plurases onlyi mosty single words.

$2=$ Recognizal)le single wor(ls only; mest use at lenst five different words turthg session.

$3=\mathrm{A}$ least one word or word approximation, but fewer than five wotls used daring session.

$8=$ No words or word approximations.

2. Frequency of Yocalization Directed to Otliers. This item is coded for the annount of soclally-directed vocallization.

$0=$ Directs vocalizations to parent/caregiver or examiner in a varicty of contexts. Must include chatting or vocalizing to be fitiendly or to express interest, as well as to make needs known.

$1=$ Directs vocalizations to parent/caregiver or examinel consistently in one context, OR directs vocalizations to parent/caregiver or examincr infrequently across a varicty of contexts.

$2=$ Directs an occasional vocalization to parent/calegiver or examiner inconsistently in a limited number of contexis. May laclude whining or crying due to frustration.

3 = Vocalizations almost never appear to be ditected to patent/caregiver or examiner, or rarcly or never yocalizes.
3. Intonation of Yocalizations or Verbalizations. 'This is a general iten that applies to all vocal izations or verhalizations, including crying and whining.

$0=$ Normal, appropriately varying intonation, wills no peculial' or' odel intonation.

$1=$ Jitle valiation in pitcl and tone; rather fat or exaggerated, or occasional peculiar intonition.

$2=$ Odd intonation or inappropriate pitcla and stress, AND/OR markedly flat and tondess medianical vocalizations, or an odd cry and few other yocalizations.

$8=N / A$ (insufficient wocalizations for assessment of intonation; includes presence of normal cry and fow other vocalizations).

4. Immediate Fcholalia.

This stem pertains to the child's immediatc repetition of the last statement or series of statements made by the parent callegivel or examiner: when coding, do not include repetitions that are al lead-In to a response to the examiner or that ate used as a memory device tn specific taskss.

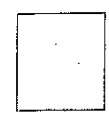

$0=$ Rurcly or never repeats others' specch.

$1=$ Occasional echoing

$2=$ Echoing workls and phr'sses regularty, but some spontaneous language (it can be stercotyped).

$3=$ Speech largely consisti of inmedate echolalla.

$8=$ rangutge too limiled to judge. 
Language and Communicalone conthated

5. Stereotyped/Idiosyncratic Use of Words or Pharases.

Cocling for this iten includes delayed echolatin or other highly repetilive utterinces with consistent intonition pailerns. These words or phrases cen be intended meaningfilly and can be appropriate to conversation at some level. The focus of the item is on the stereotyped or idlosyncratic cuablity of the phreasing or masistal use of words and/or their arbitrary association with a particutar meining. Neologisms should be coded here. Score relalye to the child's expressive language level.

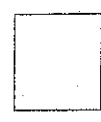

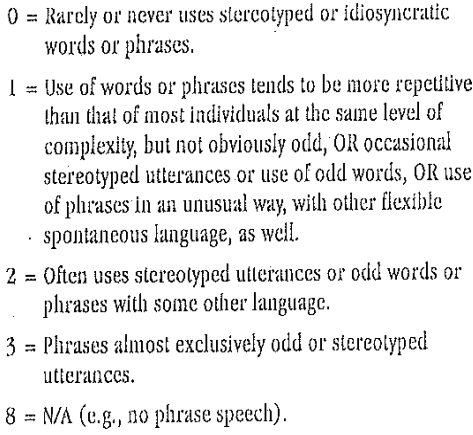

6. Use of Other's Body to Communicate. 'lhe focus of this item is on the use of another person's body as a tool. It requires movement of a limb or a part of soneone else's body witlout a previous or concurrent attempt to (lirect his/her attention using gaze

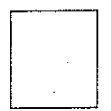

$0=$ No use of anoher person's body lo communicate, except in situations where other stralegies have not worked (c.g, when other's are conversing tad the child cannot get their altention) and ho conjunction with coordinated gatze.

1 = 'lakes another person's hand and leads him/he1" places wilhout coordinated gate, but no flicement of hatrd on objects and no use of il as a tool or to point.

2 = Placement of another persou's land or other body palt on object, OR movement of that person's hatad when $\mathrm{i}$ is holding an object, OR use of his/lier hand or other body part ats at tool or lo gesture "for" the clild (such as pointing).

$8=$ Little or no spontancous conmunicalion.
7. Pointing.

This flem describes socilly-directed pointing, which dichedes pofluting for the purpose of reguesting and/on for shared attention. The term distal here denoles pointing that is not close to touching (c.g, more than about 2 inches $/ 5 \mathrm{~cm}$ away).

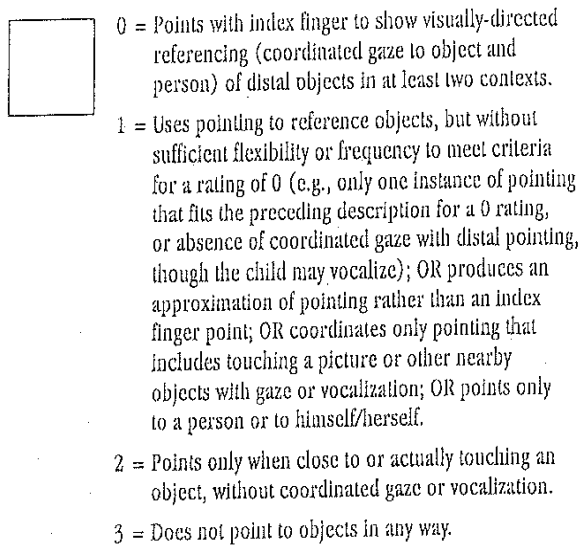

8. Gestures.

This iten pertains to the use of any kind of emolional or descriptive gestures olher than pointing. Gestures may be conventional or idiosyncratic, but they must be communicative and cannot involve moving someone else's body; do not include mannerisnss, Acting-out routines may be coded here if they are carried out in a way that is comnunicalive, spontancons, and appropritte. Odd gestures should not be included in coding at all here, unless they are the only appropriate gesurues that occu:

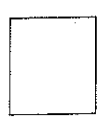

$0=$ Spontaneous use of at leasi two different gestures of any lype (descriplive, conventional, enotionel, or instruntental, excluding pointing); at leasc onc used nore than once.

$I=$ Spontaneous use of descriptive, conventional, institumental, or emotlonal gestures, but exaggerated or linited in range and/or contexls (e.g., only one or used only onces each).

$2=$ No spontaneous use of descriptive, conventional, instrumental, or conolional gestures, on inclppropriatc use only.

$8=N / \Lambda$ (e.g, linited by serere notor diffeuleies). 
7. RECIPROCAL SOCIAL INTERACTION.

SOCH

\section{Unusual Eye Contact.}

Codtng for this item requires that clent, flexible, socially modulated, and appropriate gaze that is used for a varicty of purposes be distinguished from gaze that is limited in flexilility, appropriateness, or contexts. If the child is shy initially, and his/her gaze changes markedly and consistently as he/she becomes more comfortable, do not base the code on earlier impressions. However, if eye contact never improves, coding must be based on what is observed, even if the child seems shy.
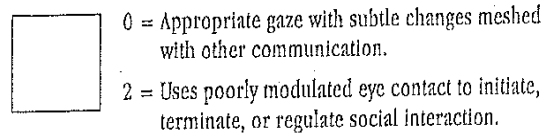

$0=A$ pproprinte gaze with subtle changes meshed with other communication.

$2=$ Uses poorly modulated eye contact to initiate, terminate, or regulate social interaction.

\section{Responsive Social Smile}

This item pertains to the chilc's facial response to a smile and/or playful verbal interaction with the examlner or parent/caregiver. To be cotled here, the child's smile must be in response to another person rather than to an action.

$0=$ Smiles inmed lately in sesponse to one of the flrst two smiles of the examiner and/or parent/caregiver This must be a clear change from nousmillng to a fully responstve smile that is not prompted by a specific request (e.g "Glve me a smile").

$1=$ Delayed or partial smile, or smiles fully or partially only after more than two sniles by the parenvearegiver or the examiner, or smiles only in response to a specilic request.

$2=$ Sniles fully or partially at the parenv/categlver or the examiner only atter being ticlled or touched in some way, OR in response to a repeated action with a plysical component (even if the child is not actually to uched),

$3=$ Docs not smile in response to another person
3. Pacial Fxpressions Directed to Others.

The rating for this item should indicate whether the child's facial expressions are directed toward another person for the purpose of communtcating affect. raclal expressions that are directed towarl objects or that are und lrected alre not rated here. Appropriate facial expresstons should be colled even if there are also odd expresstons.

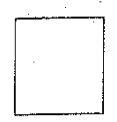

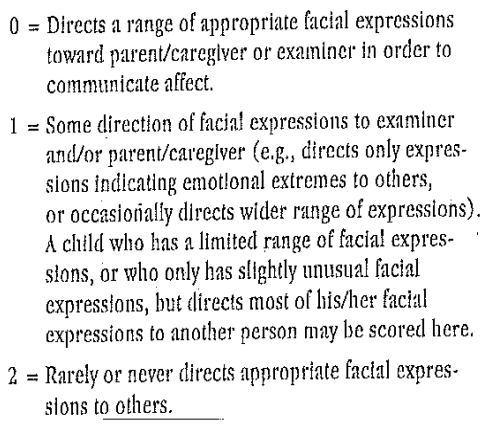

4. Integration of Gaze and Other Behaviors During Social Overtmres.

The focus of this item is on the quality of the child's attempts to inithate interacion, particularly the integration of gaze with other behaviors, not the frequency of such attempts. When assigning a rating, consicler attempts to get help or other highly motivated approaches, Rate the majority of these attempts, not the best.

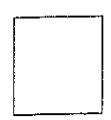

$0=$ Uses eye contact effectively with words or vocalizations of gestures to communicate sochal intention.

$I=$ Uses eve contact and vocalization Independently of each other to communicate social intention (i.e., lises botl cye contact and other strategies at different times, but does not coordinate them with each other).

$2=$ Uses etther eye contact or vocalization to communtcate social intention.

$3=$ Uses neither eyc contact nor yocaltzation to communicate social intention, or no social overtures. 
Reciprocal Soclal hiteraclion conltwed

5. Shared Enjoyment in Interaction.

Rate the child's social response during any of the activites or presses. "flis code should not be used to indicale the chiltt's general emotional state during the intervicw, "the rating applies to his/her ability to indicale pleatsure to the examner, not just to interact or respond.

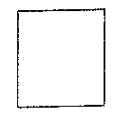

$0=$ Shows delinite and appropriate pleasure with the examiner during more than one activity. Must include pleasure in all least one activily that is not purcly physical in nature (c.g, tickling).

$1=$ Shows some appropriate pleasure in the examiner's actions dating more that one activily, or shows de? inite pleasure directed to the examincr during one interaction (may be plysical in nature).

$2=$ Shows little or no expressed pleasure in interaction with the exanined. May show pleasure in his/her own actions, in inceraction with a parent/caregiver, or in the arailable toys.

\section{Response to Name.}

This rating codes the child's response to hearing his/her name called durting a specilic press. A full response is defined as orienting to and making eye coniact with the person who calls his/lier name. The number of presses is specified becaluse of the increassed likelihood that the child will look if provided many opportunities.

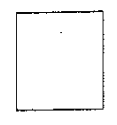

$0=$ Looks toward the examiner and makes cye contact irmediately on at least one of the first two clear presses made by the examiluer (i.e., name only is called).

$1=$ Looks loward the paren $/$ caregiver and makes eye contact inmedialely for first or second press of nume only, OR makes eye contact with the examiner inmediately for the cxaniner's thidd or fourth press of nane only.

$2=$ Does not make eye contact widl either the examiner or the partent/calegiver after his/her name is called in six altenpts, but siffts gaze briely (no eye contalct), on looks at leats once when an interesling or familiar vocalizalion or verbalization is mate (e.g. tongue clucking; "I'm gonna get you").

3 - Does not look loward citleer the exaniner or the parent/caregiver alicr any purely verbal or vocal altempt to get atlention.

\section{Requesting}

Requosting is defined as a conventional indication-lhrough gesture, yocalization, facial expression, or other means- of the clilid's cesire for a particular action or object. This cath include requests for a social routine, balloon, bunny, bubbles, and so forth, as long as they are not parl of a routine from home and are related to a specific event or object. It docs not include a general desire to be held. If the child ises more than one strategy to request different objecls or activities, rate the reguest that merits the higher rating level (i.e., closest to at rating of 0 ). When assigning this code, exclude requesis for snack liens or to leave the room.

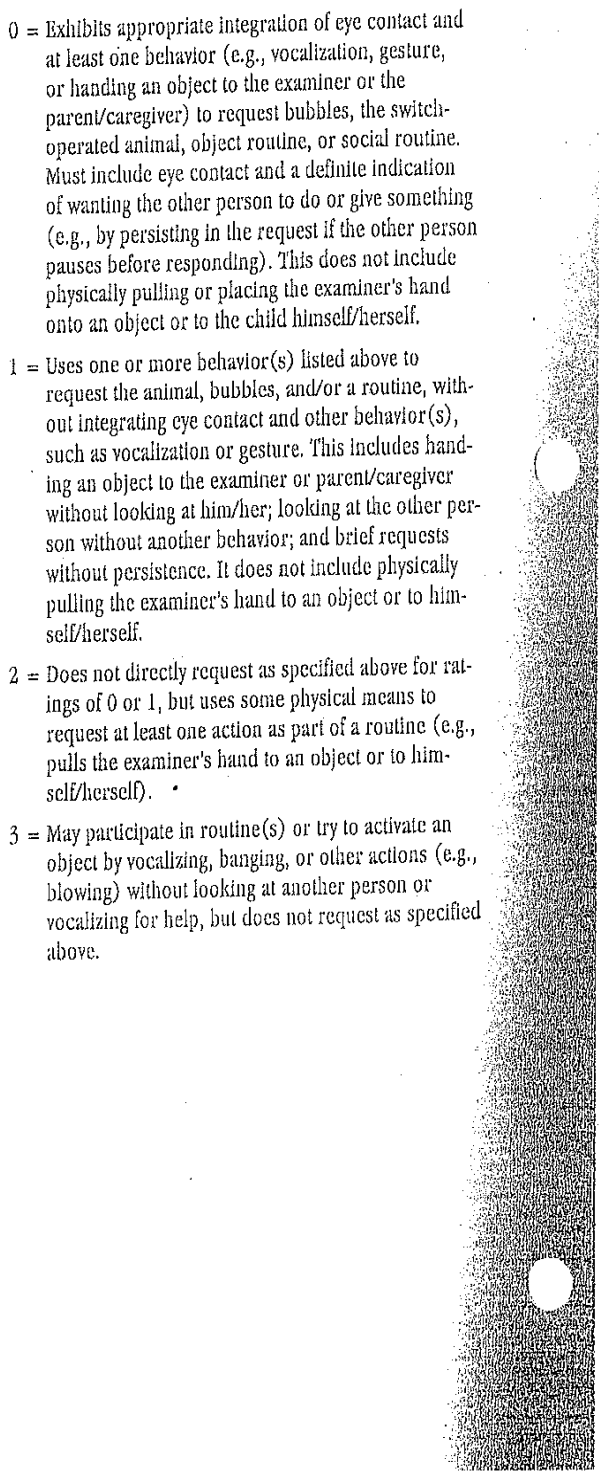


Reciprocal Soctal ruteraction continued

\section{Giving.}

This item descrbes handing objects to another person across a minge of contexts, including sliaring and getting help. It does not requite eye contact, but does imply lndependent, spontaneous release of the object.

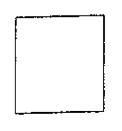
0 Spontaneously gives toys or objects to other people In a varlety of contexts throughout the ADOS evalua. tion, Including giving toys, lood, or pretend food for the purpose of sharing.

$1=$ Gives objects to other people for the purpose of getting help (e.g., In operating toys or openting food containers) ol is part of a l'outine.

$2=$ Rarely or nover gives wything to another person.

\section{Showing.}

Showing is defined as deliberately orienting or placing an object where it can be seen by another person with no Identifiable purpose of getting help or participating in a routine, For full credit, this must be accompanied by eye contact, but yocalization is not required.

$0=$ Spontaneously shows toys or objects throughout the ADOS evaluation by holding them up or placing them in front of others and using eye contact with or without vocalization.

$1=$ Shows toys or objects in a partial or inconsistent manner (e.g, holds them up and/or places them in Front of others without coordinated eye contact, looks from an object in hes/her hands to another person without clearly orienting it toward that person, or shows objects as described above for a 0 rating on one occasion only).

$2=$ Does not show objects to another person.
10. Spontaneons Initiation of Joint Attention. This rating codes the child's attempts to draw another person's attention to objects that neither of them is touching. This does not include such attempts if they are for the purpose of requesting.

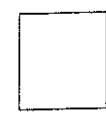

$0=$ Uses clearly Integrated eye contact to referencents object that is out of reacl by looking at the object then al the exitminer or the parent/careglver, and then back to the object. Ijec contact may be coordinated with pointing and/or wocal ization. One clear example of an attempt to draw another per'son's uttention to an object (1.e., more than just referencing) is sufficient for this rating.

$1=$ Partially references an object that is clearly out of reach. May spontaneously look and point to the object and/or yocalize, lut does not coordlnate ether of these with looking at another person, $O R$ may look at an object and then look at or point to the examines or the parent/caregiver, but not look back the object.

$2=$ No approximation of spontaneous initiation of joint attention in order to relerence an object that is out of reach.

11. Response to Joint Attention.

This rating codes the child's response to the examiner's usc of gaze and/or pointing in order to direct his/ler attention to a distant object. The rating should not be affected by the . child's understanding of language (i.e., he/she must follow the direction of the cxaminer's gaze or pointing, but does not have to understand what was said).

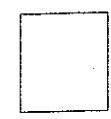

$0=$ Uses the orientation of the examiner's cyes and face alone as a cue to look toward the tainget without the need for pointing. The child must follow the examiner's gaze and turn his/her face or eyes In the direction of the target after watching the examiner do so; he/she does not actually lave to catch sight of the target.

$I=$ Responds to the examiner's pointing by looking at or toward the target.

$2=$ looks at the target when it 1 activated or placed directly in front of him/her, but does not make use of the examiner's gaze or pointing in order to locate the target from a distance.

$3=$ No interest or awateness of the target. If it is not possible to get the child's attention ln order to direct it In five altempts, assign this rating. 
Bectirocal Social hiterachou conthued

12. Quality of Social 0vertures.

This is a summary iten that focuses on the quality of the child's allenpts to initiale social-interaction, not on the

frequency of such attenpts. Special attention should be given to the form of the overtures and their appropriateness to the social context. The ralling should reflect the majority of social overtures, not merely the best ones.

$0=$ bffectively uses nonverbal and verbal means to make clear social overtures to the exaniner or the parent/caregiver. 'The overtures musi be appropriale to immediate contexts.

$1=$ Slightly unusual cuality of soclal overtures, Assign this lating if overtures are restricted to personal demands of lelated to strong inter'ssts, but with some attempt to inwolve the examiner or the parent/caregiver in that interest.

$2=0$ vertures often lack integration into contex AND/OR social quality. Also assign this mathing if there are some clearly inapplopriate overtures.

$3=$ Negligible social overtures of any kind. 


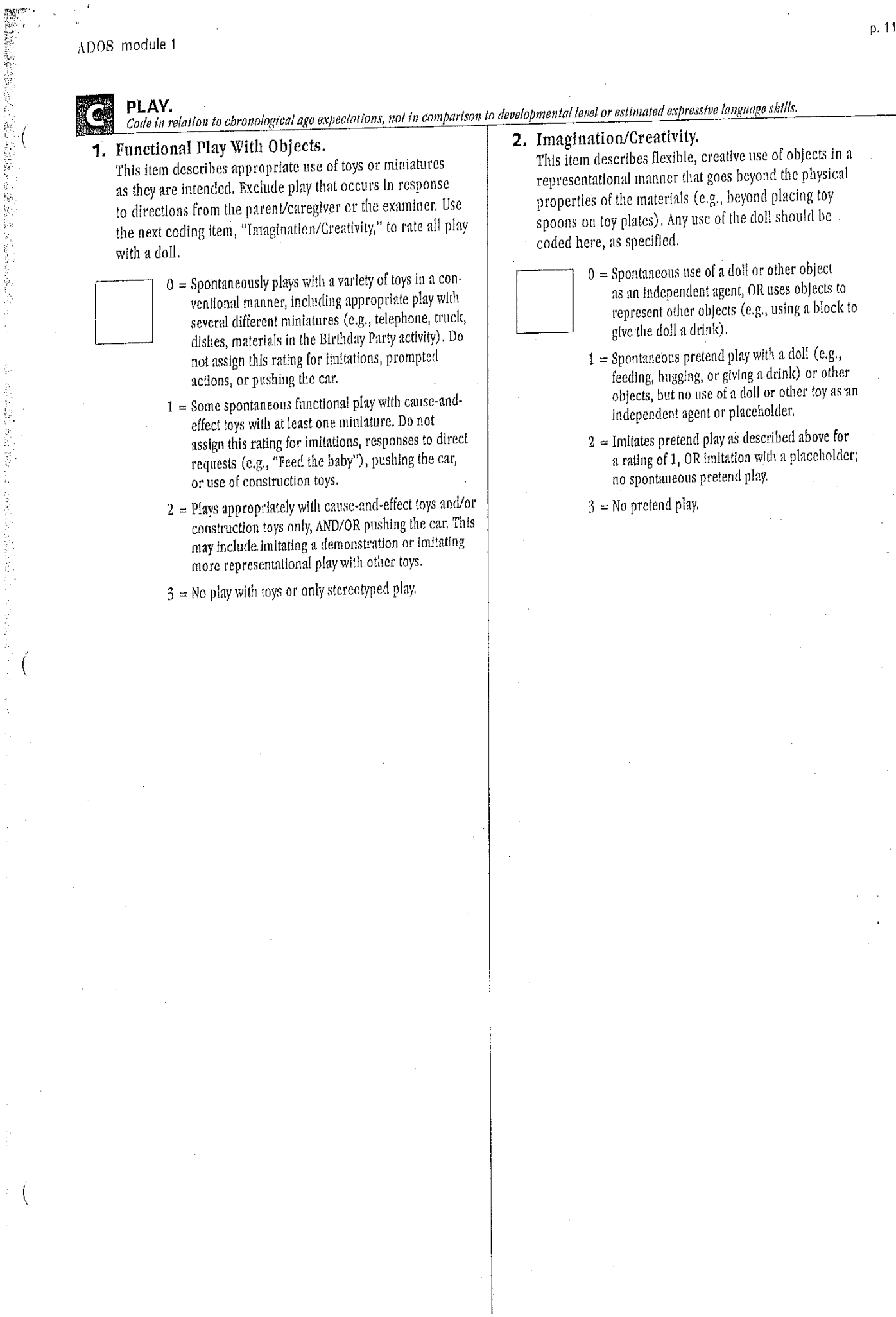


D. STEREOTYPED BEHAVIORS AND RESTRICTED INTERESTS.

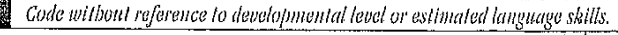

1. Unusual Sensory Interest in Play Materal/person. kate the child's interest in or unusual response to sensory alspects of toys or surroundings. If he/she hals a preoccupalion thal is based on as sensory interest, this may be coded here as one unuslal sensory interest, lor cxaniple, if ho/she slows an interest in table legs for long periods of time, this is coded later in this section of the protocol under "Unusually lepetitive Interests or Stereotyped Behaviors." If the child is interesied in table legs and likes to look at then repeatcdly, as shown by peering at them and til ing his/her head, it should be coded under "Unusually Repetitive Interests or Stereotyped Behatvors" if it is a persistent behavior, bat may also be coded here with a ralling of 1 becallase of the sensory component involved. If the child likes lo look at table legs, lhe corners of the room, the doors on the pop-up toy, and the shats of the window binds, but does not becone overly preoccupied with any of them, heshe should neceive a rating of 2 here $10 \mathrm{r}^{\circ}$ unusial sensory interests and at ating of 0 unded "Unusulily liepetilive Interests or Stereolyped Behavior's." Mouthing is not coded in this ADOS module.

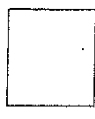

$0=$ No snifling, repetitive touching, feeling of texture, licking or biting (not mouthing), interest in the repetition of or unisually strong reactious to certain sounds, or unusual or prolonged pisual examination. $1=0$ ccisional unusual selsory interests or responses, OrR not as clear as specified below lor a lating of 2

$2=$ Definte interest in nonfunctional. clements of play misterials, OR sensory examination of himself/liciself or obers on more thath one occasion, on persistent wusustal sensory response to several materials or events

i)jecify:
2. Hand and Finger and Other Complex Mannerisms. liate unusual and/or repetitive movenents or posturiug of the hands and fingers, allons, of whole body. Clapping is not coded in this ADOS module. Do not incluke body rocking unless it involves more than the torso. linger tapping, nail biting, hair twisting, and thunb sucking are also not coded here. The child does not have to watch the movements of his/lier' fingers or hands in order to be coded here.

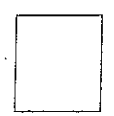

$0=$ Nonc.

$1=$ Very bricf or l'ale hand and finger manerisns or complex mannerisus, OR mauncrisnas nol als clear as specified below for a rating of 2 .

2 = Definite finger flicking or twisting, MND/OR, hand or other mannerisms or stcreotypes.

specify:

3. Self-Injurious Behavior.

Rate any betariors that involve any kind of aggressive act to self, even if not clearly harmful.

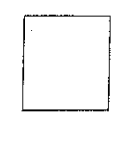

$0=$ No altempts to harm setf

$1=$ Ralec and/or dubious self-injury (e, g., at least once bites at own hand or arm, pulls own hatr, slaps own face, or bangs head).

$2=$ Self-jnjury delinitely present (e.g, more than one exaluple of heat-banging, face slapping, hail puiling, or self-biting.) 


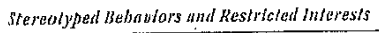

4. Unusually Repetitive Interests or Stereotyped Behaviors.

Rate any unusually repetitive or stereotyped behators, including preoccupation with unusual activities or objects, such as table legs or wristwatches; repetitive nonfunctional use of toys, stch as spinuing wheels, lining things up, or flicking the doll's eyes for more than 2 or 3 seconds; repetitive actions, such ats banging objects or putting fingers in ears; and insistence on unusial routhes or ritualized behaviors, such as specific ways of touching or moving objects, of insistence on having the parent/caregiver or the examinar act in a specific wily.

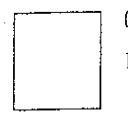

$0=$ No repetilive or stereotyped behaviors during the dDOS evalualion.

$=$ An interest or behavior that is repetitive or stereotyped to an unusual degree, including an intense interest in a particular toy or object, a definite interest in an unusual object or activity (odd for the childe's level of motor skill), an unusually routinized activity, frequent repetitive use of objects, or a clear interest in a part of an object. Shill, an untusualy routinized activity, frequent repetitive use behavior occurs in conilunction with several other activities, ant does not prevent the child from completing any ADOS activities.

$2=$ Repetitive or stereotyped interests and/or behaviors, als described above, form a sibstantial minority of the child's interests and spontaneous behayiors. These interests and behayions may interfere with the child's ability to complete ADOS atctivities, but it is possible for his/her attention to be directed to ofher objects or activilies at least momentarily. If it is necessary to remove the preoccupying objects from the room, assign this rating.

$3=$ Repetitive or stereotyped interests and/or beliaviors, as described above, form the majority of the child's interests, OR attempts to direct his/her attention to other objects or activities are met with resistance and/or distress.

Specify uniusual preoccupations, rituals, repetitive bebaviors: 


\section{OTHER ABNORMAL BEHAVIORS.}

Unless stated otborwiso, codle these iloms wibont roference to dovelopmental level or estimated langunge skills

1. Overactivity.

For this item, rate the expected ability of the child to remain still and/or seated, based on his/her general developmental level.

$0=$ Sits or stands still approprialcly when expected to do so during the assessment

$1=$ Sits briefly or stands still when expected to do $s 0$ (e.g. during the symbolic initation task, the birthday party) for aclivities besides the snack. Often fidgets, moves about, or gets up out of his/her jeat, but is not obviously restless or unusually fidgety. Difficulties in the assessment are not principally due to overactivity.

$2=$ Hardly remains still al all (not counting the snack). May move around the room in a way that is difficuit to interrupt; the level of activity distupts the assessment.

$7=$ Underactive.

2. Tantrums, Aggression, Negative or Disruptive Behavior.

This item includes any form of anger or distuption beyond communication of mild frustration or whining.

$0=$ Not upset, disruptive, negative, destructive, or aggressive during ADOS.

$1=0$ ccasional display of mild upset, anger, aggression, negativism, or disruptive behavior to the parent/caregiver or the examiner.

$2=$ Shows marked or repeated negativism, temper tantrums, or more significant aggression (e.g, hiting, biting others). Loud screaming is included here.

3. Anxiety.

A nxitity includes initial watiness, as well as more obvious signs of worry or concern.

$0=$ No obvious anxiely (e.g. trembiling or jumpiness).

$1=$ Mild signs of anxiety, especially at the beginning of the interview, OR marked anxiety onily in response

to a specific request or to one particular toy or task.

$2=$ Marked anxiety in response to more than one toy or task or several times during the evaluation. 


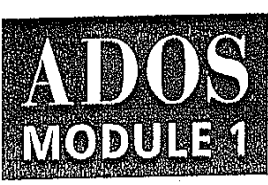

Child ID

Gender:

Examiner:

Communication

Frequency of Vocalization Directed to Others

Stereotyped/ldiosyncratic Use of Words or Phrases

Use of Other's Body to Communicate

Pointing

Gestures

\section{Reciprocal Social Interaction}

Unusual Eye Contact

Facial Expressions Directed to Others

Shared Enjoyment in Interaction

Showing

Spontaneous Initiation of Joint Attention

Response to Joint Attention

Quality of Social Overtures

tention

Date of Birh:

Date of Evaluation:

Chronological $\mathrm{kge}$

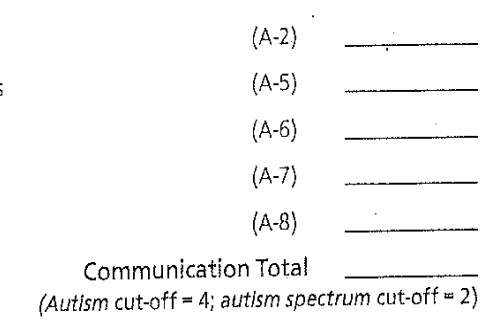

(Autism cut-off $=4$; autism spectrum cut-off $=2$ )

$(\mathrm{B}-1)$

(B-3)

(B-5)

(B-9)

(B-10)

$(\mathrm{B}-11)$

(B-12)

Social interaction Total (Autism cut-of $=7$; autism spectrum cut-off $=4$ )

Communication + Social Interaction Total

(Autism cut-off $=12$; autism spectrum cut-off $=7$ )

Play

Functional Play With Objects

(C-1)

Imagination/Creativity

(C-2)

Play Total

Stereotyped Behaviors and Restricted Interests

Unusual Sensory Interest in Play Material/Person

(D-1)

Hand and Finger and Other Complex Mannerisms

$(D-2)$

Unusually Repetitive Interests or Stereotyped Behaviors

(D-4)

Stereotyped Behaviors and Restricted Interests Total

Diagnosis

ADOS Classification:

Overall Diagnosis 
Appendix E: ESCS Manual (selected pages) 


\title{
DRAFT
}

A Manual for the Abridged

\section{EARLY SOCIAL COMMUNICATION SCALES (ESCS)}

\author{
Peter Mundy, Christine Delgado, Jessica Block, Meg Venezia, Anne Hogan, \& Jeffrey Seibert \\ University of Miami \\ (ㄷ) 2003
}

\author{
Correspondence address: \\ Dr. Peter Mundy \\ Department of Psychology \\ University of Miami \\ 5665 Ponce De Leon Blvd. \\ Coral Gables, FL 33124-0751 \\ Phone: (305) 284-2331 \\ Fax: (305) 284-4795 \\ Email: pmundy@miami.edu
}




\section{BACKGROUND}

The Early Social-Communication Scales (ESCS) is a videotaped structured observation measure that requires between 15 to 25 minutes to administer. The version described in this document has been designed to provide measures of individual differences in nonverbal communication skills that typically emerge in children between 8 and 30 months of age. It may be used with children with typical development within this age range or with children with developmental delays whose verbal age estimates fall within this range.

The ESCS was originally designed as a comprehensive clinical measure based on two organizing constructs: 1) a cognitive, Piagetian, stage-related orientation to early development which provided a means for analyzing specific behaviors' developmental complexity; and 2) a pragmatic-functional orientation which provided a means for analyzing specific behaviors' interpersonal or communicative goal (see Seibert, Hogan, \& Mundy; 1982, 1984). A set of 25 semi-structured eliciting situations were developed to encourage interaction between an adult tester and the child; approximately 110 child behaviors were noted as possible occurrences. From videotaped records, behaviors were then coded, and summarized according to a) developmental stage (simple, complex, conventional, or symbolic); b) communicative goal (to achieve social interaction between partners, to achieve joint attention to an entity or event, or to regulate the partner's behavior for assistance or compliance); and c) whether the child initiated the interaction or responded to the tester's bid. Thus, a social-communicative profile resulted which indicated the child's highest levels across the various communicative functions.

By reducing the number of items in the ESCS, this abridged version has been designed as a more practical research instrument, as well as a clinical tool. Furthermore, the scoring of the abridged version emphasizes frequency data, rather than the ordinal or four-stage related measures of early social communication development emphasized in the original ESCS (Seibert et al. 1982). The complexity construct is now reflected by the designation of lower vs. higher level behaviors. Finally, the theoretical framework of the abridged ESCS has been broadened so that the measures of the ESCS are now viewed as reflecting self regulatory and affective process, as well as epistemological and basic process elements of early social cognition (see Mundy, 1995; Mundy \& Willoughby, 1996; Mundy \& Gomes, 1997; Mundy \& Sheinkopf, 1998).

\section{Behaviors of Interest}

The videotape recordings of the ESCS enable observers to classify children's behaviors into one of three mutually exclusive categories of early social-communication behaviors. The function of these categories of behaviors may be briefly described as follows. Joint Attention Behaviors refer to the child's skill in using nonverbal behaviors to share the experience of objects or events with others. Behavioral Requests refer to the child's skill in using nonverbal behaviors to elicit aid in obtaining objects or events. Social Interaction Behaviors refer to the capacity of the child to engage in playful, affectively positive turn-taking interactions with others. (For additional description of these dimensions see Bates, 1979; Bruner \& Sherwood, 1983; Mundy et al. 1988; Mundy, 1995; Seibert, et al. 1982, 1984).

Behaviors are also classified as to whether they are child initiated bids or responses on the part of the child to a tester's bid. Thus, Initiating Joint Attention (IJA) refers to the frequency with which a child uses eye contact, pointing and showing to initiate shared attention to objects or events. Responding to Joint Attention (RJA) refers to the child's skill in following the tester's line of regard and pointing gestures. 
Initiating Behavioral Requests (IBR) refers to the child's skill in using eye contact, reaching, giving or pointing to elicit aid in obtaining an object, or object related event. Responding to Behavioral Requests (RBR) refers to the child's skill in responding to the tester's gestural or verbal simple commands to obtain an object or action from the child. Initiating Social Interaction (ISI) refers to the child's skill at initiating turn-taking sequences and the tendency to tease the tester.

Responding to Social Interaction (RSI) refers to the frequency of eye contact, gestures, and turns-taking exhibited by a child in response to turn-taking interactions initiated by the tester

Finally, a measure of social communication imitation may also be obtained from the ESCS by summing the number of times the child imitates the pointing and/or clapping gestures displayed by the tester.

The toys and other materials used in the ESCS have been selected because of their potential to elicit social interaction, joint attention, and/or behavioral request. The toys included: a) three small wind-up mechanical toys, b) three hand-operated toys, including a balloon, c) a small car and a ball that will roll easily across the table, d) a book with large distinct pictures on its pages, e) a toy comb, hat, and glasses, and e) colorful posters positioned on the walls to the left, right and behind the child. These should be at least two feet beyond the arm's length of the tester during ESCS administration. All toys used in the ESCS are positioned within view but out of reach of the child and the toys are presented one at a time during the administration of this measure.

Examples of the toys, their positioning, and the posters are provided in the accompanying reliability tapes 


\section{ROOM SET-UP}

The optimal room configuration for the ESCS is displayed in Figure 1. Furniture should be arranged so that the tester is across the table from the child and slightly to the side to allow for video recording of the child. The tester should kneel on the floor rather than sit in a chair to remain at the child's level during testing. The objects used during the assessment should be placed on a small table or chair within the child's view, but out of his/her reach.

Four large, colorful posters (approximately 24 by 36 inches) should be hung on the walls. Two posters should be placed to each side of the child. One poster on each side should be within the child's view (at approximately 60 degrees from the child's midline) and the other poster should be slightly behind the child, outside his/her view (at approximately 150 degrees from the child's midline).

A video camera should be oriented to enable the recording of a three-quarter to full-face view of the child, while also capturing a profile view of the tester.

Children may be tested with or without their parents present and may be tested seated in the parent's lap, or seated in a chair. To maintain appropriate attention to the tester, the latter is preferred for children older than 12 months (younger children will need to sit in the parent's lap). Table height should be appropriate for the testing situation. If the child will be sitting on the parent's lap, the table should be high enough for the child to comfortably fit under the table. If the child will be sitting alone, the table should be low enough that the child can reach across the table for toys (low child chairs and low child tables are recommended).

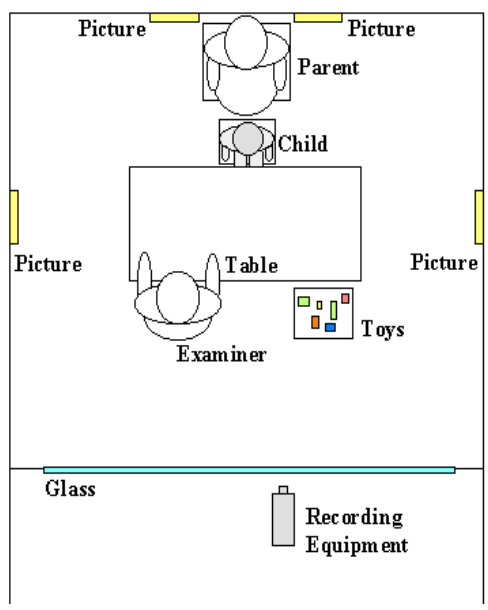

Figure 1: Room Set-Up for the Early Social Communication Scales 


\section{GENERAL ADMINISTRATION GUIDELINES}

During ESCS administration, the tester performs a variety of tasks with natural but minimized verbal interaction with the child. A reduction in tester verbalization allows for clearer differentiation of communicative bids that are initiated by the child. The tester should feel free to speak to and interact with the child during transitions in the testing procedure (e.g., while activating an object, while selecting a new object) but should keep verbal interaction to a minimum during actual task administration.

The tester presents a variety of objects and tasks to the child that have been designed to elicit social and communicative bids with the tester as well as to respond to the tester's social and communicative bids.

Specific task situations are presented in the ESCS and there is a recommended order of task presentation (see below). However, it is most important to keep in mind that a valid and optimal assessment of social communication skill development is dependent on the responsiveness of the tester to the communicative bids of the child.

The ESCS begins with the tester referring with an open hand gesture to the toys that are out of the child's reach. The tester then states to the child "What do you want to play with?" The tester should then wait for a silent count of three seconds. If the child does not initiate a bid, the tester chooses a toy to present (see below). If the child does indicate interest in an object, the tester should try to identify the object of interest and give that object to the child. When the tester presents an item, she may state something like "here it is" but should not label the item or request that the child do something with it. In addition, the tester should avoid using words like "see" or "look". Throughout the testing session, only one toy should be present on the table at a time.

In the course of the administration, the tester should be ready to put aside his or her own order of task presentation to follow the lead of the child. This is especially important in the first half (ten minutes) of testing, while rapport is being built. In the second half of testing, the need to present the remainder of all items may lead the tester to redirect the child more persistently and quickly back to the remaining items requiring presentation, while maintaining a responsive testing posture.

Throughout the specific task guidelines provided below, inter-task or task presentation interval estimates are provided. The tester should not attempt to rigidly adhere to these time estimates using a watch or clock. Rather, the tester should simply use a silent time count (e.g.,

subvocalizing "one second, two seconds, three seconds") to approximate times. After numerous ESCS presentations, this will allow the tester to develop the appropriate sense of pacing for all tasks. Strict measurement of times of presentation would likely interfere with the validity of the social interactive nature of ESCS presentation. For example, some children may be particularly hesitant or "shy" in interaction with unfamiliar adults; we have seen this type of behavior in children with and without developmental delays. In such circumstances, the tester may need to provide slightly longer pauses initially.

\section{Parent Instructions}

If the parent is present in the testing room, the tester should provide him or her with instructions similar to the following: "We will be showing your child a variety of toys and we want to see how he uses gestures, eye contact, and language to communicate with me. We recognize that your child would rather interact with you than with a less familiar person; however, it is important to try to keep your child's attention on me. If your child tries to interact with you, acknowledge him/her by nodding or saying something like 'I see it,' and then direct his attention back to me. It is also 
important that you do not help your child operate the toys. We do not expect your child to be able to operate the toys on his own. This is not a test and there is no right or wrong way to act. You can assist me by keeping your child in the chair and by picking up toys if they fall onto the floor." 


\section{ITEMS NECESSARY FOR ESCS ADMINISTRATION}

5 wind-up mechanical toys ( 3 toys for the Object Spectacle Task and 2 for the Plastic Jar Task; numerous mechanical toys should be purchased as they wear out or break relatively quickly)

3 hand-held mechanical toys (e.g., pop-up puppet, jack-in-the-box, objects activated by a pull cord)

Ball (approximately 4-6 inches in diameter)

Car (medium-sized plastic car, 4-6 inches long)

Picture book (large with distinct pictures)

Hat

Comb

Glasses

Clear plastic jar with screw-on lid (approximately 6 inches tall) 


\section{GENERAL SCORING GUIDELINES}

Detailed scoring information is provided below. A scoring worksheet is provided in Appendix $\mathrm{E}$. The number of occurrences of each behavior is used in determining the scores, unless otherwise noted.

\section{Joint Attention}

\section{Initiating Joint Attention}

Lower Level Behaviors: Eye Contact, Alternates

Higher Level Behaviors: Point, Point and Eye Contact, Show

Scoring: The following scores are typically obtained using the raw number of occurrences of each behavior:

a) Frequency of Lower Level IJA $=($ Eye Contact $)+($ Alternates $)$

b) Frequency of Higher Level IJA $=($ Point $)+($ Point and Eye Contact $)+($ Show $)$

c) Frequency of Total IJA $=($ Eye Contact $)+($ Alternates $)+($ Point $)+$ (Point and Eye Contact) $+($ Show $)$

OR Frequency of Lower Level IJA + Frequency of Higher Level IJA

d) Ratio of Higher Level IJA to Total IJA = Frequency of Higher Level IJA /

Frequency of Total IJA

\section{Responding to Joint Attention}

Lower Level Behaviors: Following Proximal Point/Touch

Higher Level Behavior: Following Line of Regard

Scoring: The following scores are typically obtained:

a) Lower Level RJA = \% correct Following Proximal Point/Touch

(number of correct responses / total number of trials) * 100

b) Higher Level RJA = \% correct Following Line of Regard

(number of correct responses / total number of look trials) * 100

c) Left/Right RJA $=\%$ correct Following Line of Regard on Left/Right trials

(number of correct responses for Left/Right trials / total number of Left/Right trials) * 100 
d) Behind RJA = \% correct Following Line of Regard on Left-Behind and Right-Behind trials

(number of correct responses for Behind trials / total number of Behind trials) * 100

\section{Behavioral Requests}

Initiating Behavioral Requests

Lower Level Behaviors: Eye Contact, Reach, Appeal

Higher Level Behaviors: Point, Point and Eye Contact, Give, Give and Eye Contact

Scoring: The following scores are typically obtained using the raw number of occurrences of each behavior:

a) Frequency of Lower Level IBR $=($ Eye Contact $)+($ Reach $)+($ Appeal $)$

b) Frequency of Higher Level IBR $=($ Point $)+($ Point and Eye Contact $)+($ Give $)+($ Give and Eye Contact)

c) Frequency of Total IBR $=($ Eye Contact $)+($ Reach $)+($ Appeal $)+($ Point $)+($ Point and Eye Contact $)+($ Give $)+($ Give and Eye Contact $)$

OR Frequency of Lower Level IBR + Frequency of Higher Level IBR

d) Ratio of Higher Level IBR to Total IBR = Frequency of Higher Level IBR /

Frequency of Total IBR

\section{Responding to Behavioral Requests}

Behavior: Follows Commands

Scoring: The following scores are typically obtained:

a) Total RBR Passes $=\%$ correct Follows Commands

((number of correct responses without gesture + number of correct responses with gesture) / total number of trials, pass plus fail) * 100

b) Total RBR Fails $=\%$ incorrect Follows Commands

(number of incorrect responses without gesture + number of incorrect responses with gesture) / total number of trials, correct plus incorrect) * 100 


\section{Social Interaction}

Initiating Social Interaction

Behaviors: Initiates Turn-Taking, Tease, Initiates Song/Tickle

Scoring: The child may get credit for Initiates Turn-Taking with the car and/or the ball. Hence the child may obtain a score of 0,1 , or 2 on this item. Therefore, a child who initiated turn-taking with the ball but did not initiate turn-taking with the car would receive a score of 1 for Initiates Turn-

Taking. With regard to Tease, the child may obtain a score of 0 (no teases), 1 (one or more lowlevel teases), or 2 (one or more high-level teases). The child should receive the score based on the highest level behavior displayed (e.g., a child with 3 low-level teases and 1 high-level tease should receive a score of 2).

The following score is typically obtained:

a) Total ISI: Initiates Turn-Taking score + Tease score + Initiates Song/Tickle

\section{Responding to Social Interaction}

Lower Level Behaviors: Eye Contact, Act, Appeal

Higher Level Behaviors: Responds to Turn-Taking, Responds to Invitation

Scoring: The child's score for the responding to turn-taking is determined based on the number of turns taken. This score should be coded separately for the ball and the car. The child receives a score of 0 for no turns, 1 for $1-3$ turns, and 2 for 4 or more turns. Therefore, the child's score for the combined turn-taking trials may range from 0 to 4 .

With regard to Response to Invitation task, the child receives a score of 1 for each correct response (placing the item on or near the tester's head) with the comb, hat, and glasses. The child's score for the combined trials may range from 0 to 3 .

The following scores are typically obtained:

a) Total Song/Tickle Response $=$ Eye Contact + Act + Appeal

b) Total Turn-Taking Response $=$ Ball score + Car score

c) Total Response to Invitation $=$ Comb score + Hat score + Glasses score

d) Total RSI = Total Song/Tickle Response + Total Turn-Taking Response + Total

Response to Social Invitation 


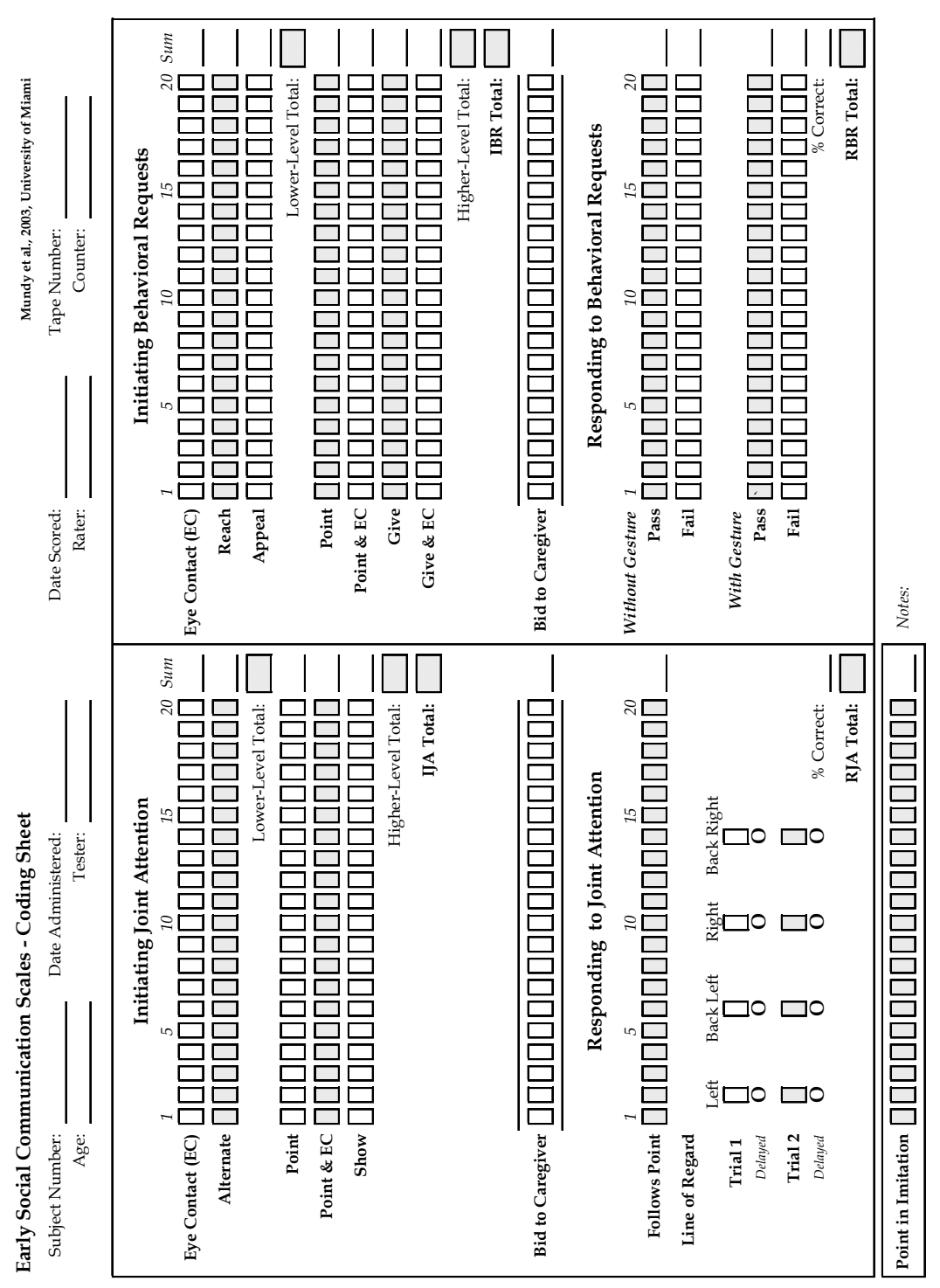




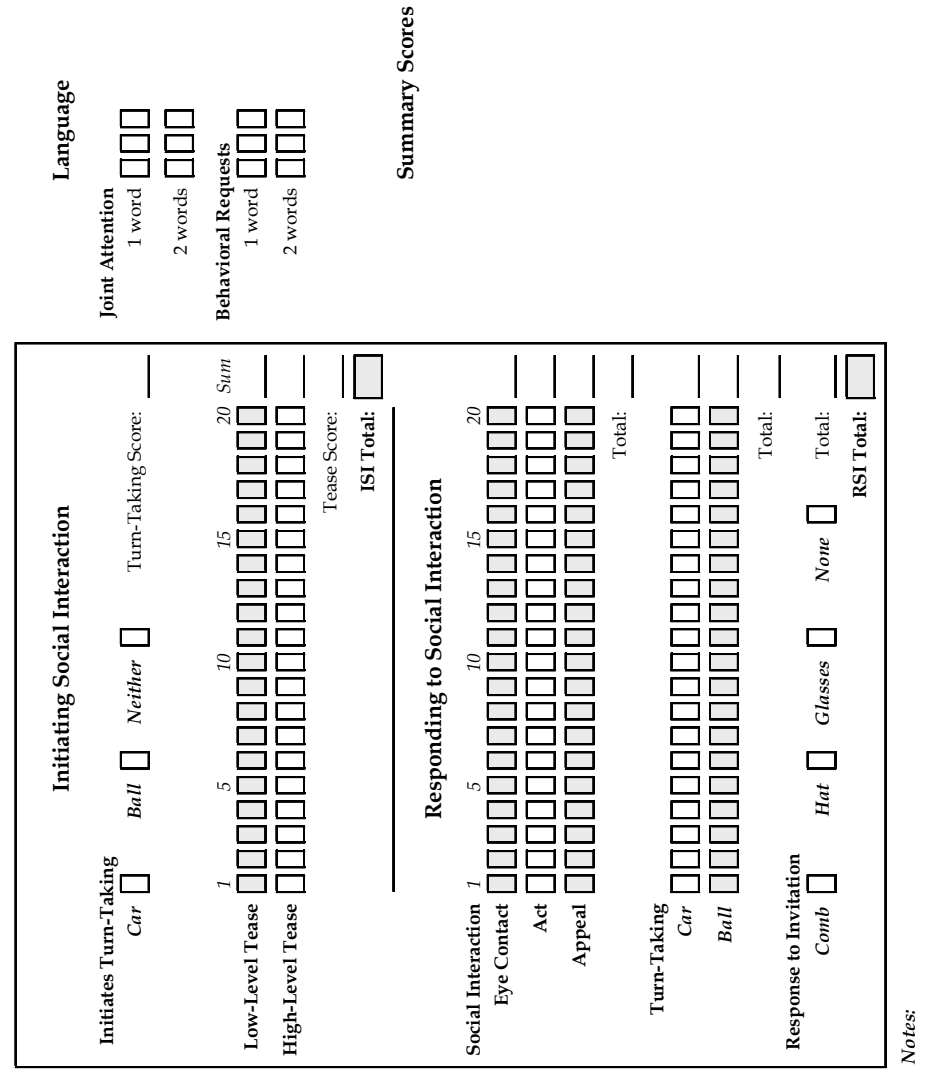


Appendix F: Sample social stimuli cards 

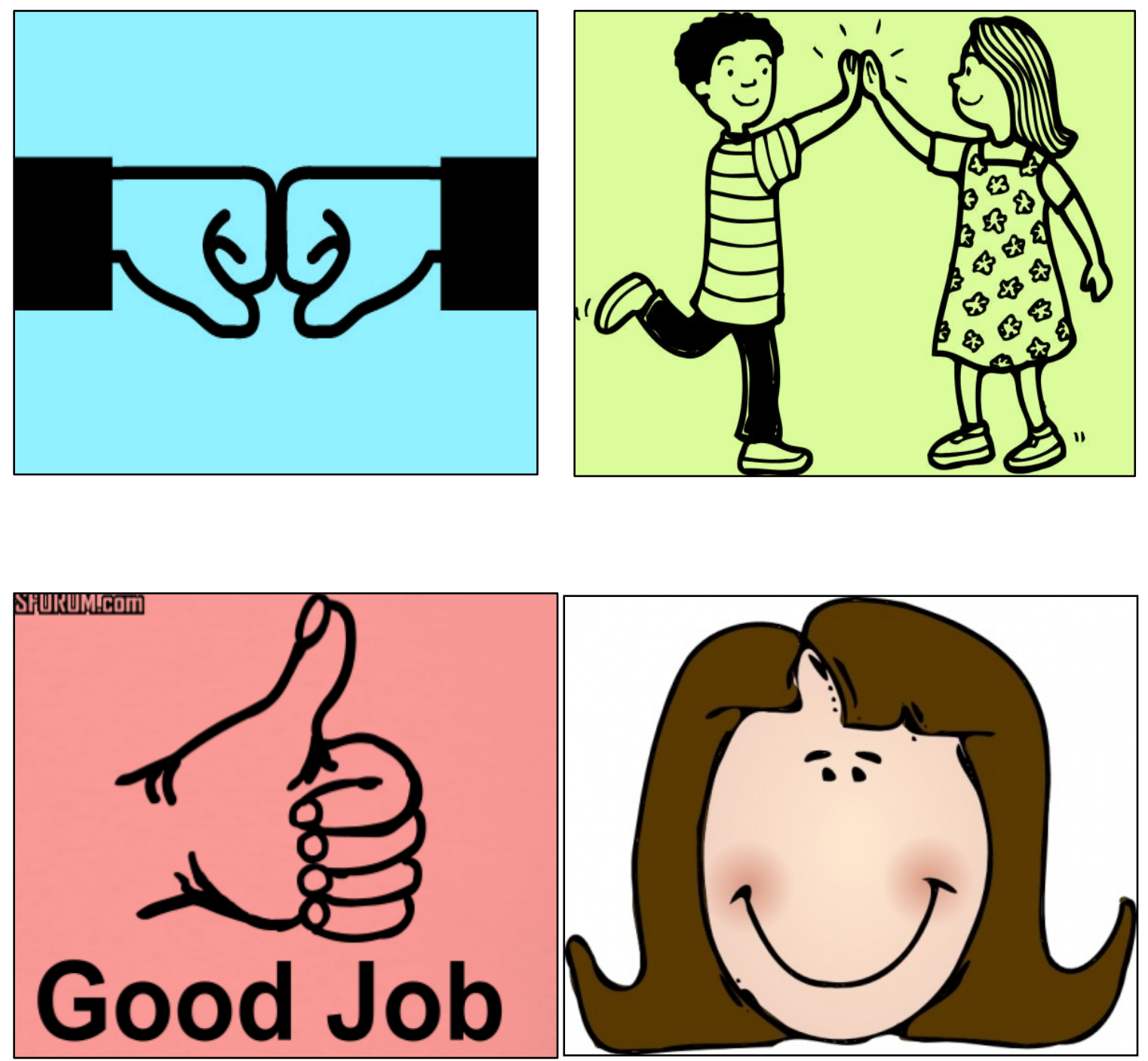
Appendix G: Sample nonsocial stimuli cards 

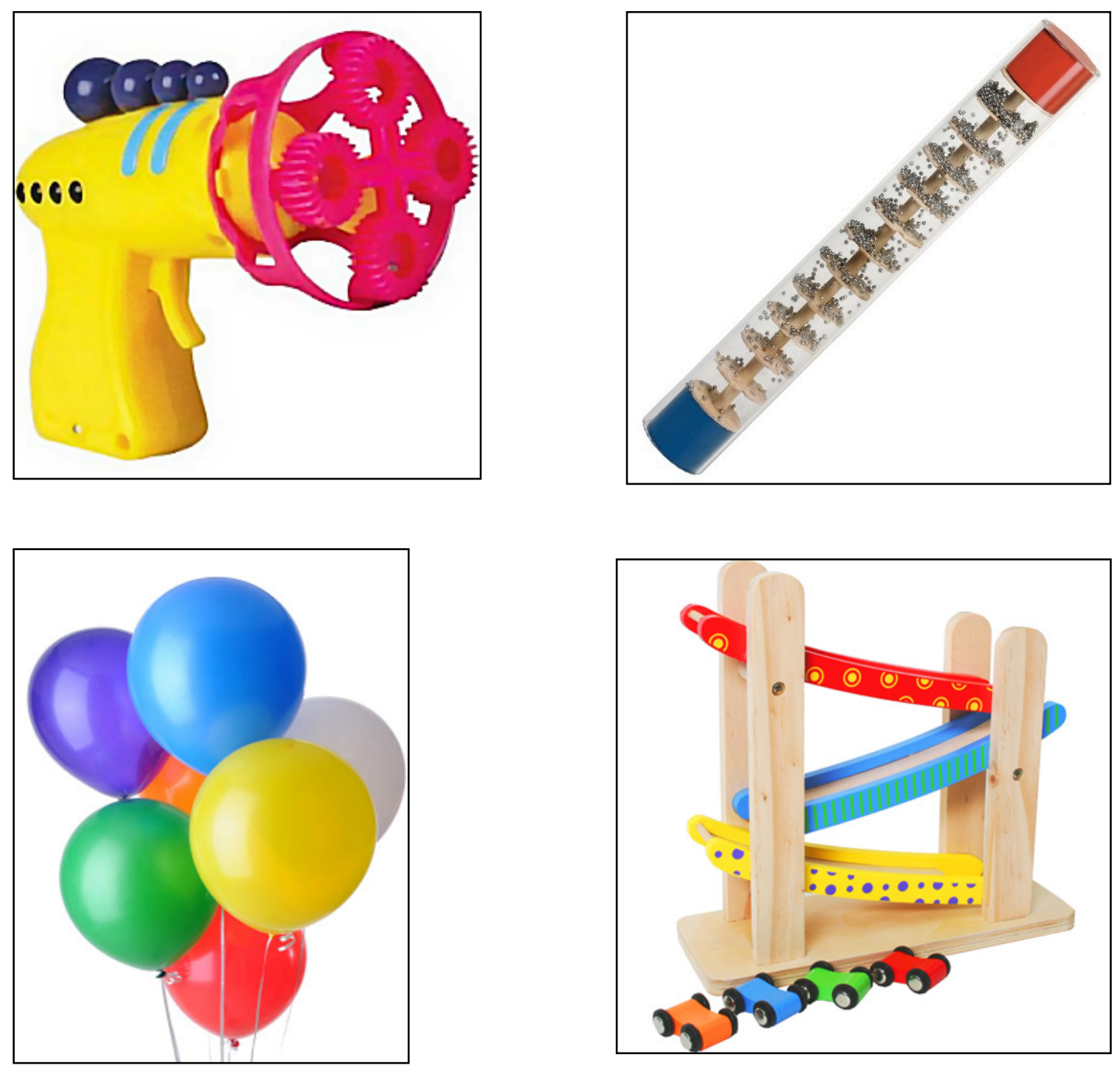
Appendix H: Reinforcer Assessments Results 

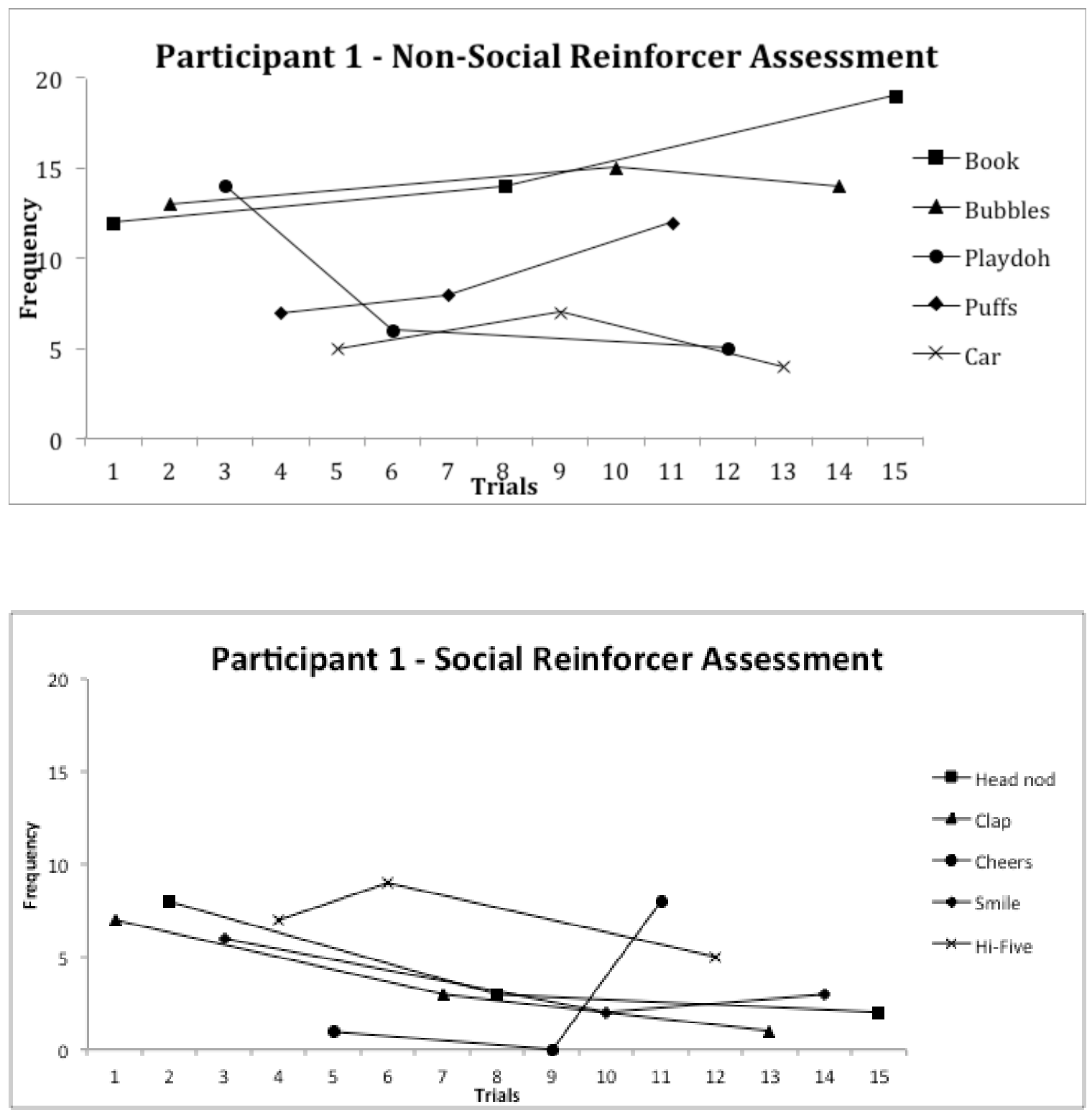

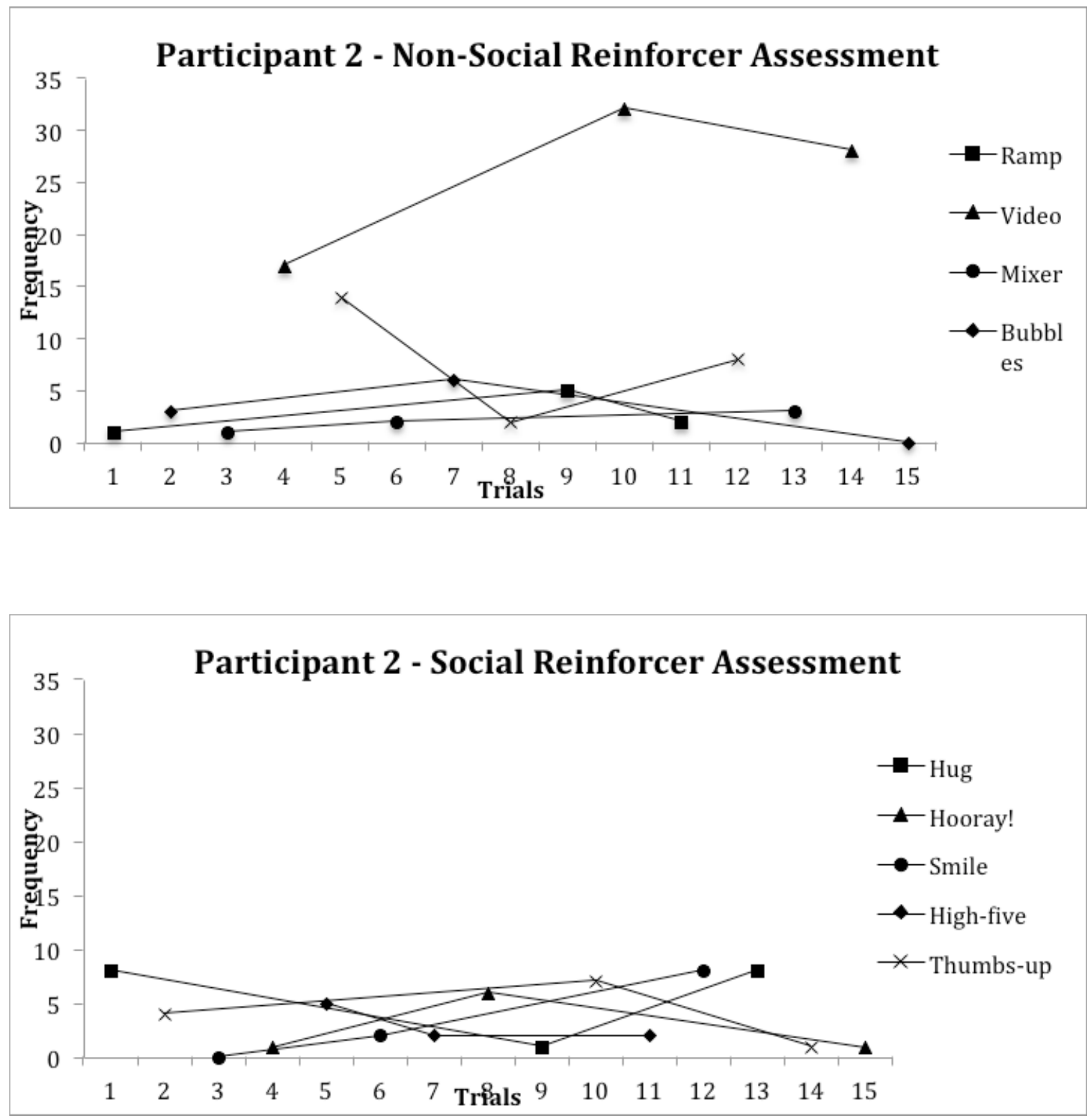

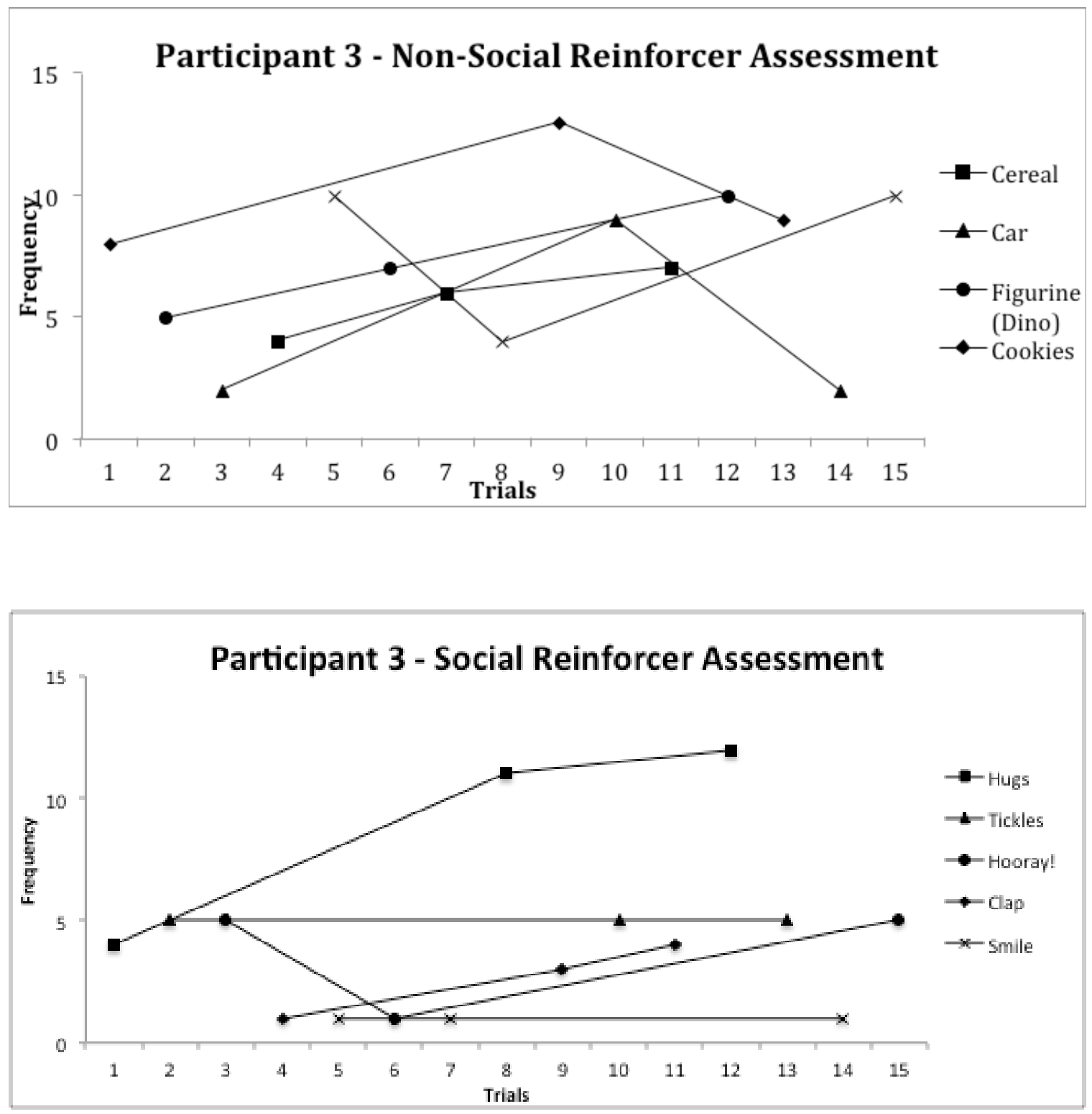

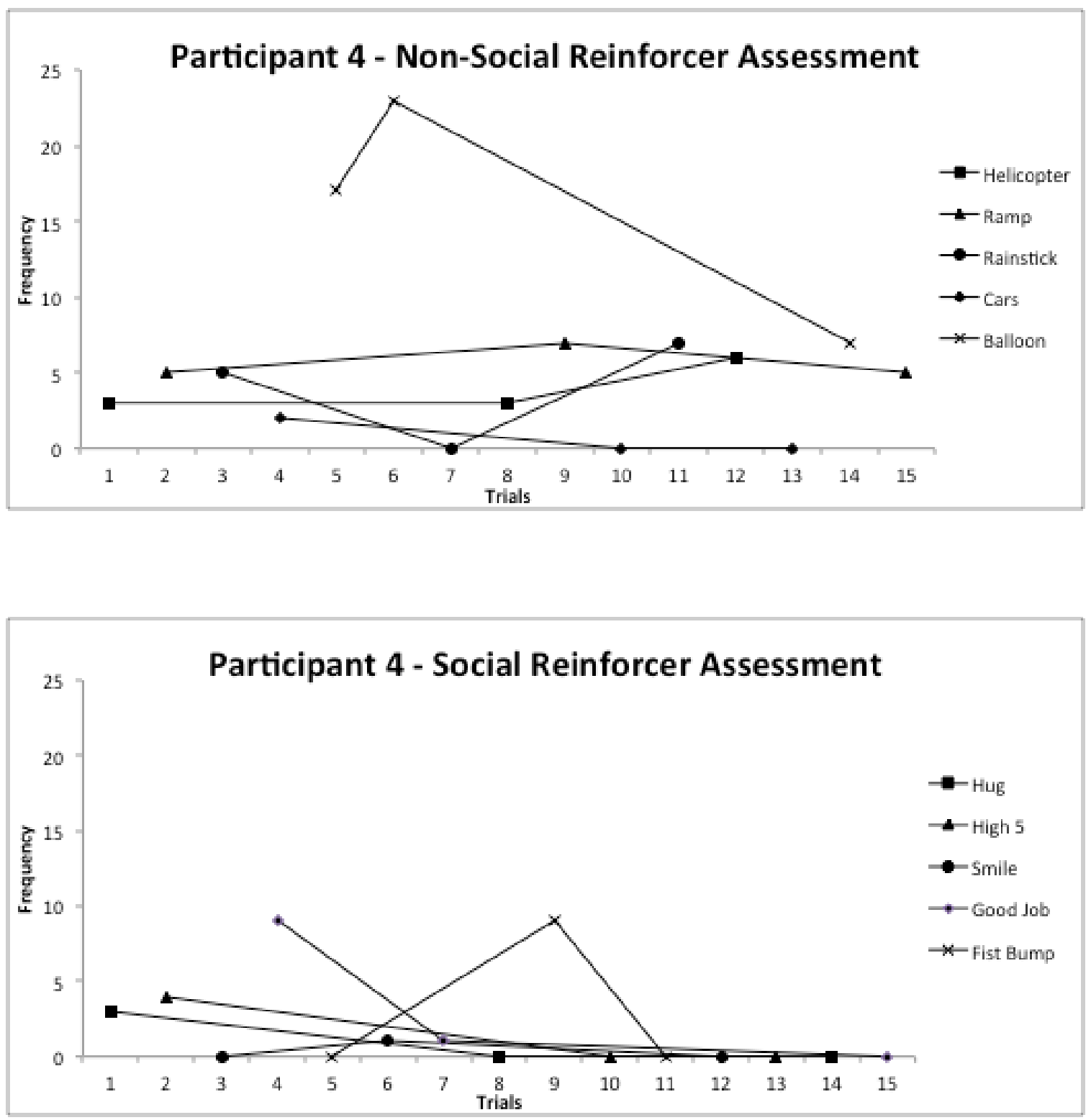

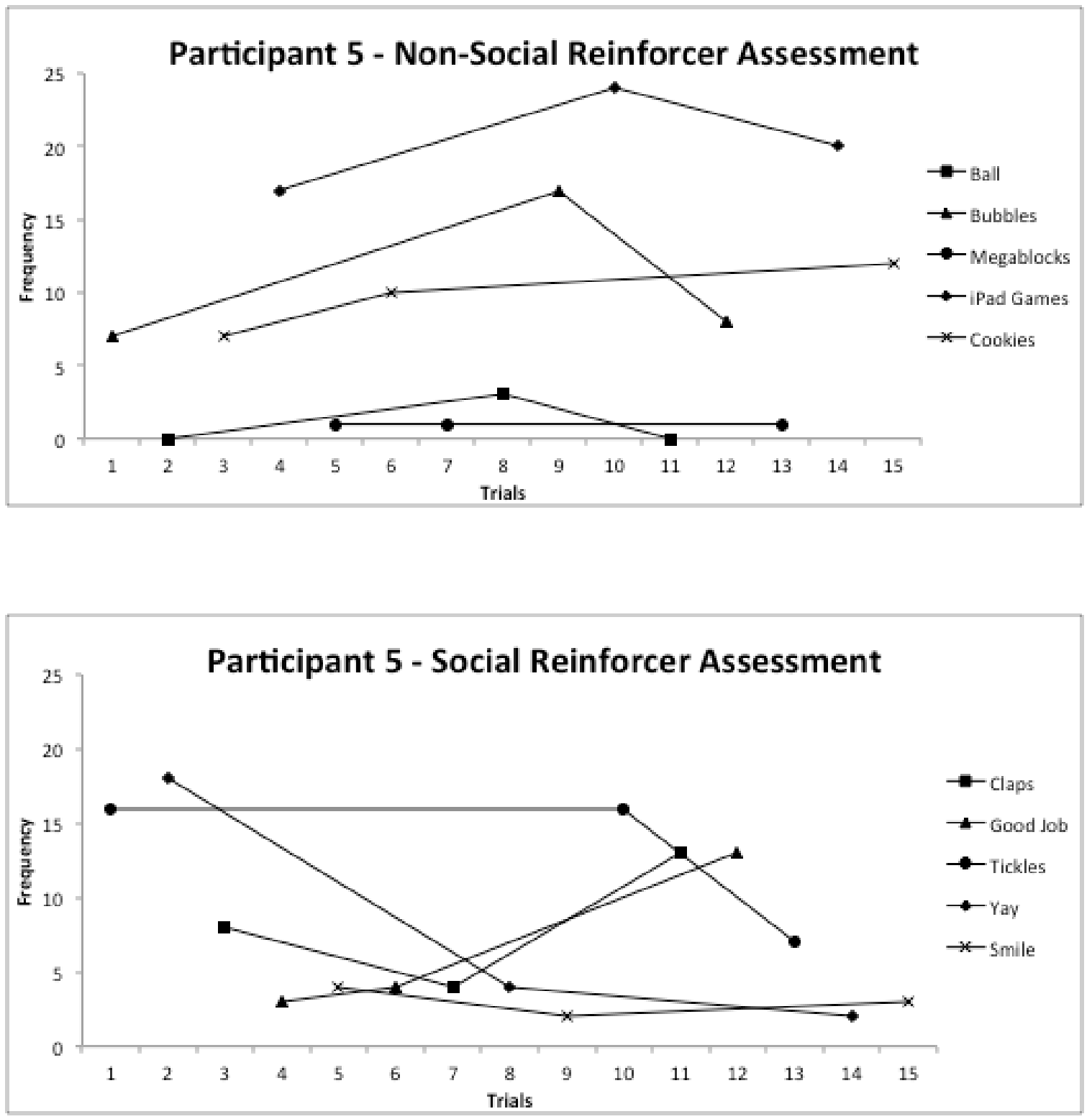

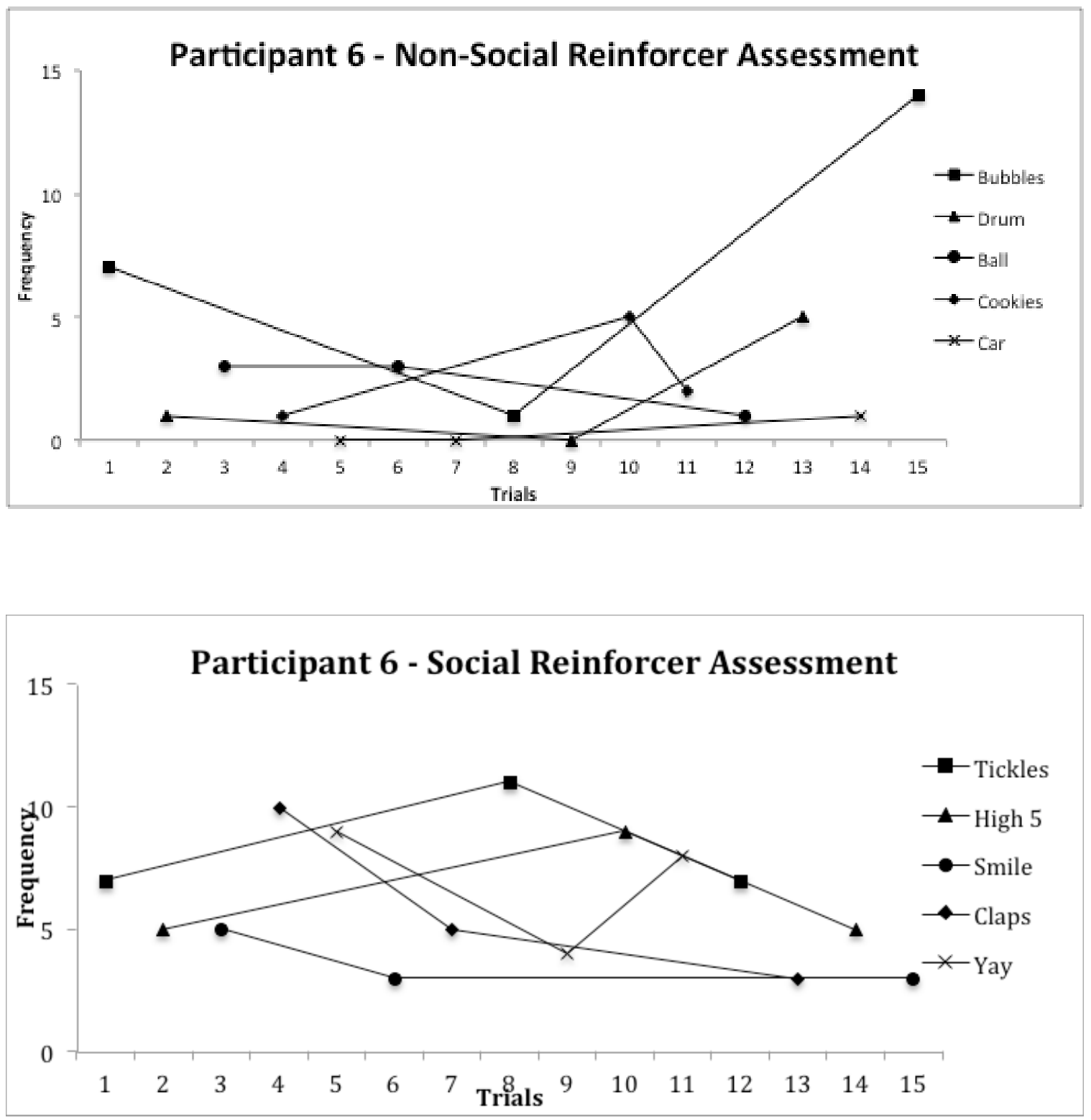
Appendix I: ESCS Individual Results 

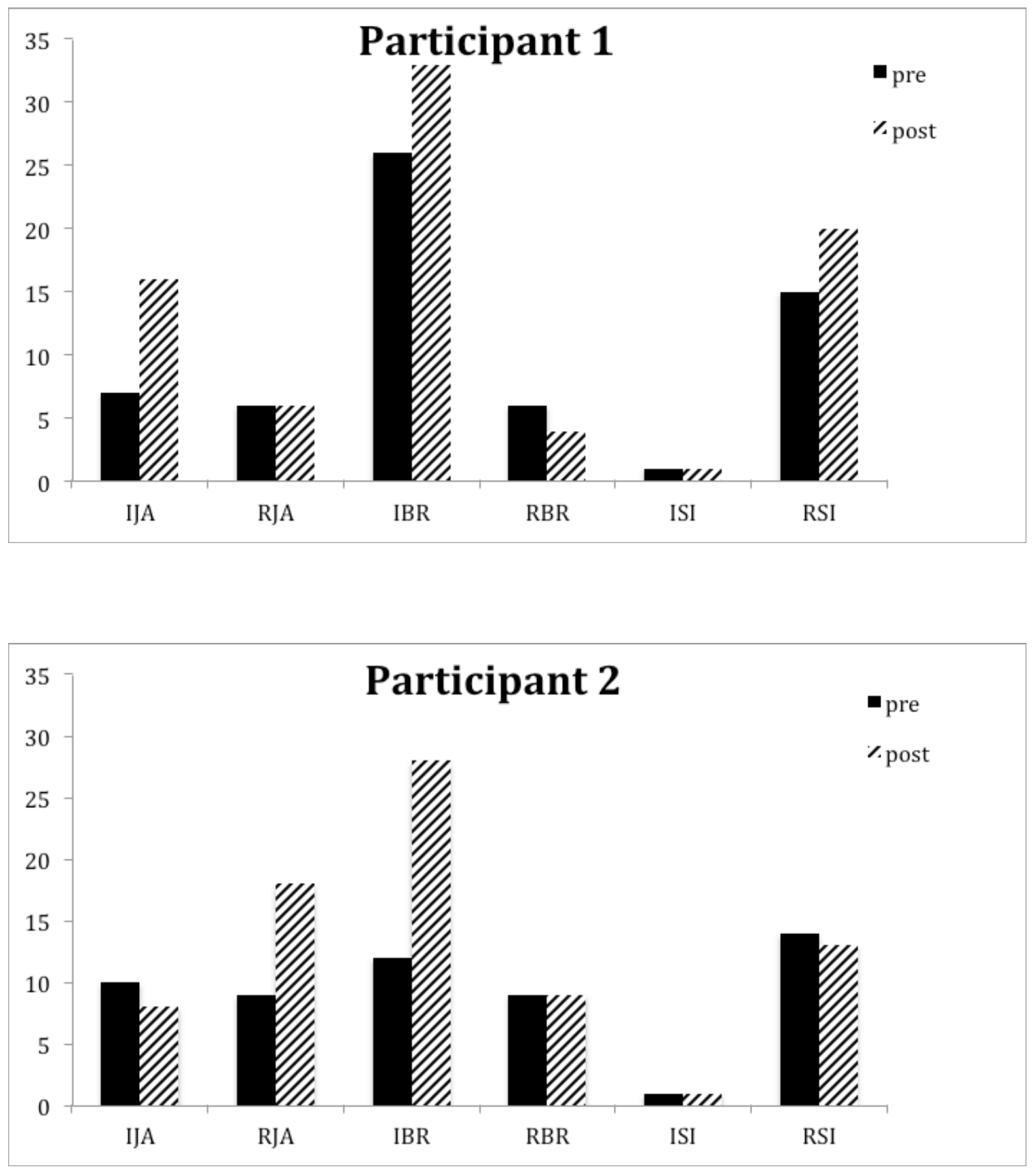

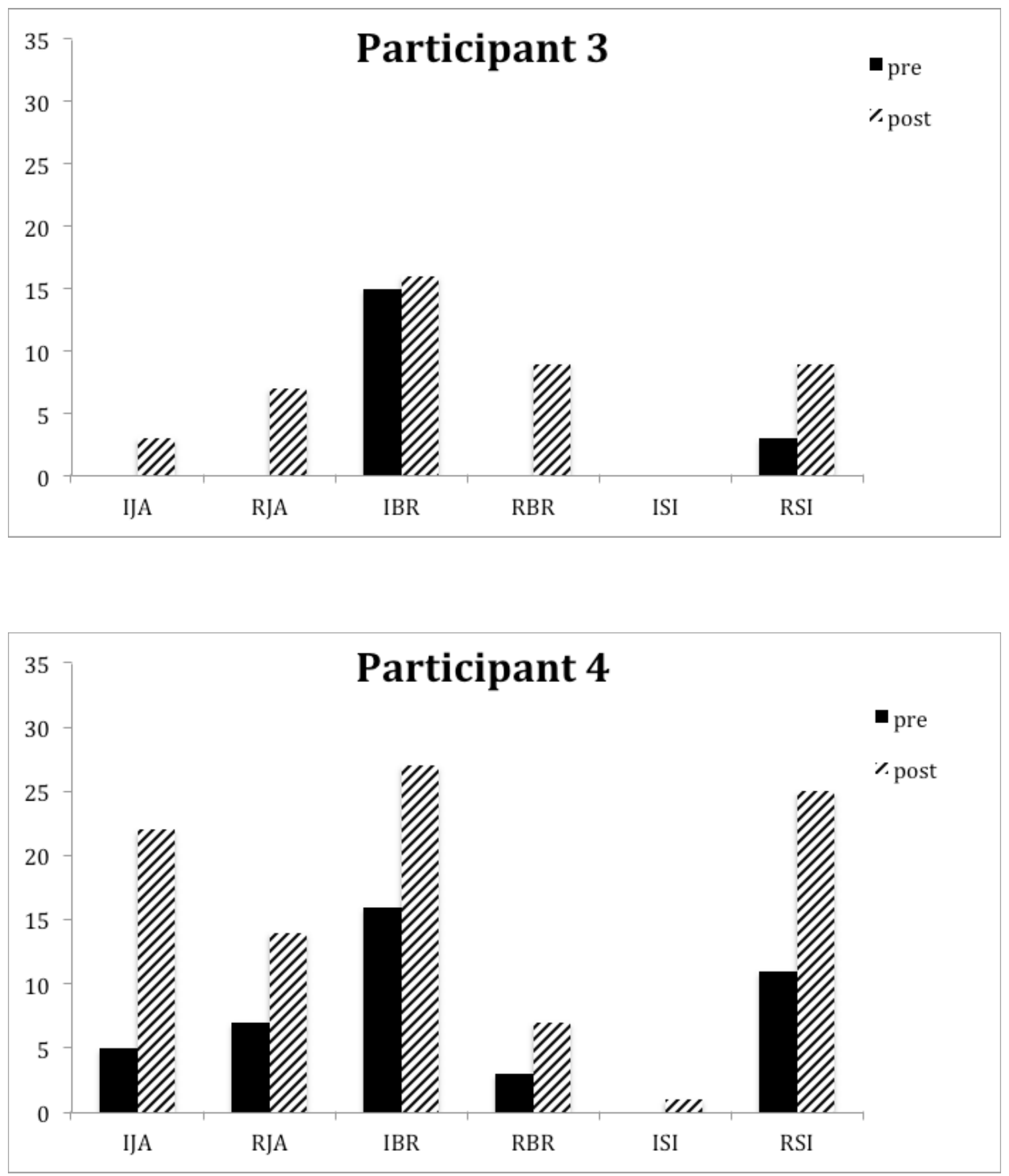

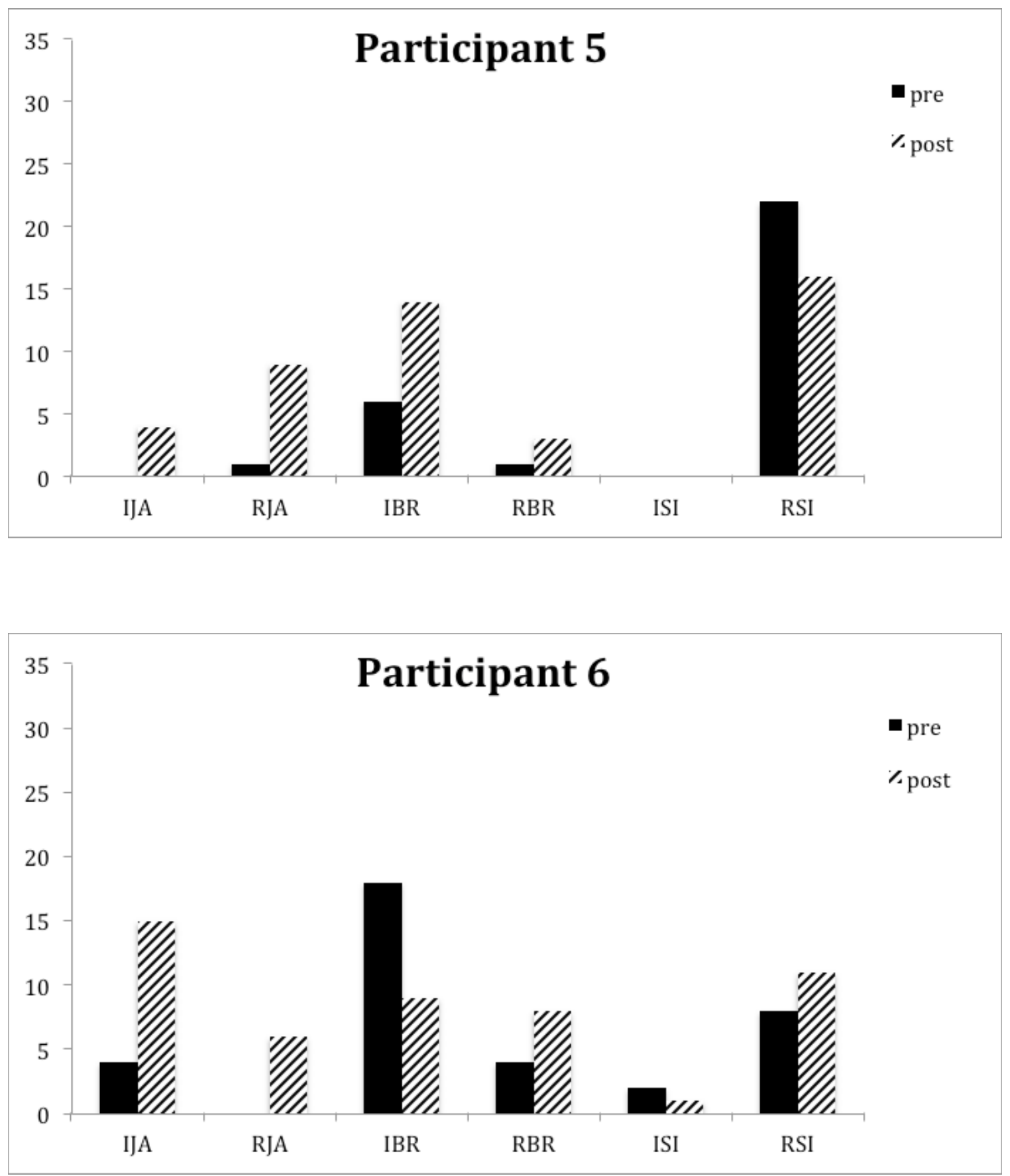


\section{VITA}

\section{PALOMA PEDRAZA RODRIGUEZ}

\section{EDUCATION}

Expected

2013

$12 / 2011$

$5 / 2006$

$5 / 2004$
Doctor in Philosophy, Developmental Psychology, Florida International University, Miami, FL

Master in Science, Psychology. Florida International University, Miami, FL

Thesis: Does Response Topography Affect Response Rates And Behavioral Persistence In Fixed-Ratio Schedules?

Master in Science, Applied Behavior Analysis. Florida Institute of Technology, Melbourne, FL

Bachelor in Science, Psychology, Florida State University, Tallahassee, FL

\section{PRESENTATIONS}

Rodriguez, P.P. (2013, September) Operant and Respondent Procedures to Establish Social Stimuli as Reinforcers in Children with autism. Paper presented at the annual Florida Association for Behavior Analysis conference, Daytona Beach, FL.

Rodriguez, P.P. (2013, May) Establishing Social Stimuli as Reinforcers. Paper presented at the annual Association for Behavior Analysis International conference, Minneapolis, MN.

Rodriguez, P. P. (2012, May) Florida International University Behavior Analysis Master's Program. Poster presented at the annual Association for Behavior Analysis International conference, Seattle, WA.

Rodriguez, P.P. (2012, September) Does Response Topography Affect Response Rates And Behavioral Persistence In Fixed-Ratio Schedules? Poster presented at the annual Florida Association for Behavior Analysis conference, Jacksonville, FL

Lubin, D. \& Pedraza, P. (2008, September) The Behavioral Language Acquisition Model: New Verbal Behavior Interventions for Children Diagnosed with autism and Other Forms of Pervasive Developmental Disorders. Paper presented at the annual Florida Association for Behavior Analysis conference, Bonita Springs, FL. 